\title{
Assessing the roles of temperature, carbon inputs and airborne pollen as drivers of fructification in European temperate deciduous forests
}

\author{
François Lebourgeois ${ }^{1, *}$, Nicolas Delpierre ${ }^{2, *}$, Eric Dufrêne ${ }^{2}$, Sébastien Cecchini ${ }^{3}$, Sébastien Macé ${ }^{3}$, \\ Luc Croisé ${ }^{3}$, Manuel Nicolas ${ }^{3}$ \\ 1. Université de Lorraine, AgroParisTech, INRA, UMR Silva, 14 rue Girardet, F-54000 Nancy, France \\ 2. Écologie Systématique Évolution, Université Paris-Sud, CNRS, AgroParisTech, Université Paris-Saclay, 91400 \\ Orsay, France
}

3. Office National des Forêts, Direction forêts et risques naturels, Département recherche, développement, innovation, Boulevard de Constance, 77300 Fontainebleau, France

1 Corresponding author: francois.lebourgeois@agroparistech.fr

* the two authors contributed equally to this paper.

\section{Summary}

- We aimed at identifying which drivers control the spatio-temporal variability of fruit production in three major European temperate deciduous tree species: Quercus robur, Quercus petraea, and Fagus sylvatica.

- We analysed the relations of fruit production with airborne pollen, carbon and water resources and meteorological data in 48 French forests over 14 years (1994-2007).

- In oak, acorn production was mainly related to temperature conditions during the pollen emission period, supporting the pollen synchrony hypothesis. In beech, a temperature signal over the two previous years eclipsed the airborne pollen load.

- Fruit production in Quercus and Fagus was related to climate drivers, carbon inputs and airborne pollen through strongly non-linear, genus-specific relations.

- Quercus and Fagus also differed as regards the secondary growth vs. fructification trade-off. While negative relationships were observed between secondary growth and fruit production in beech, more productive years benefited to both secondary growth and reproductive effort in oak.

Keywords: beech, temperate oaks, fructification, gross primary productivity, pollen, temperature, secondary growth. 


\section{Introduction}

Fruit production is a crucial step in the life cycle of trees (Silvertown 1980). A regular occurrence of fruit production is required for the natural regeneration of forests. Fruit production is also a pre-requisite for species migration whether natural or human-assisted (Vander Wall 2001; Benito-Garzon and Fernandez-Manjarres 2015; Koralewski et al. 2015; Aubin et al. 2016). In anemophilous perennial plant species such as forest trees, fruit production highly varies across years. The occurrence of a high production event synchronized among individuals from a regional population is known as a "masting" event (Kelly 1994; Koenig and Knops 2000; Kelly and Sork 2002; Wesolowski et al. 2015; Fernández-Martínez et al. 2017; Nussbaumer et al. 2016; Vacchiano et al. 2017). The hypotheses of predator satiation and maximization of pollination efficiency (i.e. higher seed/flower ratios in high-flowering years) have been proposed to explain the evolutionary emergence of masting (Kelly and Sork 2002; Satake and Bjornstad 2008; Pearse et al. 2016).

The occurrence of a mast year depends on the successful development of a large mass of viable flowers and fruit (Smaill et al. 2011; Fernandez-Martinez et al. 2012; Kasprzyk et al. 2014; Pearse et al. 2014; Pearse et al. 2016; Monks et al. 2016). The development of flowers highly affects fruit production and, in temperate forest trees, it starts with the floral transition of dormant buds during the growing season that preceeds fructification (Miyazaki et al. 2014; Delpierre et al. 2016b). It is not perfectly clear which environmental cues or internal resources determine floral transition. Yet, available nitrogen has been demonstrated as a strong signal in Fagus crenata (Miyazaki et al. 2014), and can be inhibited by too high spring temperatures (Kon et al. 2005). Both carbon and nitrogen resources are required for bud development and flowering in spring (Han and Kabeya 2017), which occurs close to leaf-out, and they are mostly drawn from the tree reserves. Because pollination is a density-dependent process in selfincompatible plants such as most forest trees, the efficiency of flower production is better in years when a large part of the tree population produces flowers (a process known as pollen coupling; Pearse et al. 2016). Density-dependence is further relaxed in years with high pollen phenological synchrony among trees (Koenig et al. 2015), which may depend on temperature conditions during bud burst (Bogdziewicz et al. 2017b). Adverse weather conditions (i.e. rain, high humidity, low wind) may affect pollen transport and compromise pollination (Kasprzyk et al. 2014), while late frost events may damage flowers (Vitasse et al. 2018). When pollination occurs, several hazards may compromise the formation of viable fruit. The least known phase occurs between pollination and fecundation; it lasts one to two months in temperate forest trees 
and may be compromised by too high temperatures (Hedhly et al. 2007). Considering these biological facts, a relatively high number of studies have investigated the role of local climate in determining fruit production in temperate forest trees (mostly temperature, Sork and Bramble 1993; Kelly et al. 2013; Pearse et al. 2014), as well as the role of air pollen concentrations (Kasprzyk et al. 2014) or climate conditions during pollen emission (Bogdziewicz et al. 2017b). Some studies even considered teleconnections (e.g. NAO, Fernandez-Martinez et al. 2017) as possible drivers of fruit production synchrony across stands at a continental scale (Vacchiano et al. 2017). However, the development of viable fruit following fecondation also requires carbon (mostly provided by photosynthesis; Hoch et al. 2013; Ichie et al. 2013) and nitrogen resources (Han et al. 2014), and non-limiting water (Misson et al. 2011). The impact of resource availability has been investigated more rarely on large datasets, albeit indirectly from the autocorrelation of fruit time series.

European beech (Fagus sylvatica) has been described as a "flowering masting" species, i.e. flowering and the subsequent airborne pollen concentrations are the main limitations to fruit production (Kasprzyck et al. 2014; Bogdziewicz et al. 2017b). Previous-year temperatures, often in the form of temperature differences between year-1 and year-2 growing seasons, have also been invoked as a putative driver of fructification in beech (Bogdziewicz et al. 2017b; Vacchiano et al. 2017). However, their functional interpretation is still unclear (Kelly et al. 2013; Pearse et al. 2014; Monks et al. 2016). A lower number of studies have addressed European deciduous oaks (Quercus petraea and Quercus robur). These studies reported a lower dependence of fruit production on pollen concentrations per se in oak (Kasprzyck et al. 2014), but evidenced an impact of pollination duration or temperature during the pollen season (Bogdziewicz et al. 2017b).

In mast years, fruit production may represent a substantial amount of tree carbon productivity. In a mature beech forest, nut production averages $42 \%$ (10-79\%) of annual wood production, and 12\% (3-20\%) of net primary productivity (Mund et al. 2010). In sessile oak, acorn production can reach 52\% of annual wood production (Delpierre et al. 2016a). In beech, as opposed to oak that has small female flowers, the resource investment of non-fertilized female inflorescences is high from the start (Abe et al. 2016). This high resource cost of reproduction prompted researchers to formulate hypothetical resource-investment scenarios (Crone and Rapp 2014; Pearse et al. 2016). Broadly, these scenarios can be categorized into (i) those involving differential allocation of current-year acquired resources (termed resource-matching, resourceswitching in Pearse et al. 2016), and (ii) those involving accumulation of resources over years (termed resource-storage and veto in Pearse et al. 2016). Recent studies demonstrated that the 
carbon needed for fruit formation was mostly derived from current-year photosynthesis (Hoch et al. 2013; Ichie et al. 2013). This finding reinforces the idea that fruit act as a competing resource sink interacting with other organs in the resource economy of trees. Several studies tracing carbon allocation to different organs suggest that beech allocates less carbon to wood growth during mast years (Mund et al. 2010; Mueller-Haubold et al. 2013; Mueller-Haubold et al. 2015), whereas no reduced allocation to wood is observed in beech or oak in other reports (Alla et al. 2012; Hoch et al. 2013; Ichie et al. 2013). Similarly, studies linking fruit production and diameter growth yielded contrasting results, with a frequent negative link between these two variables in beech (Monks and Kelly 2006; Drobyshev et al. 2010; Hacket-Pain et al. 2015) and a positive one in oak (Askeyev et al. 2005; Perez-Ramos et al. 2010; Martin et al. 2015). Fewer data are currently available as regards other resources such as nitrogen. Studies on Fagus crenata showed that nitrogen reserve formation was lower in mast years (Han et al. 2014), and possibly compromised flowering in the following year (Miyazaki et al. 2014). This mechanism may at least partly explain the repeatedly reported negative one-year autocorrelation of fruiting time series in temperate trees.

Previous papers established that beech and oak showed contrasting behaviours in terms of fructification, its proximate drivers (i.e. pollen $v s$. weather conditions), or the trade-off between reproductive effort and growth. However, they lack a clear ranking of the role of weather determinants, pollen limitation, and current- and previous-year resource availability in determining fruit production variability. These studies rarely addressed interactions among variables, thresholds, non-linear responses or resource availability, apart from indirectly including lag-1 autocorrelation of the fruit production time series. In this paper, we aim at filling this gap studying the influences of weather determinants, carbon resource availability, the airborne pollen load, and pollen-related meteorology on the spatio-temporal variability of fruit production over 14 years (1994-2007) in 48 European temperate beech (Fagus sylvatica L.) and oak (Quercus petraea and Q. robur) stands. We also assessed the link between fruit production and wood growth in these species to test for a growth versus fructification trade-off.

\section{Materials and Methods}

\section{Sampling design}

Data were collected from 48 broadleaved stands of the French Permanent Plot Network for the Monitoring of Forest Ecosystems (RENECOFOR) (Ulrich 1995). The stands covered a wide range of environmental conditions (Fig. 1 and Online Resource 1). Each stand had a surface of 
approximately two ha, with a central 0.5 -ha fenced zone. The slope was less than $5 \%$ in most stands, and elevation ranged from 20 to 1,400 m asl (mean: $350 \mathrm{~m}$ ). The maximum soil water holding capacity (SWHCm, in $\mathrm{mm}$ ) was estimated according to textural properties, soil depth, and coarse element percentages from two trenches per plot (Brêthes et al. 1997; Piedallu et al. 2011). SWHCm ranged from 45 to $200 \mathrm{~mm}$, with an average value of $120 \mathrm{~mm}$ (Online Resource $1)$.

\section{Climate data}

Mean monthly temperatures and rainfall data were obtained from the 81 closest available stations of the French Climate Network (Météo-France) (Fig. 1). To estimate water supply over the 1994-2007 period, we first computed a monthly climatic water balance (CWB) by calculating the difference between rainfall $(\mathrm{R})$ and potential evapotranspiration (PET, calculated with Turc's formula) (Lebourgeois and Piedallu 2005). Secondly, we calculated a monthly soil water balance using SWHCm values and climatic data. The Thornthwaite formula (Online Resource 2) was chosen to compute soil water balance (Thornthwaite and Mather 1955) because this method gives accurate estimations of monthly water content fluctuations from a limited number of parameters and has been successfully used in previous ecological studies (Lebourgeois et al. 2013; Trouvé et al. 2015; Piedallu et al. 2016). A complementary dataset of meteorological variables at the hourly temporal scale was obtained from SAFRAN atmospheric reanalysis (with 8-km spatial resolution, Vidal et al. 2010). It included global radiation, rainfall, wind speed, air humidity, and air temperature. We used these variables for climate forcing in the CASTANEA model (see "Process-based simulation data" section).

The NAO (North Atlantic Oscillation) refers to a meridional oscillation of atmospheric masses, with centers of action near the Icelandic low and the Azores high (Hurrell et al. 2003). Studies have already shown that NAO anomalies correlate with weather conditions at the continental scale (Mares et al. 2002; Hurrell and Deser 2010) and with local ecosystem functioning (Ottersen et al. 2001; Stenseth et al. 2003; Menzel et al. 2005; George 2014). Previous studies highlighted that NAO indices may be correlated with fruit production (Wright et al. 1999; Fernández-Martínez et al. 2017), so we also considered monthly NAO indices as candidate variables in our statistical modeling. The NAO index time series were downloaded from the Climate Prediction Center of the National Weather Service (NOAA, < www.cpc.ncep.noaa.gov/ >). 


\section{Annual fruit production}

Litterfall was collected seasonally from 1994 to 2007 (Peaucelle 2011). Ten collectors were distributed in the 0.5 -ha fenced central part of each plot. Litter collectors were $0.5-\mathrm{m}^{2}$ square traps treated against U.V. radiation and designed with a water drainage system. A sifter $(2 \times 2$ $\mathrm{mm}$ ) was placed at the bottom of the trap to retain litter. Trap distribution was regular, with 3 (2) lines throughout the 0.5-ha squared (rectangular) plot. Depending on the stand, 3 to 5 samplings were performed annually. The litter samples were separated according to organs: leaves, small branches ( $<2 \mathrm{~cm}$ diameter), and fruit (acorns and nuts) (Online Resource 3). All compartments were air-dried at $105^{\circ} \mathrm{C}$ for 24 hours before weighing. Seasonal data were aggregated over biological years from April 1 (i.e. the estimate of the start of the growing season, Peaucelle 2011) to March 31 of the following year. Litterfall mass values from sampling periods overlapping two consecutive biological years were split proportionally to the number of days belonging to each year. To ensure the robustness of the dataset, a given collection was considered as valid only if at least 8 out of 10 collectors were available on the plot. A biological year of collection was considered as valid only if less than $10 \%$ of the days of the year and no autumn day (from September 1 to December 31) were missing. Finally, litterfall production was calculated by dividing the collected data by the total surface area of all the traps, and was then reported to one hectare. Forty-one stands were monitored for at least 10 years, and 12 stands over the whole study period (1994 to 2007). Finally, totals of 347 and 219 annual fruit production data were made available for oak and beech, respectively (Online Resource 3). These data were calculated both as annual fruit biomass $\left(\mathrm{kg} \mathrm{ha}^{-1} \mathrm{y}^{-1}\right)$ and fruit number (number of fruit ha $\left.\mathrm{h}^{-1} \mathrm{y}^{-1}\right)$.

\section{Pollen count data}

To assess the influence of pollen limitation, we used pollen count data from the "Réseau National de Surveillance Aérobiologique" (RNSA). The data consist of bi-hourly counts (aggregated to the daily time scale in the present case) expressed as the number of pollen grains per $\mathrm{m}^{3}$ of air, affiliated to a particular taxon (determined at the genus level, i.e. oak and beech) by microscopy analysis. The RNSA network consists of $c a$. 90 stations spread across continental France. For each forest stand, we estimated the daily pollen aerial concentration as the inverse-distance-weighted average concentration measured in all RNSA stations in a 100$\mathrm{km}$ radius (corresponding to 3.2 RNSA stations on average, $65 \mathrm{~km}$ away from a given stand). 
For each site-year, we defined the start / peak / end of the pollen season as the day of year when $5 \% / 50 \% / 95 \%$ of the cumulative annual pollen emissions were reached.

\section{Process-based simulation data}

We used the ecophysiological process-based model CASTANEA (Dufrêne et al. 2005; Davi et al. 2009; Delpierre et al. 2012) to simulate tree carbon (C) resource availability (Guillemot et al. 2014), in the form of gross primary productivity (GPP), net primary productivity (NPP), and tree internal $\mathrm{C}$ reserve concentrations. CASTANEA simulates the stand-atmosphere $\mathrm{CO}_{2}$ exchanges at the half-hourly scale by combining photosynthesis, autotrophic respiration, carbon allocation, soil organic carbon, and soil hydrology sub-models. The model proved able to reproduce the interannual fluctuations of $\mathrm{CO}_{2}$ fluxes in European forests (Delpierre et al. 2012) as well as spatial (Guillemot et al. 2014) and interannual variability of aerial growth (Guillemot et al., 2017) in oak and beech. In this work, we used the CASTANEA parameterization developed in a previous work over the RENECOFOR network (Guillemot et al. 2014). Every year from 1994 to 2007, the hourly-to-daily simulated GPP, NPP, and C reserves were aggregated over different time periods $\left(\mathrm{gC} \mathrm{m}^{-2} \mathrm{month}^{-1}\right.$ or season ${ }^{-1}$ or year $\left.{ }^{-1}\right)$. The $\mathrm{C}$ balance was simulated for all 20 beech stands, but only for 23 oak stands out of 28 because model input parameters were not available for all stands.

\section{Tree-ring chronologies}

Stands were mature (mean age: 104 years in 2007), with typical basal areas (means: 19 - $23 \mathrm{~m}^{-}$ ${ }^{2}$ ha) and dominant heights (means: 25 - $29 \mathrm{~m}$ ) for broadleaved trees in managed high forests (Online Resource 4). To study the relationship between fruit production and growth, trees were cored in 2009. Unfortunately, it was not possible to core all the stands and all the trees as we did in 1997 (Lebourgeois et al. 2005; Mérian et al. 2011). Thus, among the 48 stands, a subsample of 30 stands was cored (25 oak stands and 5 beech stands) (Online Resource 4 ). In each plot, 10 dominant trees were cored (two cores per tree, 500 cores for oak, 100 cores for beech, 8,400 ring measurements) and cross-dated using pointer years (Mérian et al. 2011). Raw treering widths were standardized to remove the well-known strong signal linked to cambial age, stand characteristics and other resource variables (soil chemistry, soil water balance...) (Online Resource 5). To this aim, tree-ring widths predicted by the RandomForest model (see Statistical Modeling section) were subtracted from the observed values to define residual tree-ring widths (i.e. standardized values, ResRW). ResRW data were then used as an explanatory variable to test for the growth $v s$. fructification trade-off. 


\section{Statistical Modelling}

We used the non-parametric statistical method RandomForest (RF) to model the spatiotemporal variability of fruit production. RF is a machine-learning algorithm based on bootstrapped decision trees. Unlike classical regression techniques for which the relationship between the response and predictors is pre-specified (for example, straight line, quadratic) and the test is performed to prove or disprove the relationship, RF assumes no such relationship. Since no assumptions are made about the nature of the relationships among the response and predictor variables, RF allows for the possibility of interactions and nonlinearities among variables. Consequently, RF is effective in uncovering structure in data with hierarchical or non-additive variables. For all these reasons, there has been increasing interest in the use of RandomForest techniques in ecological studies within the last 10 years (Breiman 2001; Liaw and Wiener 2002; Lin and Jeon 2006; Prasad et al. 2006; Strobl et al. 2009). Briefly, RF classifies a dependent variable (fruit production in the present case) among groups defined as a combination of intervals of multiple predictors, resulting in a so-called "decision tree". RF builds each decision tree with both randomly chosen dependent variables and predictors (mtry). In fact, mtry is the randomly chosen subset of the total number of initial predictors used to find the best split at each branching node. By fitting a high number (ntree) of training individual decision trees (i.e. a "forest" of decision trees), RF captures the variance of several predictors concomitantly, so that a high number of variables can participate in the prediction. This optimizes predictive accuracy in the final tree (Breiman 2001), which is selected on the basis of its predictive ability quantified from data unused during the training phase ("out-of-bag" (OOB) data). Here, the optimized values for mtry and ntree were 4 and 2,000, respectively (Oshiro et al. 2012). RF gives two complementary variable accuracy values (Ishwaran 2007; Ehrlinger 2015): variable importance (vimp) and minimal depth (depth). If a predictor is important in the model, then randomly assigning values for that predictor should worsen predictions. vimp expresses this effect, with a higher vimp value indicating a more important predictor. Depth assumes that the most discriminant main predictors are those that most frequently split nodes nearest to the trunks of the trees where they partition large groups in the dataset. Lower values of depth indicate predictors important in splitting large groups of data. RF returns the RMSE of adjusted values calculated on the training data. It also returns the RMSE of predicted values (OOB error). It is a valid estimate of the test error for the model, since the response for each observation is predicted using only the trees that were not fit using that observation (OOB predictions). RF gives also the percentage of explained variance (i.e. the 
measure of how well OOB predictions explain the target variance of the training set). For the best predictors, we drew partial dependence plots $(\mathrm{PdP})$, which display the predicted response (Y) as a function of one of the predictors (X). PdP gives a graphical depiction of the effect of $\mathrm{X}$, highlighting both the form and, if any, the threshold of the predicted response (Ehrlinger 2015). We also drew conditioning plots (coplots) to highlight how (Y) depended on two variables $\left(\mathrm{X}_{1}, \mathrm{X}_{2}\right)$. $\mathrm{Y}$ was examined as a function of $\mathrm{X}_{1}$ conditional on $\mathrm{X}_{2}$ within $\mathrm{n}$ groups of $X_{2}$ intervals. These methods were applied using the RandomForests (Breiman 2001) and ggRandomForests packages (Ehrlinger 2015) within R 3.4.3 statistical software.

\section{Putative candidate variables of fruit production}

To apply RF modelling, we selected stands and years with a complete dataset of potential predictors. Thus, among the initial 48 stands and 566 fruit biomass site-years, analyses were performed on 43 stands (20 beech stands and 23 oak stands) accounting for 460 site-years (204 and 256, respectively). For climate data, we studied a pool of 285 candidate variables combining values or differences from current and previous years (Kelly et al. 2013; Vacchiano et al. 2017) at an annual, seasonal, or monthly scale for rainfall, temperature, wind speed, global radiation, PET, CWB... (See Climate Data section). We also included monthly NAO values (12 values per year). C resource availability was assessed from a pool of 122 simulated GPP, NPP and $\mathrm{C}$ reserves $\left(\mathrm{gC} \mathrm{m}^{-2}\right.$ month $^{-1}$ or season ${ }^{-1}$ or year $\left.^{-1}\right)$. For pollination, we studied seven variables: total annual pollen counts $\left(\mathrm{gr} \mathrm{m}^{-3} \mathrm{y}^{-1}\right)$, mean daily number of pollen grain (over the whole year or over the period of pollen emission), dates of the (i) onset, (ii) peak, and (iii) end of pollen emission, and duration (number of days) of emission. Atmospheric pollen concentrations do not provide any direct information on pollination success, so we used the pollen concentration time series and climate data to define a set of "pollen meteorology indexes". We hypothesized that warm and dry conditions during the period of pollen flight would generally increase pollination success, allowing for longer pollen residence time in the atmosphere (Kasprzyck et al. 2014). Hence the 108 pollen meteorology indexes were computed as the average temperature (daily min, max, or average), relative humidity and average rainfall, or number of days in 1- to 60-day windows from (i) the start date of pollen emission, and (ii) the observed peak date of pollen emission. Finally, for oak, current and previous-year detrended tree-ring width (ResRW) was also considered as an explanatory variable for acorn production. We further tested the importance of stand characteristics, phenological variables (leaf unfolding, leaf colouring, growing season length (Lebourgeois et al. 2010), and soil nutritional values $(\mathrm{pH}$, carbon-nitrogen ratio, saturation rate, nitrogen and phosphorus contents in the first 
two soil horizons) (Brêthes et al. 1997). As those variables never entered as discriminant predictors of fruit production in the RF models, we excluded them from the rest of the analysis.

Finally, we studied 524 variables as predictors of the fruit produced annually throughout all site-years. We performed RF modelling at the genus scale (i.e. considering $F$. sylvatica on the one hand and grouping $Q$. petraea and $Q$. robur on the other hand). For oak, we mixed data from the two species because (i) pollen data were only available at the genus level, (ii) too few data were available for Quercus robur to compute an accurate specific model, and (iii) similar fruiting patterns were observed between $Q$. petraea and $Q$. robur stands growing under similar ecological conditions (data not shown). We designed five nested RF models for oak and beech according to the nature of the candidate predictors (Table 1): model $\mathbf{C}$ included only climate data; model CG included simulated carbon balance (GPP, NPP, tree C reserves) data in addition to model C; model CGP included pollen data in addition to model CG; model CGPCP included pollen meteorology data in addition to model CGP; model CGPW (for oak) included tree-ring width data in addition to model CGPCP. All these models included previous-year fruit production to account for a possible lag-1 effect (i.e. a negative auto-correlation). Following previous works (Kelly et al. 2013; Vacchiano et al. 2017) that evidenced a strong influence of

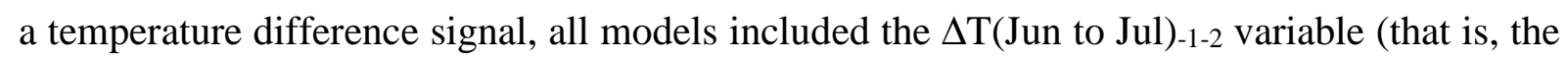
difference in average June-July temperatures between the last-but-one year (year-1) and the last-but-two year (year-2) preceding the current year; Vacchiano et al. 2017). The functional interpretation of $\Delta \mathrm{T}$ is still unclear and possibly related to resource availability (Vacchiano et al. 2017) and to resource-limited floral induction (Monks et al. 2016), so we further included the year-1 and year- 2 simulated components of the carbon balance in all models but the $\mathrm{C}$ model, which only included climate data (see above). As parsimony is an underlying requirement in the modeling effort to reduce the risk of overfitting (Evans et al. 2009), only the six best candidate predictors were retained for each final model. Relationships among predictors were also analyzed to avoid collinearity problem (Dormann et al. 2013) (Online Resource 15). As RF models gave qualitatively similar results for fruit biomass and fruit number (i.e. similar environmental drivers, data not shown), we chose to only present fruit biomass models. 


\section{Results}

\section{Fruit production and airborne pollen concentrations}

Oak stands produced an annual mean of $251 \mathrm{~kg}$ of acorns per ha (Fig. 2a), with an average amount of ca. 250,000 acorns ha ${ }^{-1} \mathrm{y}^{-1}$ (Online Resource 3). Beech stands produced a mean of $174 \mathrm{~kg}$ of nuts ha- $\mathrm{y}^{-1}$ (Fig. 2b), i.e. an average number of more than one million nuts per ha (Online Resource 3). For all three species, fruit represented only around $5 \%$ of the total amount of litterfall (Online Resource 3), and no link emerged between stand dendrometric characteristics and fruit production.

Although the total amounts of nuts was highly variable among stands, a fruit-bearing cycle with a two-year return period appeared in beech (Fig. $2 \mathrm{~b}$ and $3 \mathrm{~b}$ ). A high-production year was followed by a reduced production year (lag- 1 autocorrelation $=-0.54, \mathrm{p}<10^{-9}$, Online Resource 6), with high synchronization among populations (Online Resource 7). The highest acrosspopulation median value was observed in $2004\left(573 \mathrm{~kg} \mathrm{ha}^{-1}\right)$ and the lowest in 2005 (2.9 $\mathrm{kg} \mathrm{ha}$ $\left.{ }^{1}\right)$.

Oak fruit production appeared highly variable over the years for a given stand as well as across stands. The oak fruit-bearing cycle appeared quite different with (i) a less pronounced bisannuality of fruit production as compared to beech (but still on average a significant lag-1 autocorrelation $=-0.14, \mathrm{p}<0.03$, Online Resource 6), and (ii) no clear synchronization among populations (Fig. 2a and 3a) (Online Resource 7). Some stands produced acorns relatively regularly, whereas others produced acorns at very irregular intervals. For these stands, a long period (5 to 10 years) with no or very low acorn production was followed by a very high production year. The highest median fruit production values were observed in 2007 (438 kg ha${ }^{1}$ ). That year was also the most "synchronized" year: high production (up to $125 \%$ of the mean value) was observed for more than $60 \%$ of the stands.

The airborne pollen concentration time series reconstructed for oak (Fig. 2c) and beech (Fig. 2d) displayed contrasted patterns. Whether considering daily means or annual sums, airborne pollen concentrations were one order of magnitude higher in oak than in beech. In beech, air pollen concentrations were clearly biennial (Fig. 2d and 3d) (lag-1 autocorrelation $=-0.41$, $\mathrm{p}<10^{-7}$, Online Resource 6); that behaviour was not so marked in oak (lag-1 autocorrelation = $0.23, \mathrm{p}<0.01$, Online Resource 6). In beech, pollen emission was synchronized across stands (Fig. 2c and 3c). 


\section{Ecological determinism of fruit production}

\section{Oak stands}

The best RF models (CGPCP and CGPW) explained around 16\% of the spatio-temporal variance of acorn biomass (Table 1 and Fig. 4). The mean temperature in the 16-day period following the onset of pollen emission (Tpol16) and spring (April) temperature were the most important predictors, followed by previous September temperature, summer and spring water balance, and August GPP. In the CGPW model, RF also linked current-year wood growth and fruit crop. Whatever the model, neither the airborne pollen concentration nor previous-year resources (under the form of simulated components of the carbon balance or previous-year acorn crop) were identified as discriminant predictors of acorn production.

Partial dependence plots showed strong nonlinearity of the acorn production response, with a sharp shift in predicted biomass for air temperature thresholds of $13^{\circ} \mathrm{C}$ for the onset of pollen emission, $11^{\circ} \mathrm{C}$ in April, and $16.5^{\circ} \mathrm{C}$ in previous September (Fig. 4). Warm temperatures during these periods were associated with increased acorn biomass. The highest marginal effect was observed during pollen emission, when a $13^{\circ} \mathrm{C}$ to $17^{\circ} \mathrm{C}$ rise more than tripled acorn biomass (Fig. 4). In April, a 2.5-increase in predicted biomass was observed when the temperature rose from $11^{\circ} \mathrm{C}$ to $15^{\circ} \mathrm{C}$. Given the major role of these drivers, the partial dependence of the remaining variables looked flat (Fig. 4). Lastly, predicted fruit biomass was all the higher as annual radial growth increased (ResRW > 0) (Fig. 4). Conditioning plots showed that the interaction of increasing temperatures in the 16-day period following the onset of pollen emission (Tpol16) with increasing April temperatures, summer GPP or summer CWB (less negative, i.e. wetter, values) favored a high fruit biomass production (Fig. 5a, c-d). Similarly, the co-occurrence of both high spring temperatures and high radial growth was observed at siteyears of high acorn production (Fig. 5b). Overall, the RF models overestimated observed low values and underestimated observed high fruit production values (Online Resource 8).

\section{Beech stands}

The proportion of variance explained by the RF models was higher for beech $(\sim 45 \%)$ than for oak ( 16\%) (Table 1 and Fig. 6). The RF models highlighted a high dependency of fruit 
production on temperature, followed by pollen and GPP. Fruit production was closely linked to thermal conditions, (i) during the previous years through $\Delta \mathrm{T}$ (Jun to Jul) $)_{-1-2}$ (i.e. the difference in average June-July temperatures between year -1 and -2) and T(Jun-Jul)-2 (i.e. the average June-July temperature (in ${ }^{\circ} \mathrm{C}$ ) in year -2), and (ii) in February and October of the current year. Unlike for oak, the airborne pollen concentration and NAO variables appeared relevant to predict fruit biomass, but no pollen meteorology indexes were selected by the RF models (Table 1 and Fig. 6). Lastly, RF models identified late-season GPP (November) as a marginal predictor of fruit production.

Among the predictors selected to explain the variance in beech fruit production, $\Delta \mathrm{T}(\mathrm{Jun}-\mathrm{Jul})_{-1-}$ 2 was clearly dominant, and made the partial dependence of the remaining variables look rather flat (Fig. 6). A positive difference in summer temperatures between the two previous years (i.e. the summer of year -1 warmer than the summer of year -2) led to a $\sim 3$-fold fruit biomass increase (Fig. 6). Warmer conditions in current February and October also promoted annual fruit production. The respective thresholds were $6^{\circ} \mathrm{C}$ and $11^{\circ} \mathrm{C}$, corresponding to rises in biomass values of $45 \%$ and $67 \%$. In contrast, a warm summer two years before fruit production $\left(\sim 17^{\circ} \mathrm{C}\right.$ threshold) decreased annual production by $40 \%$ (Fig. 6). Finally, daily values of airborne pollen concentrations above $5 \mathrm{gr} \mathrm{m}^{-3}$ led to a $30 \%$ increase of biomass. Increasing November GPP also promoted biomass, with a threshold value of $5 \mathrm{gC} \mathrm{m}^{-2}$ (+20\%, Fig. 6). Conditioning plots showed that when summer temperature differences $(\Delta \mathrm{T})$ were negative (i.e. when the summer of year-1 was colder than the summer of year-2), the fruit biomass remained low whatever the values of the other parameters (Fig. 7a-c). Thus, pollen and autumn environmental drivers (temperature in October or GPP in November) promoted biomass more efficiently in the case of positive differences in summer temperatures between the two previous years. Similarly to oak, the RF models overestimated observed low values and underestimated observed high fruit production values (Online Resource 9). 


\section{Discussion}

\section{Contrasting determinants of fruit production in oak and beech}

In oak, fruit production in year $y$ increased with current spring temperatures (Fig. 4), as already observed across the Quercus genus under both warm temperate (Fearer et al. 2008) and Mediterranean climates (Koenig et al. 1996; Pearse et al. 2014). More precisely, we evidenced that temperatures during the 16-day window following the start of pollen emission was a key predictor of fruit production in oak. These results support the pollen synchrony hypothesis already reported in oak (Bogdziewicz et al. 2017a, b for Q. petraea, Q. robur and Q. ilex and Koenig et al. 2015 for Californian oaks). Moreover, they are reinforced by the negative correlation observed in our data between pollen emission duration and temperature (Spearman $\rho=-0.53, \mathrm{p}<10^{-9}$, Online Resource 10 ). Interestingly, we did not identify pollen count data as a predictor of fruit production in oak; this suggests that the measured regional air pollen concentration was not a critical determinant of fruit production in our dataset. Similar observations were made on oaks in Eastern (Kasprzyk et al. 2014; Bogdziewicz et al. 2017b) and Mediterranean Europe (Fernandez-Martinez et al. 2012), in line with the decoupling of flower and fruit production (Ducousso et al. 1993; Bogdziewicz et al. 2017b) in these species.

Oaks are highly self-incompatible (Ducousso et al. 1993). Therefore we hypothesize that years of high synchronization of pollen emission among trees is characterised by high competition among pollen grains emitted by genetically (hence phenologically) distant individuals, favouring pollination success (Almeida-Neto and Lewinsohn 2004; Savolainen et a. 2007). On the other hand, in years of low synchronization, female flowers would more frequently be pollinated by pollen emitted by genetically similar trees, belonging to their phenological class (e.g. "early" or "late" tree), yielding a lower pollination success due to higher genetic resemblance. More generally, we should point out that most of the discussions about pollination success (Pearse et al. 2015, Bogdziewicz et al. 2017a, b) take into account pollen emissions, but rarely take into account female flower responsiveness (Rapp et al. 2013). Yet this latter point deserves attention because the development of male and female flowers is asynchronous (protandry) in oak, and the time window of pistillate flower responsiveness is rather short (Ducousso et al. 1993). Thermal dependence of flower formation can be hypothesized to interpret the positive dependence of fruit production of year $y$ September temperatures on year $-1(y-1)$ September temperatures (Fig. 4), but finds no direct support in the literature. 
Aside from the prominent influence of temperature, our results show that oak fruit production may be limited by resource (carbon and water) availability. We evidenced a positive dependence of acorn production on the August carbon (GPP) and water availability of the current year, when the phenological synchrony limitation is released (Fig. 5). This result is coherent with data showing that the mass development of acorns occurs mostly in AugustSeptember in northern temperate oaks (Sharp and Sprague 1967; Bonnet-Masimbert 1984; N. Delpierre, unpublished results on sessile oak). With respect to carbon, these results confirm the role of current-year photosynthesis (Hoch et al. 2013, Ichie et al. 2013, Han and Kabeya 2017), as opposed to dependence on carbon reserves accumulated during previous years. RF analysis indeed did not retain simulated carbon reserves or previous-year GPP or previous-year acorn crop as influent predictors of current-year acorn production. The small but positive influence of the August water balance was not particularly expected in these mesic forests (as opposed to its usual mention under Mediterranean climates, e.g. Perez-Ramos et al. 2010, Bogdziewicz et al. 2017a), and will deserve further investigations. It may echo the higher sensitivity of organ growth to water limitation, as compared to the sensitivity of photosynthesis, (Hsiao and Acevedo 1974; Körner, 2015), reported for wood growth in mesic conditions (Delpierre et al. 2016a).

In beech, our results confirm a prominent relationship with the temperature differential index $(\Delta \mathrm{T})$ of the two previous years, as initially proposed by Kelly et al. (2013) and reported in Vacchiano et al. 2017. The functional interpretation of temperature differential indexes has been discussed by Pearse et al. 2014. These authors showed that the success of $\Delta \mathrm{T}$ to explain interannual variability of Quercus lobata fruit production was "not as a cue but rather explained by its close relationship to the proximate drivers that have a direct, mechanistic relationship with acorn crop size". The proximate drivers in question were temperature during previous April (related to the pollen coupling hypothesis) and the previous-year acorn crop (related to the resource-limitation hypothesis). Our RF modelling approach included putative predictors related to both sets of hypotheses (i.e. pollen weather conditions for pollen coupling, and simulated $\mathrm{C}$ resources in the previous years for resource-limitation). The fact that these variables were not included in the final RF models (Table 1) suggests a low impact of these drivers on fruit production in beech, leaving open the question of the functional meaning of $\Delta \mathrm{T}$ (Kelly et al. 2013). We further noticed that removing $\Delta \mathrm{T}$ or $\mathrm{T}$ from the set of putative drivers over the previous years did not allow for previous-year resource variables to enter the RF model, whether simulated from CASTANEA or measured on the previous year crop. This did not 
support the resource-limitation or resource-signalling hypothesis (postulated e.g. in Vacchiano et al. 2017). However, we highlighted that a large part of our C-resource variables were simulated, not measured (except on previous year crops). Although the model we used for simulations fitted well with measured C flux (Delpierre et al. 2012), wood growth (Guillemot et al. 2017) and C reserve (Davi et al. 2009) data, its evaluation in the RENECOFOR stands remained partial. Therefore we cannot be fully sure about the validity of the C-resource data used in the RF approach. We did not include simulated $\mathrm{N}$ resources (Han et al. 2014) in our analyses because CASTANEA simulations of the $\mathrm{N}$ cycle still need validation against local data.

Besides the influence of $\Delta \mathrm{T}$, we evidenced positive relationships between fruit production in beech and current-year February and October temperatures, as well as with November GPP (Fig. 6). The latter was not particularly expected because (i) only a small part of fruit production is shed in November in beech (Lebret et al. 2001), and (ii) fruit maturation (i.e. fruit mass increase) is reported to occur much earlier, in July and August (Oswald, 1984). Interestingly, the $\Delta \mathrm{T}$ variable fully eclipsed the role of the airborne pollen load, which appeared as the most important predictor of fruit production in beech (Kasprzyk et al. 2014; Bogdziewicz et al. $2017 \mathrm{~b}$ ) when $\Delta \mathrm{T}$ was not taken into account (data not shown, but in this "no- $\Delta \mathrm{T}$ " model, the $\mathrm{R}^{2}=0.28$ was much lower than in the present model $\mathrm{R}^{2}>0.40$, Table 1 ). In both cases (i.e. considering $\Delta \mathrm{T}$ or not in the RF model), we observed a clear threshold-type dependence of fruit production on the airborne pollen load (Fig. 6). The average beech airborne pollen concentration in the RNSA data (7 grains $\mathrm{m}^{-3}$ of air) was one order of magnitude lower than for oak (41 grains $\mathrm{m}^{-3}$ of air), consistent with other datasets accounting for the relative abundances of tree species (Geburek et al. 2012). We hypothesized that these low pollen loads reduced the probability of pollination (Lyles et al. 2015) and in turn fructification in beech. Beech airborne pollen loads showed a distinct biennial pattern (Fig. 2d and 3d), which echoed the bienniality of floral initiation already reported in this species (Bonnet-Masimbert 1984). Bienniality is possibly caused by hormonal inhibition of reproductive bud initiation during a year of fruit production, similarly to observations in orchard trees (Mc Laughlin and Greene 1991).

\section{Descriptive power of statistical analyses for fructification time series}

We chose to work on quantitative, continuous fructification data, contrary to other approaches based on semi-quantitative categorical tree crop data (Drobyshev et al. 2010; Hacket-Pain et al. 
2015; Vacchiano et al. 2017). Whichever the data type (quantitative or categorical), analyses of long-term forest tree fructification time series are characterised by their low descriptive power. A review of the literature showed that the percentage of variance in the fructification time series explained by statistical models steeply decreases with the number of site-years (Online Resources 11 and 12). This pattern probably arose from the progressive reduction ability of statistical models to describe datasets of increasing variance related to environmental conditions and/or population ontogeny or genetic differentiation. As we aimed to describe spatio-temporal variation of fruit production across temperate forests, we gave the opportunity to our machinelearning approach to include both spatial (stand age, dendrometric measurements, soil nutrient and water reserve characteristics) and spatio-temporal (pollen, weather-related and simulated carbon fluxes) predictors. Since spatial predictors were systematically excluded by the RF algorithm, we can conclude that populations cannot be differentiated based on the site characteristics we tested.

Another source of variance that possibly affected the descriptive ability of our approach is the presence of noise in both the dependent variables (fructification time series) and predictors. The average amount of fruit produced per stand area unit was difficult to measure in forests ${ }^{1}$ (Online Resource 13), notably in tree species presenting pulsed intermittent fruit production characterised by a very large amplitude. Contrary to most published studies, we worked with natural quantitative biomass data (not log-transformed or categorical data, Online Resource 11). We believe that an accurate description of the spatio-temporal variability of fruit production (which is by essence highly variable, hence heteroscedastic, in temperate forests) will be best approached using quantitative biomass data because they preserve the natural variability of the signal. This natural variability needs to be described if we are to extrapolate the results in a quantitative mechanistic framework aimed at understanding the impact of fructification on ecosystem functioning. The RF framework we used for our analysis was a non-parametric method, therefore free of any assumption about data distribution (Breiman 2001).

The pollen count data used as predictors were not measured in forests, but in urban areas located 4 to 101 (mean 65) km from the RENECOFOR stands. For beech, the overall cross-site synchronicity of the pollen time series $(54 \%$ of site pair combinations yielded significant

\footnotetext{
${ }^{1}$ e.g. intra-stand spatial variation of fruit production reached an average coefficient of variation of $106 \%$ across ten litter traps representing a 2.5- $\mathrm{m}^{2}$ sampling area over four years of moderate to good acorn production (20132016) in a temperate sessile oak forest (FR-Fon ICOS research station, www.barbeau.u-psud.fr) (Berveiller D, Delpierre N. and Dufrêne E., unpublished data).
} 
correlations of their pollen rank time series) gave us confidence in the use of distant pollen data as a proxy for local forest pollen concentrations. Pollen time series were much less synchronous across oak stands (23\% of stand pair combinations yielded significant correlations of their pollen rank time series). Such spatial heterogeneity may have compromised the use of distant pollen measurements as representative estimates of local pollen concentrations.

\section{Assessing the hypothesis of a growth $v$ s. reproduction trade-off}

The hypothesis-testing of a trade-off between traits is often impaired by multiple collinearities among the candidate traits and environmental variables (Knops et al. 2007; Hacket-Pain et al. 2015). To avoid such a hurdle, we first standardized tree ring width data (TRW, a proxy for tree secondary growth, Online Resource 5) and thereafter used ring width indexes as predictors in the RF model. We observed a positive link between growth and the stand reproductive effort in oak (Fig. 4), so that no trade-off was observed in this dataset between these two carbon sinks. Such positive relationships have already been observed in both temperate and Mediterranean Quercus species at the population level (Askeyev et al. 2005; Perez-Ramos et al. 2010; Alla et al. 2012; Martin et al. 2015), while negative relationships have also been reported at the individual tree level (Martin et al. 2015). Together with the identification of positive links between summer (August) carbon and water availability on fruit production (Fig. 5), these results support the hypothesis that resource availability is an important driver of plant production in Quercus species: "good" production years favour structural C investments in multiple tissues (Perez-Ramos et al. 2010).

Our dataset was more restricted for beech stands, with only 66 site-years' worth of TRW data collected in only 5 stands, so that we did not include this predictor in the main analysis. Yet, the RF analysis conducted on this shorter dataset revealed an opposite pattern in beech as compared to oak (Online Resource 14). In beech, the link between secondary growth and reproductive effort was negative. This confirms a trade-off between these two traits, as already exposed in the literature for this species (Drobyshev et al. 2010; Mund et al. 2010; Hacket-Pain et al. 2015), and more generally in the Fagus genus (Kon et al. 2005).

Finally, since previous-year $\mathrm{C}$ resources were not selected in the fruit production models, the hypothesis of C-resource accumulation as a necessary condition for fruiting (termed resourcestorage in Pearse et al. 2016) is not supported by our results. 


\section{Conclusions and perspectives}

We tested the influence of weather conditions, airborne pollen (under the form of both pollen load and pollen climatology), and carbon and water resources as putative predictors of fruit production. In oak, our results confirmed that fruit production was linked to temperature cues, and further evidenced a marginal positive dependence on current summer carbon and water resources. Temperatures during the pollen emission period were the best predictor of fruit production, supporting the pollen synchrony hypothesis based on an unprecedented large dataset (see Bogdziewicz et al. 2017b for evidence on a smaller dataset). In a previous study conducted on the same tree populations, we identified carbon acquisition as the main -but not sole - driver of wood production in oak (Guillemot et al. 2015). Since the role of carbon inputs appeared to be of secondary importance as regards fruit production, our results point to a differential role of resource (carbon) availability in the limitation of organ (wood vs. fruits) growth in oak. In beech, our results confirmed earlier studies reporting a trade-off between secondary growth and reproductive effort. We further confirmed that fructification of beech was primarily related to the differential summer temperature index ( $\Delta \mathrm{T}$, Kelly et al. 2013). Our results add to the discussion relative to the interpretation of the $\Delta \mathrm{T}$ index since the RF approach did not select variables of previous-year resources, whether under the form of simulated $\mathrm{C}$ fluxes from the two preceding years or the form of previous-year fruit crop, considered jointly with $\Delta \mathrm{T}$ in the same RF model or separately from $\Delta \mathrm{T}$ in another RF model. Yet, these variables have been found or hypothesized as correlated with the $\Delta \mathrm{T}$ index (Monks et al., 2016; Vacchiano et al. 2017). When $\Delta \mathrm{T}$ was not taken into account, the RF model pointed to the amount of airborne pollen as the best predictor of fruit production in beech. All processes involving pollen, i.e. initiation and maturation of male flowers, anther dehiscence, pollen flight, and pollination, respond to environmental cues. Internal (carbon and/or nutrient resource) tree limitations also respond to environmental cues, but they remain largely unknown and deserve further investigations.

Our study aimed to understand the sources of variability of fruit production in temperate deciduous trees throughout large spatial and temporal scales. To this aim, we used climate, Cresource and pollen-related variables aggregated from months to years. We believe that further progress could arise from the identification of finer time windows, in relation to flower/fruit development phenophases (e.g. see Sharp and Sprague 1967). 
Finally, the formulation of a realistic process-based model of fruit production requires further work. This is obvious when considering the low to moderate share of variance explained by the non-parametric RF method across our large dataset ( $c a .16 \%$ and $45 \%$ of variance in the fruit signals explained in oak and beech, respectively). Candidate approaches for investigation will notably imply refining the coarse description of resource availability currently used in resourcebudget models (Abe et al. 2016). For example, these models will have to be coupled with ecophysiological models able to simulate the dynamics of carbon, water (Delpierre et al. 2012; Guillemot et al. 2017), and nutrients (notably N; Han and Kabeya 2017) at the individual scale (Oddou-Muratorio and Davi, 2014).

\section{Acknowledgements}

This paper builds on data gathered over thousands of hours of field and technical work done by: the Office National des Forêts (ONF) foresters, who collected and classified litterfall data; and collaborators of the RNSA network who prepared and analysed pollen observation data. We warmly thank them for their work. We thank Hilaire Martin and Baco Said-Allaoui for their work on early related projects, Sebastien Daviller and Raphaël Aussenac for their helpful technical assistance, and Valentin Journé for pointing papers on the seasonality of fruit production in beech. Finally, we thank two anonymous reviewers for constructive comments that helped improving the paper.

\section{Authors' contributions}

F.L., N.D. and E.D. designed the research. F.L and N.D analysed the data and wrote the manuscript, with inputs from E.D. S.C., S.M., L.C., and M.N. collected and prepared the fructification data. F.L. collected and prepared the ring width and climate data. N.D. prepared the CASTANEA simulations and the pollen data.

Conflict of Interest: The authors declare that they have no conflict of interest. 


\section{References}

Abe T, Tachiki Y, Kon H, Nagasaka A, Onodera K, Minamino K, Han QM, Satake A (2016) Parameterisation and validation of a resource budget model for masting using spatiotemporal flowering data of individual trees. Ecology Letters 19:1129-1139

Alla AQ, Camarero JJ, Maestro-Martinez M, Montserrat-Marti G (2012) Acorn production is linked to secondary growth but not to declining carbohydrate concentrations in current-year shoots of two oak species. Trees 26: 841-850

Almeida-Neto M, Lewinsohn TM (2004) Small-scale spatial autocorrelation and the interpretation of relationships between phenological parameters. Journal of Vegetation Science 15: 561-568

Askeyev OV, Tischin D, Sparks TH, Askeyev IV (2005) The effect of climate on the phenology, acorn crop and radial increment of pedunculate oak (Quercus robur) in the middle Volga region, Tatarstan, Russia. Int J Biomet 49: 262-266

Aubin I, Munson AD, Cardou F, Burton PJ, Isabel N, Pedlar JH, Paquette A, Taylor AR, Delagrange S, Kebli H, et al (2016) Traits to stay, traits to move: a review of functional traits to assess sensitivity and adaptive capacity of temperate and boreal trees to climate change. Environ Rev 24: $164-186$

Benito-Garzon M, Fernandez-Manjarres J (2015) Testing scenarios for assisted migration of forest trees in Europe. New Forests 46: 979-994

Bogdziewicz M, Fernandez-Martinez M, Bonal R, Belmonte J, Espelta JM (2017a) The Moran effect and environmental vetoes: phenological synchrony and drought drive seed production in a Mediterranean oak. Proceedings of the Royal Society B-Biological Sciences 284: 20171784

Bogdziewicz M, Szymkowiak J, Kasprzyk I, Grewling L, Borowski Z, Borycka K, Kantorowicz W, Myszkowska D, Piotrowicz K, Ziemianin M, Pesendorfer MB (2017b) Masting in windpollinated trees: system-specific roles of weather and pollination dynamics in driving seed production. Ecology 98:2615-2625

Bonnet-Masimbert M. 1984. Biologie florale et cycle de reproduction de quelques arbres forestiers. Douglas, pin sylvestre, chêne. In: Pesson P, Louveaux J (eds) Pollinisation et productions végétales, INRA éditions, 219-242

Breiman L (2001) RandomForests. Machine Learning 45: 5-32

Brêthes A, Ulrich E, Lanier M, Clausse M, Colombet M, Curt T, Delahaye-Panchout M, Bermaux B, Douzon G, Duthy X, Guitton J, Nouals D, Savoie JM, Sinet JF, Poulin F, Musch J (1997) Caractéristiques pédologiques des 102 peuplements du réseau. Office National des Forêts

Crone EE, Rapp JM (2014) Resource depletion, pollen coupling, and the ecology of mast seeding. In: Ostfeld, R.S., Power, A.G. (Eds.), Year in Ecology and Conservation Biology, pp. 21-34 
Davi H, Barbaroux C, Francois C, Dufrene E (2009) The fundamental role of reserves and hydraulic constraints in predicting LAI and carbon allocation in forests. Agr Forest Meteorol 149: 349361

Delpierre N, Berveiller D, Granda E, Dufrene E (2016a) Wood phenology, not carbon input, controls the interannual variability of wood growth in a temperate oak forest. New Phytologist 210:459470

Delpierre N, Soudani K, Francois C, Le Maire G, Bernhofer C, Kutsch W, Misson L, Rambal S, Vesala T, Dufrene E (2012) Quantifying the influence of climate and biological drivers on the interannual variability of carbon exchanges in European forests through process-based modelling. Agr Forest Meteorol 154: 99-112

Delpierre N, Vitasse Y, Chuine I, Guillemot J, Bazot S, Rutishauser T, Rathgeber CBK (2016b) Temperate and boreal forest tree phenology: from organ-scale processes to terrestrial ecosystem models. Annals of Forest Science 73:5-25

Dormann CF, Elith J, Bacher S, Buchmann C, Carl G, Carre G, Marquez JRG, Gruber B, Lafourcade B, Leitao PJ, Munkemuller T, McClean C, Osborne PE, Reineking B, Schroder B, Skidmore AK, Zurell D, Lautenbach S (2013) Collinearity: a review of methods to deal with it and a simulation study evaluating their performance. Ecography 36: 27-46

Drobyshev I, Overgaard R, Saygin I, Niklasson M, Hickler T, Karlsson M, Sykes MT (2010) Masting behaviour and dendrochronology of European beech (Fagus sylvatica L.) in southern Sweden. For Ecol Manag 259: 2160-2171

Ducousso A, Michaud H, Lumaret R (1993) Reproduction and gene flow in the genus Quercus L. Ann For Sci 50: $91 \mathrm{~s}-106 \mathrm{~s}$

Dufrêne E, Davi H, François C, Le Maire G, Le Dantec V, Granier A (2005) Modelling carbon and water cycles in a beech forest Part I: Model description and uncertainty analysis on modelled NEE. Ecol Model 185: 407-436

Ehrlinger J (2015) ggRandomForests: Random Forests for Regression. [WWW document] URL _. [accessed 1 September 2016]

Evans JS, Murphy MA, Holden ZA, Cushman SA (2009) Modeling Species Distribution and Change Using Random Forest. C.A. Drew et al. (eds.), Predictive Species and Habitat Modeling in Landscape Ecology, Concepts and Applications, DOI 10.1007/978-1-4419-7390-0_8, Springer Science+Business Media, LLC 2011, 139-159

Fearer TM, Norman GW, Pack JC, Sr., Bittner S, Healy WM (2008) Influence of physiographic and climatic factors on spatial patterns of acorn production in Maryland and Virginia, USA. J Biogeogr 35: 2012-2025

Fernandez-Martinez M, Belmonte J, Espelta JM (2012) Masting in oaks: Disentangling the effect of flowering phenology, airborne pollen load and drought. Acta Oecol 43: 51-59 
Fernández-Martínez, M., Vicca, S., Janssens, I. A., Espelta, J. M., \& Peñuelas, J. (2017). The North Atlantic Oscillation synchronises fruit production in western European forests. Ecography 40: 864-874.

Geburek T, Hiess K, Litschauer R, Milasowszky N (2012) Temporal pollen pattern in temperate trees: expedience or fate? Oikos 121: 1603-1612

George SS (2014) An overview of tree-ring width records across the Northern Hemisphere. Quaternary Sci Rev 95: 132-150

Guillemot J, Delpierre N, Vallet P, François C, Martin-StPaul NK, Soudani K, Nicolas M, Badeau V, Dufrêne E (2014) Assessing the effects of management on forest growth across France: insights from a new functional - structural model. Ann Bot doi:10.1093/aob/mcu059

Guillemot J, Francois C, Hmimina G, Dufrêne E, Martin-StPaul NK, Soudani K, Marie G, Ourcival JM, Delpierre N (2017) Environmental control of carbon allocation matters for modelling forest growth. New Phytol 214: 180-193

Guillemot J, Martin-StPaul NK, Dufrêne E, François C, Soudani K, Ourcival JM, Delpierre N (2015) The dynamic of the annual carbon allocation to wood in European tree species is consistent with a combined source-sink limitation of growth: implications for modelling. Biogeosciences 12: 2773-2790

Hacket-Pain AJ, Friend AD, Lageard JGA, Thomas PA (2015) The influence of masting phenomenon on growth-climate relationships in trees: explaining the influence of previous summers' climate on ring width. Tree Physiol 35: 319-330

Han Q, Kabeya D (2017) Recent developments in understanding mast seeding in relation to dynamics of carbon and nitrogen resources in temperate trees. Ecological Research DOI 10.1007/s11284017-1494-8:1-8

Han Q, Kabeya D, Iio A, Inagaki Y, Kakubari Y (2014) Nitrogen storage dynamics are affected by masting events in Fagus crenata. Oecologia 174: 679-687

Hedhly A, Hormaza JI, Herrero M (2007) Warm temperatures at bloom reduce fruit set in sweet cherry. J Appl Bot Food Qual 81: 158-164

Hoch G, Siegwolf RTW, Keel SG, Korner C, Han QM (2013) Fruit production in three masting tree species does not rely on stored carbon reserves. Oecologia 171: 653-662

Hsiao TC, Acevedo E (1974) Plant responses to water deficits, water-use efficiency and drought resistance. Agricultural Meteorology 14, 59-84.

Hurrell JW, Deser C (2010) North Atlantic climate variability: The role of the North Atlantic Oscillation. J Marine Syst 79: 231-244

Hurrell JW, Kushnir Y, Ottersen G, Visbeck M (2003) An Overview of the North Atlantic Oscillation. The North Atlantic Oscillation: Climatic Significance and Environmental Impact. Geophysical Monograph 134: 1-35 
Ichie T, Igarashi S, Yoshida S, Kenzo T, Masaki T, Tayasu I (2013) Are stored carbohydrates necessary for seed production in temperate deciduous trees? J Ecol 101: 525-531

Ishwaran E (2007) Variable importance in binary regression trees and forests. Elect J Statistics 1: 519537

Kasprzyk I, Ortyl B, Dulska-Jez A (2014) Relationships among weather parameters, airborne pollen and seed crops of Fagus and Quercus in Poland. Agr Forest Meteorol 197: 111-122

Kelly D (1994) The evolutionary ecology of mast seeding. Trends in Ecology \& Evolution 9: 465-470

Kelly D, Geldenhuis A, James A, Holland EP, Plank MJ, Brockie RE, Cowan PE, Harper GA, Lee WG, Maitland MJ, Mark AF, Mills JA, Wilson PR, Byrom AE (2013) Of mast and mean: differentialtemperature cue makes mast seeding insensitive to climate change. Ecol. Lett. 16: 90-98

Kelly D, Sork VL (2002) Mast seeding in perennial plants: Why, how, where? Annu Rev Ecol Systemat 33: $427-447$

Knops JMH, Koenig WD, Carmen WJ (2007) Negative correlation does not imply a tradeoff between growth and reproduction in California oaks. P Natl Acad Sci 104: 16982-16985

Koenig WD, Knops JMH (2000) Patterns of annual seed production by northern hemisphere trees: A global perspective. Am Nat 155: 59-69

Koenig WD, Knops JMH, Carmen WJ, Pearse IS (2015) What drives masting? The phenological synchrony hypothesis. Ecology 96: 184-192

Koenig WD, Knops JMH, Carmen WJ, Stanback MT, Mumme RL (1996) Acorn production by oaks in central coastal California: Influence of weather at three levels. Can J For Res 26: 1677-1683

Kon H, Noda T, Terazawa K, Koyarna H, Yasaka M (2005) Proximate factors causing mast seeding in Fagus crenata: the effects of resource level and weather cues. Can J Bot 83: 1402-1409

Koralewski TE, Wang HH, Grant WE, Byram TD (2015) Plants on the move: Assisted migration of forest trees in the face of climate change. For Ecol Manag 344: 30-37

Körner C (2015) Paradigm shift in plant growth control. Current Opinion in Plant Biology 25: 107-114

Lebourgeois F, Bréda N, Ulrich E, Granier A (2005) Climate-tree-growth relationships of European beech (Fagus sylvatica L.) in the French Permanent Plot Network (RENECOFOR). Trees 19: $385-401$

Lebourgeois F, Gomez N, Pinto P, Mérian P (2013) Mixed stands reduce Abies alba tree-ring sensitivity to summer drought in the Vosges mountains, western Europe. For Ecol Manag 303: 61-71

Lebourgeois F, Piedallu C (2005) Appréhender le niveau de sécheresse dans le cadre des études stationnelles et de la gestion forestière à partir d'indices bioclimatiques. Rev For Fr 57: 331-356

Lebourgeois F, Pierrat JC, Perez V, Piedallu C, Cecchini S, Ulrich E (2010) Simulating phenological shifts in French temperate forests under two climatic change scenarios and four driving GCMs. Int J Biomet 54: 563-581

Lebret M, Nys C, Forgeard F (2001) Litter production in an Atlantic beech (Fagus sylvatica L.) time sequence. Ann. For. Sci. 58: 755-768. 
Liaw A, Wiener M (2002) Classification and regression by randomForest. R News 2-3: 18-22

Lin Y, Jeon Y (2006) Random forests and adaptive nearest neighbors. J Am Stat Assoc 101: 578-590

Lyles D, Rosenstock TS, Hastings A (2015) Plant reproduction and environmental noise: How do plants do it? J Theor Biol 371: 137-144

Mares I, Mares C, Mihailescu M (2002) NAO impact on the summer moisture variability across Europe. Phys Chem Earth 27: 1013-1017

Martin D, Vazquez-Pique J, Carevic FS, Fernandez M, Alejano R (2015) Trade-off between stem growth and acorn production in holm oak. Trees 29: 825-834

McLaughlin, J. M., Greene, D. W (1991) Fruit and hormones influence flowering of apple. II. Effects of hormones. J Amer Soc Hort Sci, 116: 450-453

Menzel A, Sparks TH, Estrella N, Eckhardt S (2005) 'SSW to NNE' - North Atlantic Oscillation affects the progress of seasons across Europe. Global Change Biol 11: 909-918

Mérian P, Bontemps JD, Bergès L, Lebourgeois F (2011) Spatial variation and temporal instability in climate-growth relationships of sessile oak (Quercus petraea [Matt.] Liebl.) under temperate conditions. Plant Ecol 212: 1855-1871

Misson L, Degueldre D, Collin C, Rodriguez R, Rocheteau A, Ourcival JM, Rambal S (2011) Phenological responses to extreme droughts in a Mediterranean forest. Global Change Biology $17: 1036-1048$

Miyazaki Y, Maruyama Y, Chiba Y, Kobayashi MJ, Joseph B, Shimizu KK, Mochida K, Hiura T, Kon H, Satake A (2014) Nitrogen as a key regulator of flowering in Fagus crenata: understanding the physiological mechanism of masting by gene expression analysis. Ecology Letters 17:12991309

Monks A, Kelly D (2006) Testing the resource-matching hypothesis in the mast seeding tree Nothofagus truncata (Fagaceae). Austral Ecol 31: 366-375

Monks A, Monks JM, Tanentzap AJ (2016) Resource limitation underlying multiple masting models makes mast seeding sensitive to future climate change. New Phytol 210: 419-430

Mueller-Haubold H, Hertel D, Leuschner C (2015) Climatic Drivers of Mast Fruiting in European Beech and Resulting C and N Allocation Shifts. Ecosystems 18: 1083-1100

Mueller-Haubold H, Hertel D, Seidel D, Knutzen F, Leuschner C (2013) Climate Responses of Aboveground Productivity and Allocation in Fagus sylvatica: A Transect Study in Mature Forests. Ecosystems 16: 1498-1516

Mund M, Kutsch WL, Wirth C, Kahl T, Knohl A, Skomarkova MV, Schulze ED (2010) The influence of climate and fructification on the inter-annual variability of stem growth and net primary productivity in an old-growth, mixed beech forest. Tree Physiol 30: 689-704

Nussbaumer A, Waldner P, Etzold S, Gessler A, Benham S, Thomsen IM, Jorgensen BB, Timmermann V, Verstraeten A, Sioen G, et al (2016) Patterns of mast fruiting of common beech, sessile and 
common oak, Norway spruce and Scots pine in Central and Northern Europe. For Ecol Manag 363: $237-251$

Oddou-Muratorio S, Davi H (2014) Simulating local adaptation to climate of forest trees with a PhysioDemo-Genetics model. Evol. Appl. 7: 453-467

Oshiro TM, Perez PS, Baranauskas JA (2012) How Many Trees in a Random Forest? Machine Learning and Data Mining in Pattern Recognition 7376: 154-168

Oswald H (1984) Floraison, pollinisation et fructification chez le Hêtre (Fagus sylvatica L.). In: Pesson P, Louveaux J (eds) Pollinisation et productions végétales, INRA éditions, pp 243-258

Ottersen G, Planque B, Belgrano A, Post E, Reid PC, Stenseth NC (2001) Ecological effects of the North Atlantic Oscillation. Oecologia 128: 1-14

Pearse IS, Koenig WD, Funk KA, Pesendorfer MB (2015) Pollen limitation and flower abortion in a wind-pollinated, masting tree. Ecology 96: 587-593

Pearse IS, Koenig WD, Kelly D (2016) Mechanisms of mast seeding: resources, weather, cues, and selection. New Phytol 212: 546-562

Pearse IS, Koenig WD, Knops JMH (2014) Cues versus proximate drivers: testing the mechanism behind masting behavior. Oikos 123: 179-184

Peaucelle M (2011) Time trends in forest litterfall production and relationships with environmental changes: An exploratory approach on data collected from 1995 to 2007 in the RENECOFOR monitoring network. Office National des Forêts, Département des Recherches Techniques, France

Perez-Ramos IM, Ourcival JM, Limousin JM, Rambal S (2010) Mast seeding under increasing drought: results from a long-term data set and from a rainfall exclusion experiment. Ecology 91: 30573068

Piedallu C, Gégout JC, Bruand A, Seynave I (2011) Mapping soil water holding capacity over large areas to predict potential production of forest stands. Geoderma 160: 355-366

Piedallu C, Gégout JC, Lebourgeois F, Seynave I (2016) Soil aeration, water deficit, nitrogen availability, acidity and temperature all contribute to shaping tree species distribution in temperate forests. J Veg Sci 27: 387-399

Prasad AM, Iverson LR, Liaw (2006) Newer classification and regression tree techniques: Bagging and random forests for ecological prediction. Ecosystems 9: 181-199

Rapp JM, McIntire EJB, Crone EE (2013) Sex allocation, pollen limitation and masting in whitebark pine. J. Ecol. 101: 1345-1352

Satake A, Bjornstad ON (2008) A resource budget model to explain intraspecific variation in mast reproductive dynamics. Ecol Res 23: 3-10

Savolainen O, Pyhajarvi T, Knurr T (2007) Gene flow and local adaptation in trees. Annual Review of Ecology Evolution and Systematics 38: 595-619 
Sharp WM, Sprague VG (1967) Flowering and fruiting in white oaks, pistillate flowering acorn development weather and yields. Ecology 48: 243-251

Silvertown JW (1980) The evolutionary ecology of mast seeding in trees. Biological J Linnean Soc 14: $235-250$

Smaill SJ, Clinton PW, Allen RB, Davis MR (2011) Climate cues and resources interact to determine seed production by a masting species. J Ecol 99: 870-877

Sork V, Bramble J (1993) Prediction of acorn crops in three species of North American oaks: Quercus alba, Q rubra and Q velutina. Ann For Sci 50: 128s-136s

Stenseth NC, Ottersen G, Hurrell JW, Mysterud A, Lima M, Chan KS, Yoccoz NG, Adlandsvik B (2003) Studying climate effects on ecology through the use of climate indices: the North Atlantic Oscillation, El Nino Southern Oscillation and beyond. Proc Biol Sci 270: 2087-2096

Strobl C, Malley J, Tutz G (2009) An Introduction to Recursive Partitioning: Rationale, Application and Characteristics of Classification and Regression Trees, Bagging and Random Forests. Psychol Methods 14: 323-348

Thornthwaite CW, Mather JR (1955) The water balance. Drexel Institute of Climatology Laboratory, Climatology publication 8: 1-104

Trouvé R, Bontemps JD, Seynave I, Collet C, Lebourgeois F (2015) Stand density, tree social status and water stress influence allocation in height and diameter growth of Quercus petraea (Liebl.). Tree Physiol 35: 1035-1046

Ulrich E (1995) Le réseau RENECOFOR : objectifs et réalisation. Rev For Fr 47: 107-124

Vacchiano G, Hacket-Pain A, Turco M, Motta R, Maringer J, Conedera M, Drobyshev I, Ascoli D (2017) Spatial patterns and broad-scale weather cues of beech mast seeding in Europe. New Phytol doi: 10.1111/nph.14600

Vander Wall SB (2001) The evolutionary ecology of nut dispersal. Botanical Review 67: 74-117

Vidal J-P, Martin E, Franchisteguy L, Baillon M, Soubeyroux J-M (2010) A 50-year high-resolution atmospheric reanalysis over France with the Safran system. Int J Climatol 30: 1627-1644

Vitasse Y, Schneider L, Rixen C, Christen D, Rebetez M (2018) Increase in the risk of exposure of forest and fruit trees to spring frosts at higher elevations in Switzerland over the last four decades. Agricultural and Forest Meteorology 248:60-69

Wesolowski T, Rowinski P, Maziarz M (2015) Interannual variation in tree seed production in a primeval temperate forest: does masting prevail? Eur J Forest Res 134: 99-112

Wright SJ, Carrasco C, Calderon O, Paton S (1999) The El Nino Southern Oscillation variable fruit production, and famine in a tropical forest. Ecology 80: 1632-1647 


\section{Legends of the Figures and Tables}

Fig. 1 Geographical location of the 48 broadleaved stands of the RENECOFOR network and the 81 climatic stations of the Météo-France network. Black circles: 28 Quercus plots (9 Quercus robur and 19 Quercus petraea plots); Grey triangles: 20 Fagus sylvatica stands; Crosses: 81 climatic stations (36 with rainfall (R) only; 33 with temperatures (T) only; 12 with both R and T (Source: Météo-France)).

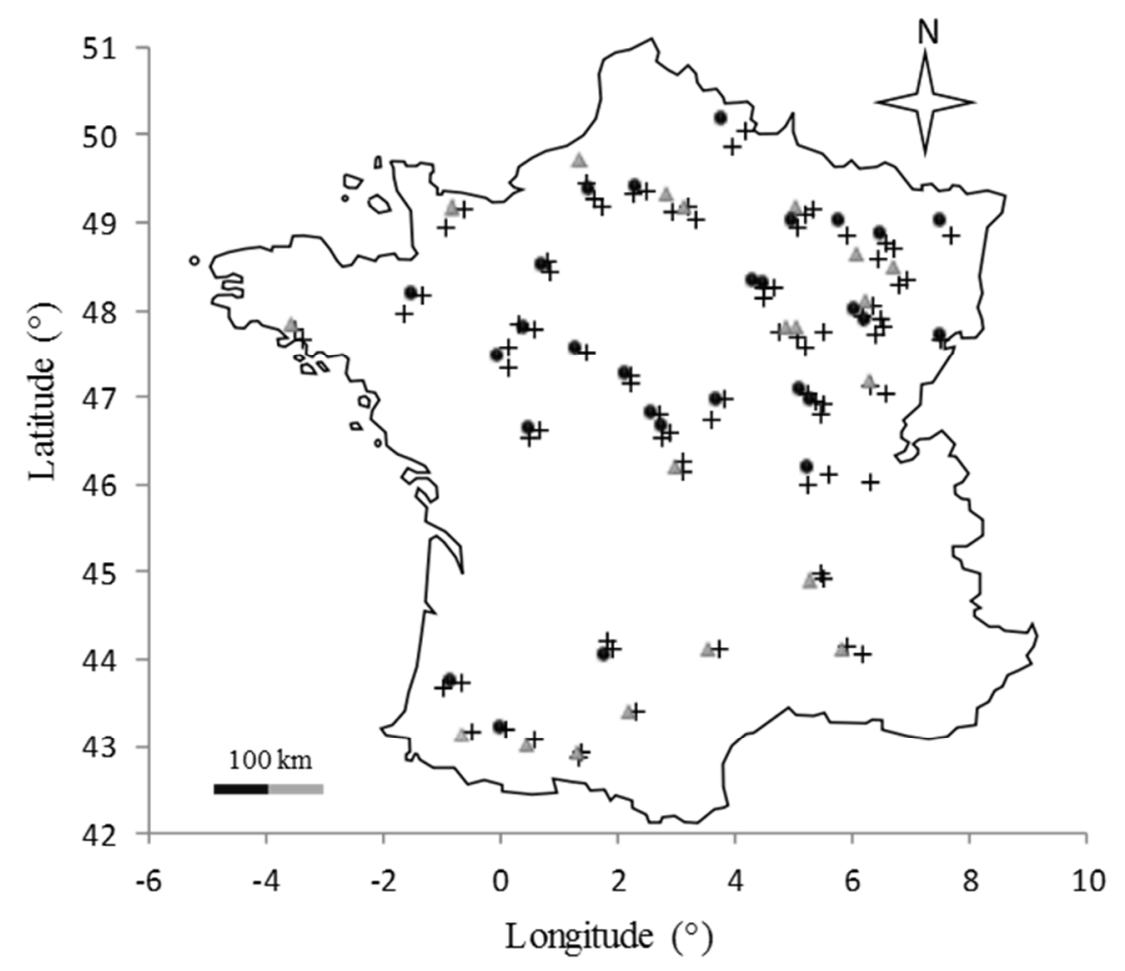


Fig. 2 Interannual variability of fruit biomass production ( $a, b)$ and air pollen concentrations (c, d) in the French temperate deciduous forests of the RENECOFOR network. Grey lines depict measured (fruit) or inferred (pollen) data at the individual stand level. The black line depicts interannual variation of the median value, established across stands.
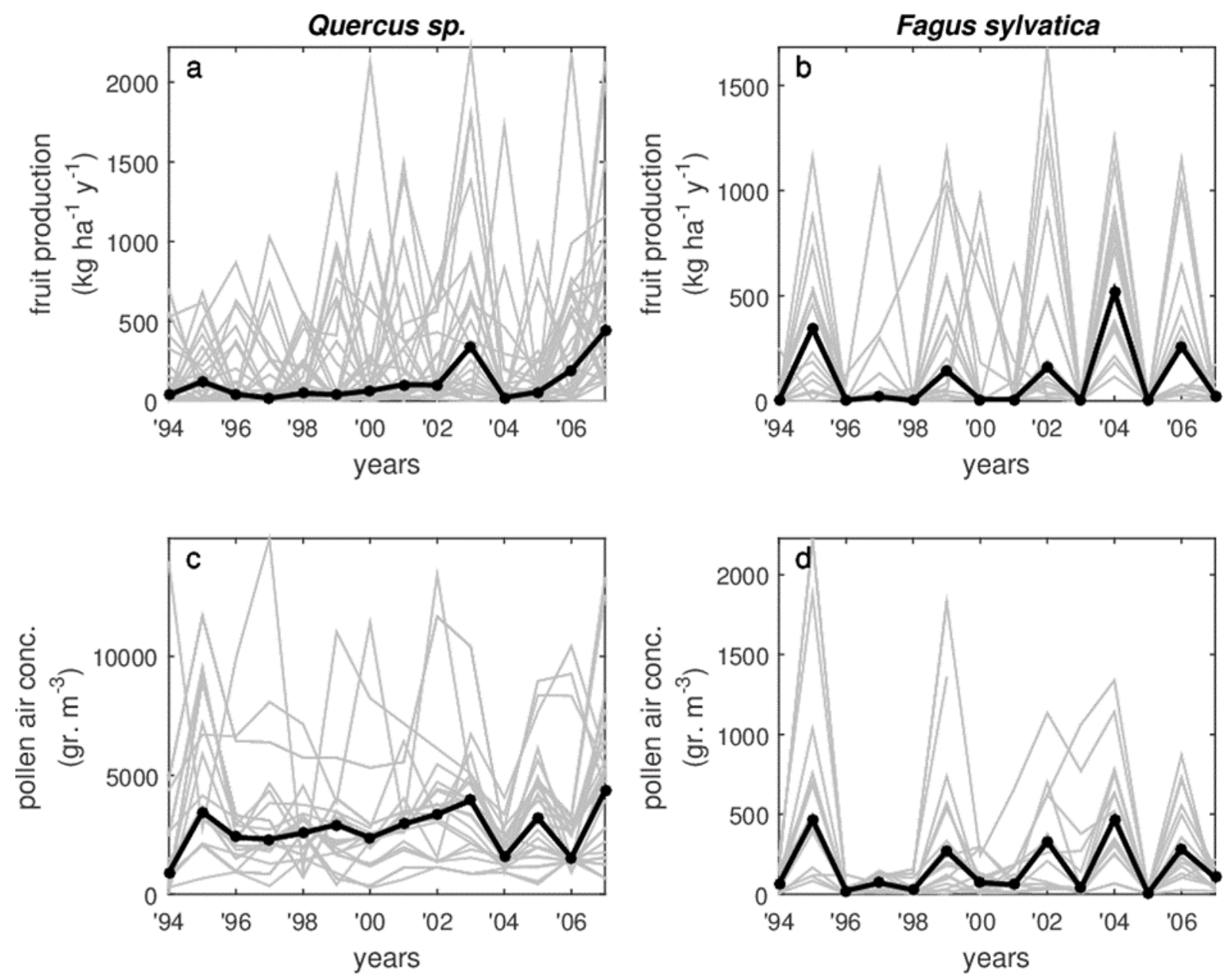
Fig. 3 Periodograms of fruit biomass production (a, b) and air pollen concentration (c, d) time series in French temperate deciduous forests of the RENECOFOR network. Grey lines depict established periodograms at the individual stand level. The black line depicts interannual variation of the median value, established across stands.
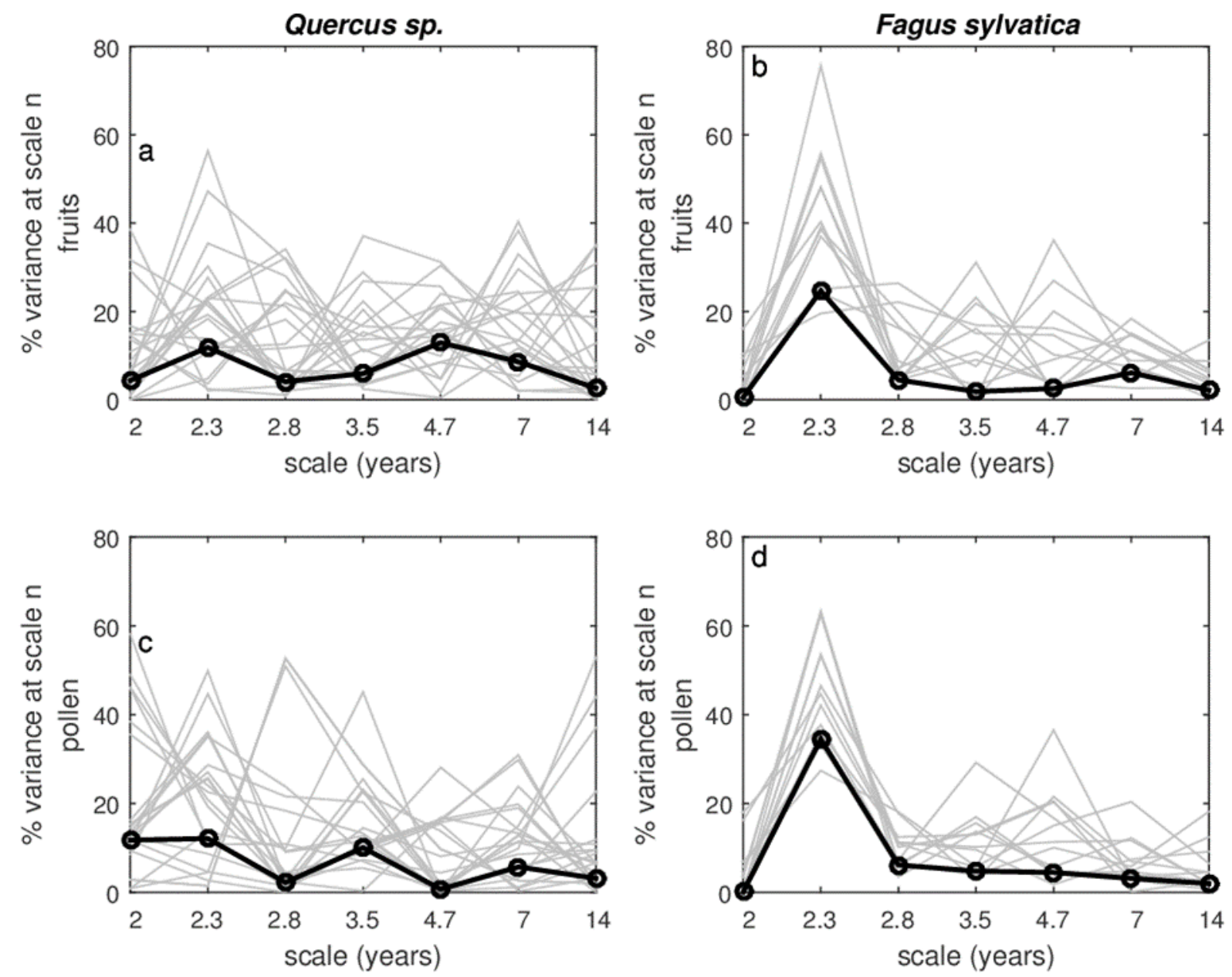
Fig. 4 Partial dependence plots of the six best significant predictors for predicted acorn biomass in the 23 oak stands ( $\mathrm{n}=256$ data) for the CGPW model. Each plot gives a graphical description of the effect of the predictor and highlights threshold response effects. The last graph gives VIMP and DEPTH values for each predictor (sorted from VIMP values). See text and Table 1 for details.
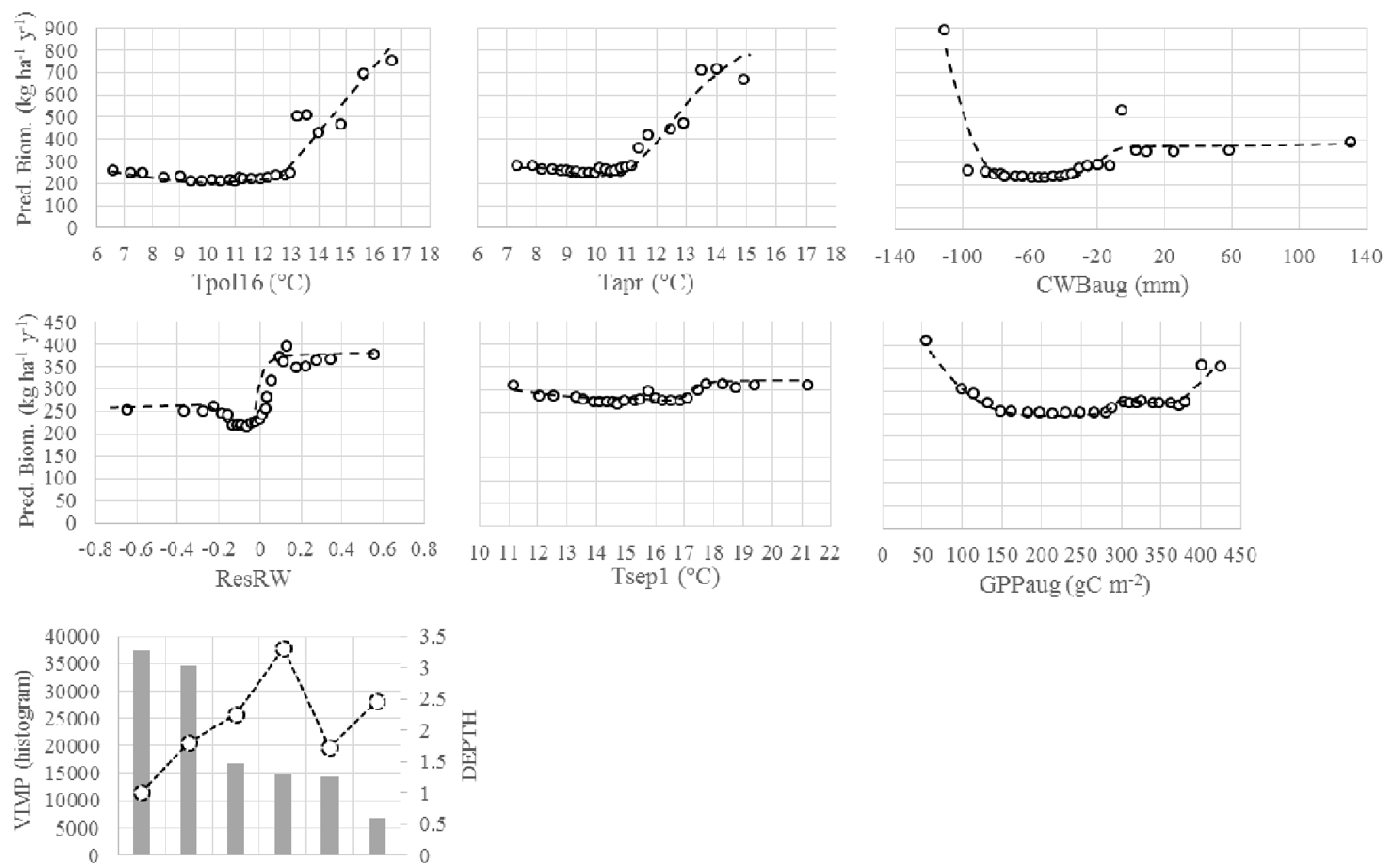
Fig. 5 Conditioning plots of fruit production in the 23 oak stands ( $\mathrm{n}=256$ data). Predicted fruit biomass $\left(\mathrm{kg} \mathrm{ha}^{-1} \mathrm{y}^{-1}\right)$ as a function of the mean temperature during the first 16 days of pollen emission (Tpol16 in ${ }^{\circ} \mathrm{C}$ ) stratified by [a] April temperatures $\left({ }^{\circ} \mathrm{C}\right),[\mathrm{b}]$ tree-ring growth (ResRW, no unit), [c] Climatic Water Balance in August (mm) or [d] Gross Primary Productivity in August $\left(\mathrm{gC} \mathrm{m}^{-2}\right)$ (see text for details).

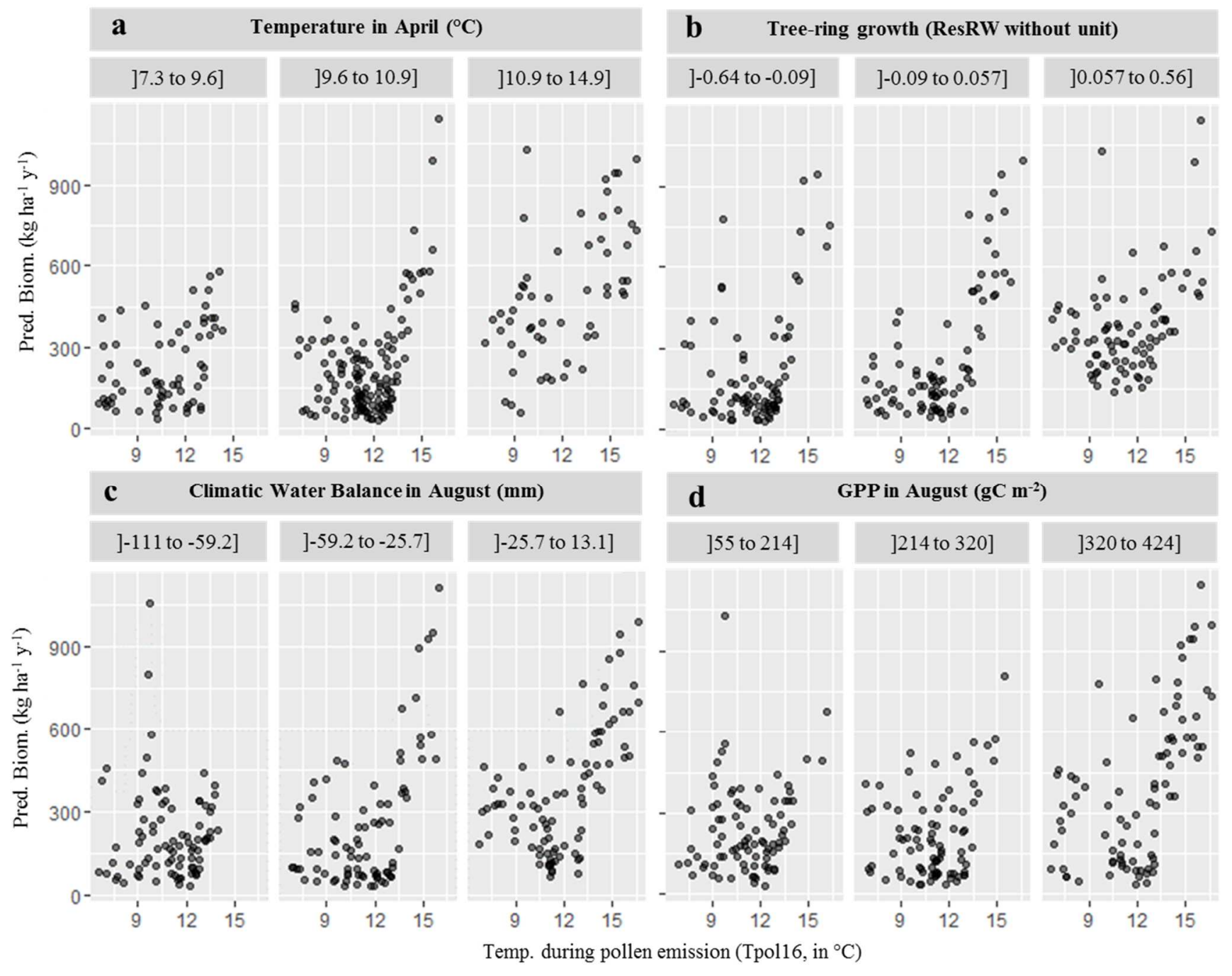


Fig. 6 Partial dependence plots of the six best significant predictors for nut biomass in the 20 beech stands ( $\mathrm{n}=204$ data). Each plot gives a graphical depiction of the effect of the predictor and highlights threshold response effects of the CGP* model. The last graph gives VIMP and DEPTH values for each predictor. See text and Table 1 for details.
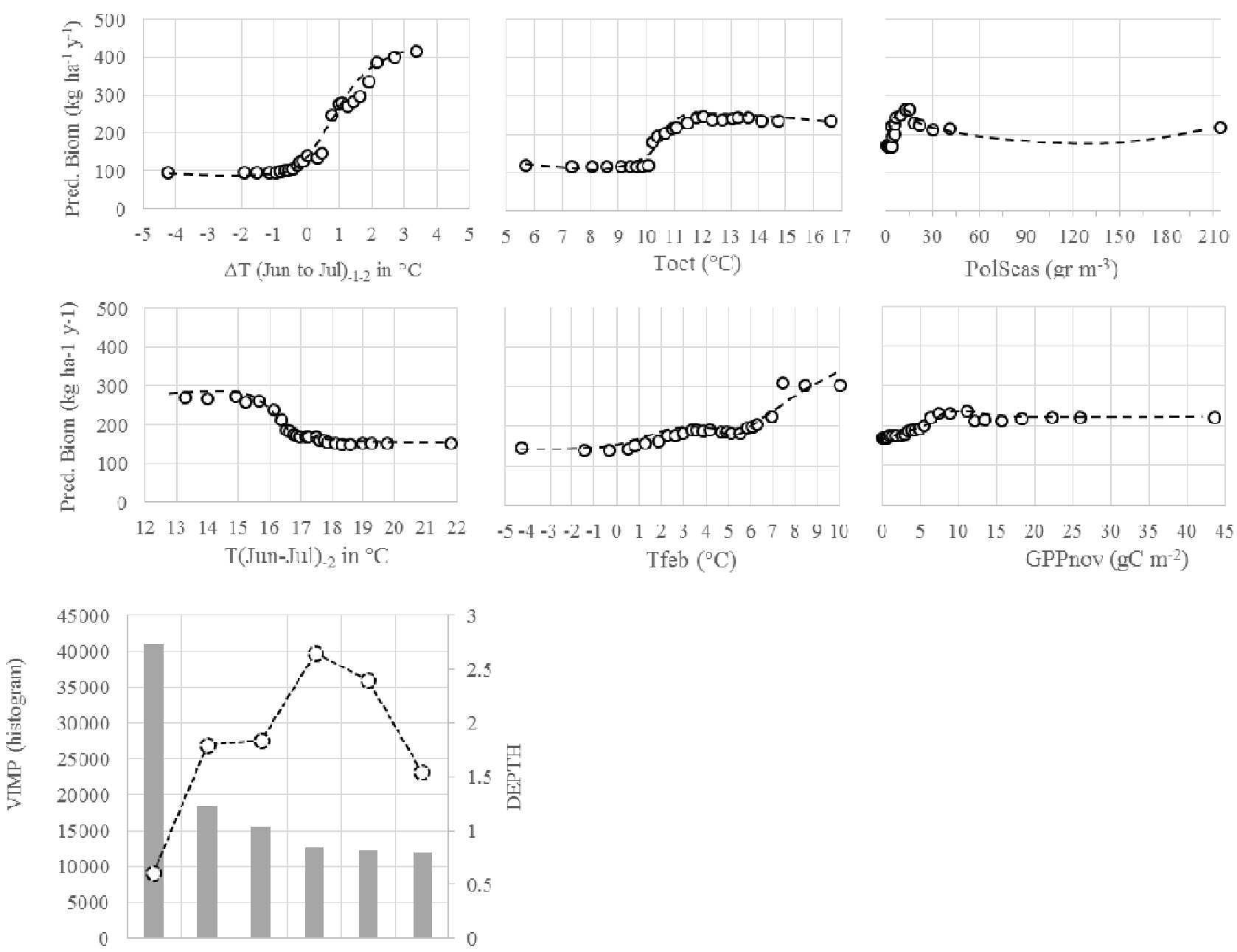
Fig. 7 Conditioning plots of fruit production for the 20 beech stands ( $n=204$ data). Predicted fruit biomass $\left(\mathrm{kg} \mathrm{ha}^{-1} \mathrm{y}^{-1}\right)$ as a function of summer temperature (mean June and July) differences between years -1 and $-2\left(\Delta \mathrm{T}\right.$ in $\left.{ }^{\circ} \mathrm{C}\right)$ stratified by mean daily air pollen concentrations during the emission period $\left(\mathrm{gr} \mathrm{m}^{-3}\right)$ [a], current mean temperature in October $\left({ }^{\circ} \mathrm{C}\right)[\mathbf{b}]$, or Gross Primary Productivity in November $\left(\mathrm{gC} \mathrm{m}^{-2}\right)$ [c] (see text for details).
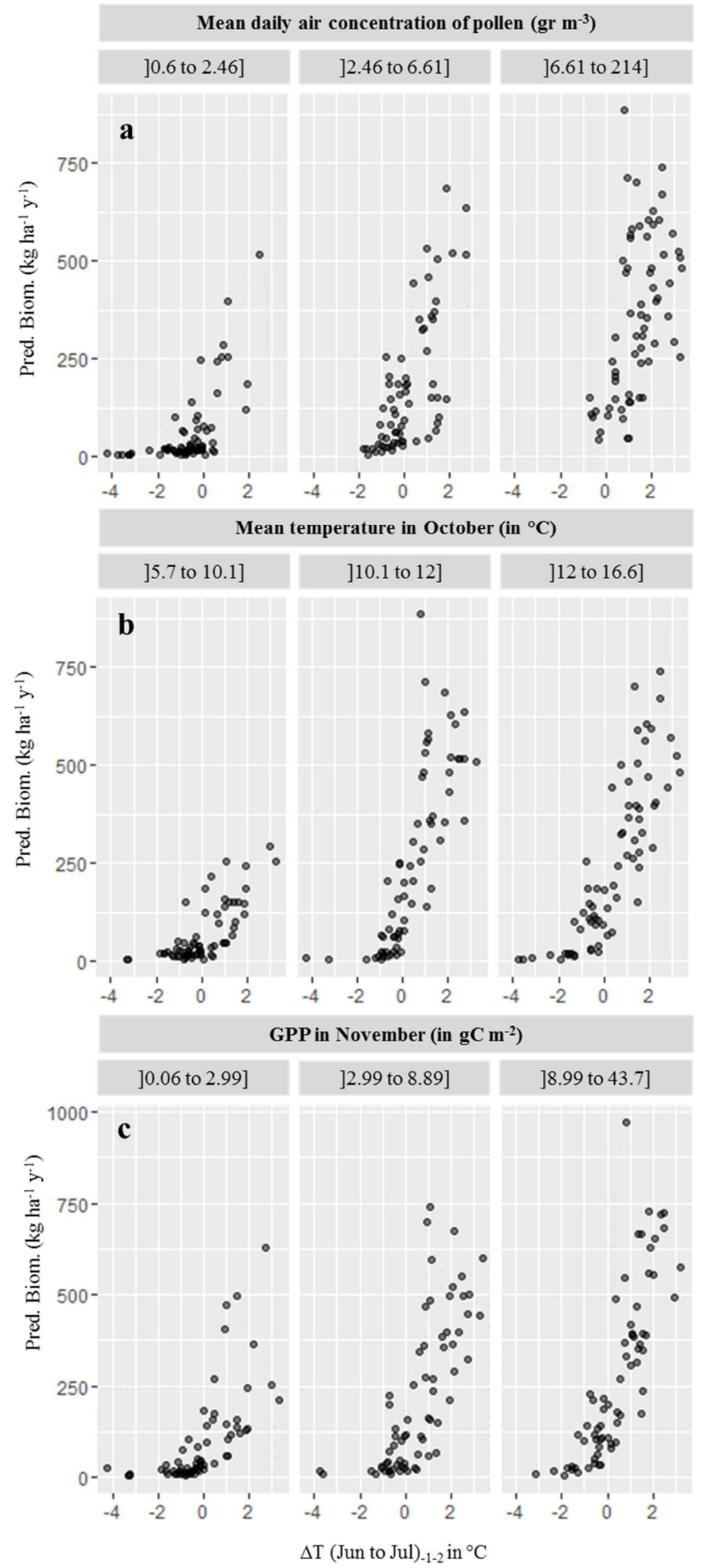
Table 1. Summary of the different RandomForest models obtained for the two species and fruit biomass (Biom. in $\mathrm{kg} \mathrm{ha}^{-1} \mathrm{y}^{-1}$ ). Each model gives the percentages of explained variance, and the RMSEs on the adjusted and predicted values obtained with the six best predictors. For the retained predictors: 1 or $2=$ previous years $(-1=$ one year, $-2=$ two years); capital letters: parameter type; small letters: month or period (except for PolSeas and ResRW). jas = mean value from July to September; as = mean value from August to September; Tpol16 = mean temperature during the first 16 days of pollen emission (in ${ }^{\circ} \mathrm{C}$ ). $\Delta \mathrm{T}$ (Jun to Jul) -1-2 $=$ Difference (in ${ }^{\circ} \mathrm{C}$ ) between mean June to July summer temperatures in year -1 and year -2 ; T (Jun-Jul) $-2=$ Difference (in ${ }^{\circ} \mathrm{C}$ ) between mean temperatures in June and July in year -2 ; PolSeas = mean daily number of pollen grains emitted during the pollen emission period (gr. $\left.\mathrm{m}^{-3}\right)$. Fruit number results (numbers of fruit ha ${ }^{-1} \mathrm{y}^{-1}$ ) were similar but with higher percentages of explained variance (18.2 to 26.8 for Quercus, and 41.6 to 48.4 for Fagus). CGP*: model without NAO values. 


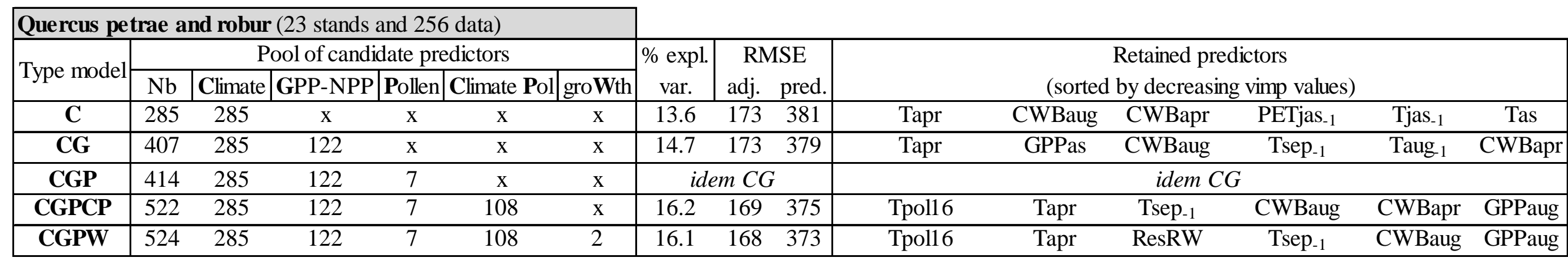

\begin{tabular}{|c|c|c|c|c|c|c|c|c|c|c|c|c|c|c|}
\hline \multicolumn{7}{|c|}{ Fagus sylvatica (20 stands and 204 data) } & \multirow{3}{*}{$\begin{array}{c}\% \text { expl. } \\
\text { var. }\end{array}$} & \multirow{3}{*}{\begin{tabular}{c}
\multicolumn{2}{c|}{ RMSE } \\
adj. \\
pred.
\end{tabular}} & \multirow{3}{*}{\multicolumn{4}{|c|}{$\begin{array}{c}\text { Retained predictors } \\
\text { (sorted by decreasing vimp values) }\end{array}$}} & & \\
\hline \multirow{2}{*}{ Type model } & \multicolumn{6}{|c|}{ Pool of candidate predictors } & & & & & & & & \\
\hline & $\mathrm{Nb}$ & Climate & GPP-NPP & Pollen & Climate Pol & groWth & & & & & & & & \\
\hline $\mathbf{C}$ & 285 & 285 & $\mathrm{x}$ & $\mathrm{x}$ & $\mathrm{x}$ & $\mathrm{x}$ & 44.2 & $106 \quad 242$ & $\Delta \mathrm{T}(\mathrm{Jun} \text { to } \mathrm{Jul})_{-1-2}$ & Toct & Tfeb & $\mathrm{T}(\mathrm{Jun}-\mathrm{Jul})_{-2}$ & NAOapr & PETfeb \\
\hline CG & 407 & 285 & 122 & $\mathrm{x}$ & $\mathrm{x}$ & $\mathrm{x}$ & 46.3 & $104 \quad 238$ & $\Delta \mathrm{T}(\mathrm{Jun} \text { to } \mathrm{Jul})_{-1-2}$ & Toct & Tfeb & $\mathrm{T}(\mathrm{Jun}-\mathrm{Jul})_{-2}$ & GPPnov & NAOapr \\
\hline CGP & 414 & 285 & 122 & 7 & $\mathrm{x}$ & $\mathrm{x}$ & 43.1 & $108 \quad 246$ & $\Delta \mathrm{T}(\mathrm{Jun} \text { to } \mathrm{Jul})_{-1-2}$ & Toct & PolSeas & T(Jun-Jul) $)_{-2}$ & Tfeb & NAOapr \\
\hline CGP* & 402 & 273 & 122 & 7 & $\mathrm{x}$ & $\mathrm{x}$ & 42.9 & $108 \quad 246$ & $\Delta \mathrm{T}(\mathrm{Jun} \text { to } \mathrm{Jul})_{-1-2}$ & Toct & Tfeb & PolSeas & T(Jun-Jul) & GPPnov \\
\hline CGPCP & 522 & 285 & 122 & 7 & 108 & $\mathrm{x}$ & iden & $n C G P$ & & & idem $C$ & & & \\
\hline
\end{tabular}




\section{Short legends for Online Resources (Figures and Tables)}

\section{Online Resource 1 Ecological characteristics of the RENECOFOR network stands}

\begin{tabular}{|c|c|c|c|c|c|c|c|c|c|c|c|c|c|c|c|c|c|c|c|c|c|}
\hline \multirow{2}{*}{ Species } & \multirow{2}{*}{$\begin{array}{l}\text { Site } \\
\text { code }\end{array}$} & \multirow{2}{*}{$\begin{array}{c}\text { Name } \\
\text { of the forest }\end{array}$} & \multirow[t]{2}{*}{ Long. } & \multirow[t]{2}{*}{ Lat. } & \multirow{2}{*}{$\begin{array}{c}\begin{array}{c}\text { Altitude } \\
\text { (m) }\end{array} \\
\end{array}$} & \multirow{2}{*}{$\begin{array}{c}\text { Slope } \\
(\%)\end{array}$} & \multirow[t]{2}{*}{ Aspect } & \multicolumn{2}{|c|}{ Climate } & \multirow{2}{*}{$\begin{array}{l}\text { SWHCm } \\
(\mathrm{mm})\end{array}$} & \multirow{2}{*}{$\begin{array}{c}\text { Humus } \\
\text { C/N }\end{array}$} & \multicolumn{5}{|c|}{ Soil horizon $(0-10 \mathrm{~cm})$} & \multicolumn{5}{|c|}{ Soil horizon $(20-40 \mathrm{~cm})$} \\
\hline & & & & & & & & $\operatorname{Pr}$ & $\mathrm{Te}$ & & & $\mathrm{C} / \mathrm{N}$ & pH & S/T & $\mathbf{N}$ & $\mathbf{P}$ & $\mathrm{C} / \mathrm{N}$ & $\mathrm{pH}$ & $\mathrm{S} / \mathrm{T}$ & $\mathbf{N}$ & $\mathbf{P}$ \\
\hline & QR 10 & de Larivour & 4.30 & 48.34 & 115 & 0 & 1 & 656 & 11.2 & 120 & 24.0 & 14.0 & 4.0 & 81.8 & 3 & 0.025 & 12.0 & 4.1 & 87.2 & 1.1 & 0.008 \\
\hline & QR 18 & de Verneuil & 2.57 & 46.83 & 175 & 0 & I & 799 & 11.8 & 175 & 32.0 & 18.0 & 4.2 & 86.6 & 2.2 & 0.013 & 17.0 & 4.3 & 92.2 & 0.9 & 0.005 \\
\hline है & QR 40 & de Gamarde & -0.84 & 43.74 & 20 & 5 & $\mathrm{NE}$ & 1124 & 14.4 & 140 & 35.0 & 13.0 & 4.5 & 79.4 & 1.2 & 0.015 & 11.0 & 4.4 & 77 & 0.6 & 0.006 \\
\hline 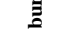 & QR 49 & de Monnaie & -0.04 & 47.46 & 57 & 0 & I & 770 & 11.6 & 170 & 28.0 & 14.0 & 3.8 & 62.8 & 1 & 0.014 & 5.0 & 4.2 & 32.1 & 0.25 & 0.005 \\
\hline$\overline{2}$ & QR 55 & de Haudronville & 5.77 & 49.02 & 220 & 0 & I & 741 & 11.0 & 150 & 35.0 & 15.0 & 4.3 & 84.7 & 2.8 & 0.043 & 12.0 & 4.3 & 88.8 & 1 & 0.007 \\
\hline$气$ & QR 59 & de Mormal & 3.75 & 50.17 & 149 & 3 & I & 699 & 10.6 & 200 & 23.0 & 13.0 & 3.6 & 27 & 2.3 & 0.043 & 12.0 & 4.1 & 57.7 & 0.8 & 0.017 \\
\hline 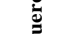 & QR 65 & d'Azereix & -0.04 & 43.20 & 370 & 12 & $\mathrm{SE}$ & 1423 & 13.6 & 140 & 41.0 & 12.0 & 4.2 & 38.6 & 2.5 & 0.013 & 9.0 & 4.2 & 22.2 & 1.4 & 0.005 \\
\hline & QR 70 & d'Anjeux & 6.22 & 47.88 & 240 & 0 & I & 1199 & 10.5 & 170 & 25.0 & 14.0 & 4.2 & 60.8 & 1.7 & 0.022 & 13.0 & 4.2 & 46.9 & 0.8 & 0.01 \\
\hline & QR 71 & de Pourlans & 5.24 & 46.96 & 190 & 0 & 1 & 818 & 11.5 & 180 & 40.0 & 15.0 & 4.0 & 52.8 & 1.5 & 0.026 & 14.0 & 4.1 & 62.1 & 0.7 & 0.011 \\
\hline & QP 01 & de Seillon & 5.24 & 46.17 & 260 & 3 & 1 & 1360 & 12.0 & 170 & 22.0 & 12.0 & 4.1 & 18.6 & 3.5 & 0.022 & 13.0 & 4.1 & 10.8 & 0.8 & 0.008 \\
\hline & QP 03 & de Tronçais & 2.73 & 46.67 & 260 & 0 & I & 774 & 11.7 & 75 & 28.0 & 17.0 & 3.8 & 35 & 1.4 & 0.02 & 16.0 & 4.2 & 22.1 & 0.4 & 0.009 \\
\hline & QP 10 & du Temple & 4.45 & 48.30 & 160 & 0 & I & 656 & 11.2 & 200 & 26.0 & 18.0 & 3.7 & 26.5 & 1.5 & 0.028 & 10.0 & 3.8 & 26.4 & 0.7 & 0.006 \\
\hline & QP 18 & de Vierzon & 2.13 & 47.25 & 176 & 1 & I & 772 & 12.3 & 130 & 31.0 & 18.0 & 3.7 & 22.4 & 1 & 0.014 & 20.0 & 4.1 & 7.9 & 0.31 & 0.005 \\
\hline & QP 21 & de Citeaux & 5.07 & 47.07 & 220 & 0 & I & 818 & 11.5 & 200 & 32.0 & 15.0 & 4.1 & 50.1 & 1.3 & 0.018 & 16.0 & 4.1 & 38.1 & 0.5 & 0.004 \\
\hline & QP 27 & de Lyons & 1.50 & 49.37 & 175 & 0 & I & 878 & 11.3 & 170 & 30.0 & 18.0 & 3.8 & 23.8 & 1.9 & 0.025 & 13.0 & 3.9 & 24.4 & 0.64 & 0.005 \\
\hline & QP 35 & de Rennes & -1.54 & 48.18 & 80 & 0 & I & 702 & 12.4 & 120 & 22.0 & 22.0 & 3.4 & 9.2 & 2 & 0.019 & 11.0 & 4.1 & 6.8 & 0.67 & 0.009 \\
\hline & QP 41 & de Blois & 1.26 & 47.56 & 127 & 0 & I & 672 & 11.8 & 175 & 36.0 & 19.0 & 3.7 & 30.5 & 2.3 & 0.023 & 16.0 & 3.8 & 12.9 & 0.4 & 0.005 \\
\hline & QP 51 & de Chatrices & 4.96 & 49.03 & 180 & 2 & $\mathrm{~S}$ & 815 & 9.9 & 55 & 28.0 & 20.0 & 3.3 & 43.5 & 2 & 0.036 & 19.0 & 3.4 & 21 & 0.62 & 0.014 \\
\hline 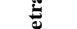 & QP 57a & d'Amelecourt & 6.48 & 48.86 & 315 & 4 & $\mathrm{NE}$ & 745 & 10.4 & 140 & 31.0 & 13.0 & 4.0 & 40.5 & 1.44 & 0.035 & 11.0 & 3.9 & 25.9 & 0.81 & 0.021 \\
\hline & QP 57b & de Mouterhouse & 7.46 & 49.02 & 320 & 15 & NW & 982 & 10.0 & 80 & 26.0 & 22.0 & 3.2 & 13.9 & 2 & 0.014 & 24.0 & 4.3 & 6.2 & 0.4 & 0.005 \\
\hline & QP 58 & de Vincence & 3.66 & 46.96 & 270 & 15 & SW & 806 & 11.2 & 150 & 38.0 & 16.0 & 4.2 & 44.7 & 1.7 & 0.015 & 14.0 & 4.1 & 24.1 & 0.9 & 0.007 \\
\hline & QP 60 & de Hez-Froidmont & 2.29 & 49.39 & 55 & 1 & I & 653 & 10.9 & 125 & 25.0 & 13.0 & 3.8 & 49.5 & 1.3 & 0.031 & 13.0 & 3.9 & 34.7 & 0.3 & 0.004 \\
\hline & QP 61 & de Reno Valdieu & 0.67 & 48.52 & 220 & 5 & SE & 841 & 10.4 & 110 & 29.0 & 17.0 & 3.8 & 43 & 2.5 & 0.013 & 15.0 & 3.8 & 31.7 & 1 & 0.004 \\
\hline & QP 68 & de la Hardt & 7.47 & 47.69 & 256 & 0 & I & 792 & 10.9 & 85 & 29.0 & 16.0 & 4.0 & 39.3 & 1.9 & 0.062 & 16.0 & 4.1 & 18.9 & 0.6 & 0.02 \\
\hline & QP 72 & de Bercé & 0.38 & 47.79 & 170 & 0 & I & 715 & 12.3 & 135 & 24.0 & 23.0 & 3.5 & 21.4 & 1.7 & 0.028 & 24.0 & 3.9 & 9.4 & 0.2 & 0.005 \\
\hline & QP 81 & de Grésigne & 1.75 & 44.04 & 300 & 18 & SE & 867 & 12.8 & 85 & 38.0 & 18.0 & 3.7 & 28.5 & 3.1 & 0.028 & 14.0 & 3.9 & 22 & 0.7 & 0.003 \\
\hline & QP 86 & de Moulière & 0.49 & 46.62 & 116 & 4 & NW & 713 & 12.0 & 80 & 24.0 & 23.0 & 3.2 & 26.8 & 1.8 & 0.02 & 25.0 & 4.0 & 6.4 & 0.4 & 0.005 \\
\hline & QP 88 & de Darney & 6.04 & 48.02 & 330 & 0 & 1 & 1427 & 10.3 & 185 & 37.0 & 17.0 & 4.0 & 26.7 & 2.1 & 0.026 & 14.0 & 4.0 & 22.4 & 0.8 & 0.011 \\
\hline & FS 02 & de Retz & 3.13 & 49.19 & 145 & 0 & 1 & 623 & 12.0 & 200 & 31 & 15.0 & 3.9 & 40.9 & 1.4 & 0.049 & 11.0 & 3.9 & 40.5 & 0.6 & 0.019 \\
\hline & FS 03 & des Colettes & 3.00 & 46.19 & 590 & 15 & $\mathrm{~N}$ & 838 & 11.0 & 88 & 30.0 & 19.0 & 3.7 & 16.9 & 2.4 & 0.013 & 11.0 & 4.1 & 7.2 & 0.7 & 0.005 \\
\hline & FS 04 & du Jabron & 5.80 & 44.13 & 1300 & 50 & $\mathrm{~N}$ & 708 & 13.2 & 120 & 30.0 & 16.0 & 6.0 & 100 & 3.3 & 0.014 & 12.0 & 7.4 & 100 & 2.2 & 0.006 \\
\hline & FS 09 & de Soulan & 1.28 & 42.93 & 1250 & 32 & SW & 1666 & 10.4 & 100 & 30.0 & 16.0 & 3.7 & 21.6 & 6.5 & 0.014 & 15.0 & 4.1 & 9.4 & 2.9 & 0.006 \\
\hline & FS 14 & de Cerisy & -0.86 & 49.18 & 90 & 4 & I & 848 & 11.3 & 95 & 22.0 & 18.0 & 3.6 & 14.4 & 2.5 & 0.021 & 14.0 & 4.1 & 6.8 & 0.8 & 0.007 \\
\hline & FS 21 & de Lugny & 4.86 & 47.81 & 400 & 3 & $\mathrm{NE}$ & 865 & 10.6 & 55 & 42.0 & 18.0 & 6.0 & 100 & 5.7 & 0.037 & 13.0 & 7.4 & 100 & 3 & 0.019 \\
\hline & FS 25 & la Verrière du Grosbois & 6.27 & 47.18 & 570 & 2 & W & 1352 & 9.0 & 105 & 29.0 & 14.0 & 5.2 & 100 & 3.8 & 0.028 & 11.0 & 4.8 & 100 & 1.9 & 0.009 \\
\hline & FS 26 & de Lente & 5.30 & 44.92 & 1320 & 12 & W & 1712 & 12.2 & 50 & 28.0 & 14.0 & 5.9 & 100 & 7.8 & 0.04 & 11.0 & 6.9 & 100 & 4.9 & 0.019 \\
\hline & FS 29 & de Carnoet & -3.54 & 47.84 & 50 & 0 & 1 & 942 & 12.2 & 140 & 26.0 & 20.0 & 4.3 & 18.1 & 2.4 & 0.034 & 17.0 & 4.2 & 15.1 & 0.8 & 0.014 \\
\hline & FS 30 & de l'Aigoual & 3.55 & 44.12 & 1400 & 25 & SW & 2014 & 5.6 & 50 & 23.0 & 22.0 & 3.7 & 17.9 & 4.4 & 0.024 & 21.0 & 4.2 & 9.5 & 2.4 & 0.026 \\
\hline & FS 52 & d'Auberive & 5.07 & 47.80 & 440 & 0 & 1 & 996 & 10.0 & 45 & 40.0 & 15.0 & 6.4 & 100 & 3 & 0.009 & 12.0 & 7.4 & 100 & 1.7 & 0.004 \\
\hline$A$ & FS 54a & des Hauts Bois & 6.71 & 48.51 & 325 & 5 & $\mathrm{E}$ & 780 & 10.9 & 110 & 45.0 & 16.0 & 4.1 & 39.5 & 1.7 & 0.025 & 14.0 & 4.1 & 12.7 & 0.7 & 0.009 \\
\hline & FS 54b & de Haye & 6.07 & 48.65 & 390 & 2 & I & 780 & 10.9 & 60 & 34.0 & 14.0 & 5.0 & 100 & 4.3 & 0.012 & 11.0 & 7.2 & 100 & 3.4 & 0.009 \\
\hline & FS 55 & de Lachalade & 5.00 & 49.17 & 250 & 0 & I & 834 & 11.5 & 80 & 30.0 & 20.0 & 3.8 & 18.5 & 0.9 & 0.013 & 16.0 & 4.0 & 8.1 & 0.3 & 0.005 \\
\hline & FS 60 & de Compiègne & 2.87 & 49.32 & 138 & 0 & I & 738 & 11.2 & 88 & 35.0 & 16.0 & 4.9 & 100 & 2.2 & 0.026 & 12.0 & 6.2 & 100 & 0.6 & 0.005 \\
\hline & FS 64 & d'Ance & -0.66 & 43.15 & 400 & 44 & NW & 1422 & 13.5 & 110 & 35.0 & 13.0 & 4.3 & 76.8 & 2.2 & 0.012 & 9.0 & 4.2 & 63.1 & 1.1 & 0.014 \\
\hline & FS 65 & de Bize & 0.44 & 43.03 & 850 & 25 & NW & 1058 & 12.7 & 88 & 29.0 & 16.0 & 3.7 & 20 & 4.7 & 0.095 & 9.0 & 4.1 & 7.3 & 1.9 & 0.032 \\
\hline & FS 76 & d'Eawy & 1.33 & 49.72 & 210 & 0 & I & 920 & 10.5 & 145 & 26.0 & 16.0 & 3.7 & 15.3 & 1.7 & 0.018 & 12.0 & 4.1 & 6.8 & 0.5 & 0.01 \\
\hline & FS 81 & de la Montagne Noire & 2.18 & 43.41 & 700 & 0 & 1 & 1144 & 11.5 & 100 & 27.0 & 15.0 & 3.9 & 19.1 & 4.8 & 0.053 & 14.0 & 4.3 & 11 & 1.7 & 0.026 \\
\hline & FS 88 & du Ban d'Harol & 6.24 & 48.11 & 400 & 3 & W & 1427 & 10.4 & 100 & 32.0 & 15.0 & 3.9 & 14.1 & 1.4 & 0.011 & 16.0 & 4.0 & 11.9 & 0.7 & 0.005 \\
\hline
\end{tabular}

Online Resource 1 Ecological characteristics of the 48 broadleaved stands of the network RENECOFOR. Pr = average annual amount of precipitation (in mm, 19942013); $\mathrm{Te}=$ mean annual temperature (in ${ }^{\circ} \mathrm{C}, 1994-2013$ ). $\mathrm{SWHCm}=$ maximum soil water reserve content (in $\mathrm{mm}$ ); $\mathrm{C} / \mathrm{N}=$ total carbon to total nitrogen ratio; $\mathrm{pH}$ $(\mathrm{CaCl} 2)=$ acidity measurement; $\mathrm{S} / \mathrm{T}=$ saturation rate $(\%) ; \mathrm{N}$ and $\mathrm{P}=$ nitrogen and phosphorus contents in $\mathrm{p}$. mille. Total $\mathrm{N}$ for $0-10 \mathrm{~cm}$ and organic $\mathrm{N}$ for $20-40 \mathrm{~cm}$. $\mathrm{P}$ $=\mathrm{P}_{2} \mathrm{O}_{5}$ Dyer. 
Online Resource 2 Climatic characteristics along the longitudinal gradient
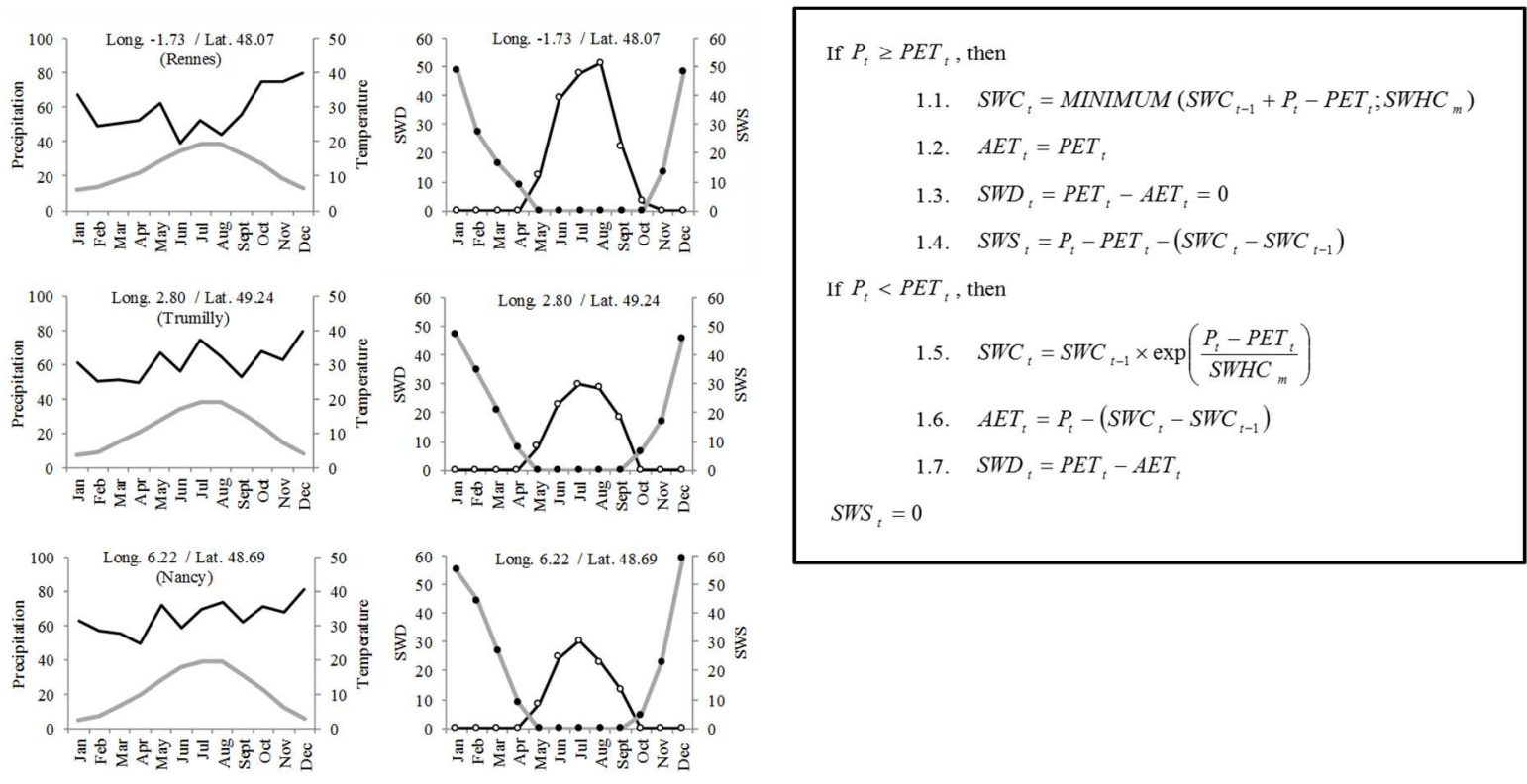

Online Resource 2 Climatic characteristics along the longitudinal gradient (from oceanic to semicontinental climate). Left: mean monthly precipitation (black line in $\mathrm{mm}$ ) and temperature (grey line in ${ }^{\circ} \mathrm{C}$ ) for the period 1994-2013 for 3 stations of the French Network Météo-France (Rennes, Trumilly and Nancy). Right: Mean soil water deficit (SWD in mm, white circles) and soil water surplus (SWS in mm, black circles) for the period 1994-2013. Calculations have been made with a SWHCm of $120 \mathrm{~mm}$ (method form Thornthwaite and Mather, 1955). 
Online Resource 3 Crown, fruit production and phenology in the RENECOFOR network stands

\begin{tabular}{|c|c|c|c|c|c|c|c|c|c|c|c|c|}
\hline \multirow{2}{*}{ Species } & \multirow{2}{*}{$\begin{array}{l}\text { Site } \\
\text { code }\end{array}$} & \multicolumn{3}{|c|}{ Crown $\left(\mathrm{kg} \mathrm{ha}^{-1} \mathrm{y}^{-1}\right)$} & \multicolumn{2}{|c|}{ Fruit (kg or nbha $\left.a^{-1} y^{-1}\right)$} & \multirow[b]{2}{*}{$\mathrm{n}$} & \multicolumn{5}{|c|}{ Leaf phenology } \\
\hline & & Leaves & Branches & Rest & Biomass & Number & & $\mathrm{LU}$ & $\mathrm{n}$ & LC & $\mathrm{n}$ & GSL \\
\hline \multirow{10}{*}{ 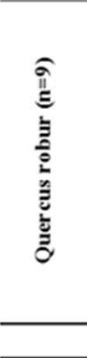 } & QR 10 & $2444(323)$ & $1418(474)$ & $1920(463)$ & $323(506)$ & $407857(520482)$ & 14 & $103(6)$ & 9 & $293(9)$ & 8 & $187(11)$ \\
\hline & QR 18 & $1678(662)$ & $450(349)$ & $808(502)$ & $60(68)$ & $69111(63735)$ & 9 & 99 & 1 & $306(6)$ & 2 & 203 \\
\hline & QR 40 & $1651(1611)$ & $526(459)$ & $124(129)$ & $444(423)$ & $244971(211715)$ & 7 & $79(5)$ & 9 & $324(11)$ & 10 & $249(10)$ \\
\hline & QR 49 & $2459(459)$ & $1069(222)$ & $1860(578)$ & $273(317)$ & $266923(282242)$ & 13 & $87(9)$ & 10 & $299(7)$ & 11 & $211(9)$ \\
\hline & QR 55 & $1063(201)$ & $478(256)$ & $2902(480)$ & $242(465)$ & $168833(300744)$ & 12 & $109(7)$ & 9 & $287(10)$ & 10 & $179(7)$ \\
\hline & QR 59 & $2301(405)$ & $1038(261)$ & $1895(306)$ & $185(263)$ & $134286(190731)$ & 14 & $108(9)$ & 11 & $292(13)$ & 11 & $183(18)$ \\
\hline & QR 65 & $2316(381)$ & $819(246)$ & $512(149)$ & $318(361)$ & $223722(238754)$ & 12 & $94(5)$ & 10 & $298(10)$ & 10 & $205(11)$ \\
\hline & QR 70 & $2027(347)$ & $786(233)$ & $1440(298)$ & $225(542)$ & $186000(349760)$ & 14 & $113(6)$ & 11 & $295(5)$ & 11 & $183(8)$ \\
\hline & QR 71 & $2145(348)$ & $1034(301)$ & $2088(343)$ & $191(283)$ & $218286(274218)$ & 14 & $99(6)$ & 8 & $307(11)$ & 8 & $208(10)$ \\
\hline & & $2009(776)$ & $846(440)$ & $1506(910)$ & $251(386)$ & 218050 (309181) & 109 & 99 (13) & 78 & $299(14)$ & 81 & $201(25)$ \\
\hline \multirow{20}{*}{ 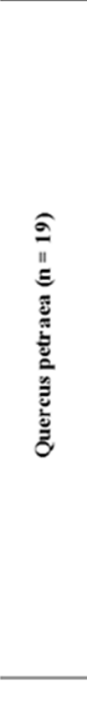 } & QP 01 & $2790(250)$ & $956(437)$ & $1297(252)$ & $270(292)$ & $296769(305843)$ & 13 & $97(7)$ & 9 & $300(15)$ & 10 & $204(12)$ \\
\hline & QP 03 & $2757(402)$ & $900(357)$ & $655(231)$ & $247(245)$ & 216778 (177989) & 11 & $92(9)$ & 10 & $302(6)$ & 11 & $211(9)$ \\
\hline & QP 10 & $2885(637)$ & $1020(347)$ & $1111(329)$ & $292(394)$ & $500222(769089)$ & 14 & $98(8)$ & 10 & $298(14)$ & 10 & $198(18)$ \\
\hline & QP 18 & $2697(758)$ & $847(329)$ & $658(212)$ & $345(436)$ & $290545(340224)$ & 11 & $96(9)$ & 9 & $303(13)$ & 10 & $206(16)$ \\
\hline & QP 21 & $2785(405)$ & $1179(452)$ & $1468(319)$ & $298(563)$ & 288143 (495139) & 14 & $95(6)$ & 11 & $297(10)$ & 11 & $203(11)$ \\
\hline & QP 27 & $1643(226)$ & $869(359)$ & $2723(603)$ & $226(203)$ & $289000(247055)$ & 14 & $108(7)$ & 7 & $305(8)$ & 7 & $197(7)$ \\
\hline & QP 35 & $2336(219)$ & $1027(305)$ & $1527(296)$ & $197(311)$ & 330751 (545387) & 9 & $99(10)$ & 9 & $322(12)$ & 6 & $218(16)$ \\
\hline & QP 41 & $2918(695)$ & $1162(364)$ & 693 (199) & $247(523)$ & $218154(409745)$ & 13 & $90(10)$ & 9 & $310(10)$ & 11 & $222(15)$ \\
\hline & QP 51 & $1310(467)$ & $455(261)$ & $2629(599)$ & $170(284)$ & $224182(328943)$ & 11 & $102(9)$ & 9 & $290(8)$ & 9 & $185(11)$ \\
\hline & QP 57a & $2569(312)$ & $847(263)$ & $1634(385)$ & $417(630)$ & $380190(473105)$ & 14 & $101(9)$ & 9 & $287(8)$ & 11 & $187(15)$ \\
\hline & QP 57b & $2163(237)$ & $727(343)$ & $1059(211)$ & $125(157)$ & $144000(176321)$ & 14 & $111(7)$ & 11 & $288(15)$ & 11 & $177(12)$ \\
\hline & QP 58 & $2371(279)$ & $752(338)$ & $1454(291)$ & $316(607)$ & $355833(607162)$ & 12 & $102(9)$ & 11 & $302(6)$ & 11 & $200(11)$ \\
\hline & QP 60 & $3119(271)$ & $1326(443)$ & $1278(223)$ & $491(571)$ & 520857 (630291) & 14 & $100(9)$ & 9 & $308(10)$ & 11 & $209(13)$ \\
\hline & QP 61 & $2658(817)$ & $934(397)$ & $1409(477)$ & $207(292)$ & $261692(384612)$ & 13 & $96(10)$ & 11 & $298(4)$ & 11 & $202(12)$ \\
\hline & QP 68 & 971 (1108) & $260(154)$ & $2840(590)$ & $95(141)$ & $157846(253994)$ & 13 & $106(5)$ & 9 & $299(9)$ & 10 & $192(11)$ \\
\hline & QP 72 & $2514(369)$ & $781(302)$ & $1079(181)$ & $42(60)$ & $57818(71406)$ & 11 & $96(9)$ & 10 & $300(11)$ & 11 & $203(10)$ \\
\hline & QP 81 & $2749(844)$ & $962(477)$ & $284(154)$ & $291(276)$ & 230741 (219237) & 12 & $92(7)$ & 11 & $299(7)$ & 9 & $209(11)$ \\
\hline & QP 86 & $2807(425)$ & $1631(1181)$ & $887(219)$ & 340 (492) & 264154 (302417) & 13 & $95(10)$ & 11 & $301(7)$ & 11 & $206(8)$ \\
\hline & QP 88 & $2003(261)$ & $778(262)$ & $1659(297)$ & $155(294)$ & $180833(292584)$ & 12 & $106(5)$ & 10 & $296(4)$ & 10 & $190(6)$ \\
\hline & & $2423(763)$ & $917(513)$ & $1387(764)$ & $251(398)$ & $278000(413145)$ & 238 & $99(10)$ & 185 & 300 (12) & 191 & $201(16)$ \\
\hline \multirow{21}{*}{ 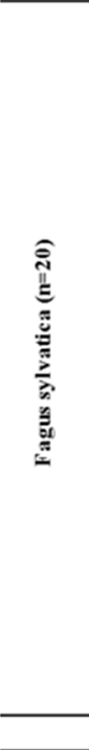 } & FS 02 & $3158(585)$ & $1020(516)$ & $1053(313)$ & $178(272)$ & $963687(1351698)$ & 13 & $108(8)$ & 11 & $313(8)$ & 11 & $206(8)$ \\
\hline & FS 03 & 2957 (1299) & $709(546)$ & $495(178)$ & $134(242)$ & 949538 (1892241) & 13 & $112(7)$ & 6 & $289(14)$ & 7 & $175(17)$ \\
\hline & FS 04 & $3502(1513)$ & $870(614)$ & $38(10)$ & $180(342)$ & 980769 (1709072) & 13 & $116(7)$ & 11 & $292(4)$ & 11 & $176(10)$ \\
\hline & FS 09 & $2381(795)$ & $767(524)$ & $13(14)$ & $280(394)$ & $1961809(2808612)$ & 9 & $110(6)$ & 8 & $292(8)$ & 9 & $184(10)$ \\
\hline & FS 14 & 3235 (493) & $1297(1109)$ & $37(27)$ & $464(509)$ & $3060182(3120152)$ & 11 & $110(5)$ & 9 & $280(8)$ & 9 & $170(10)$ \\
\hline & FS 21 & $1944(631)$ & $504(319)$ & $205(44)$ & $83(176)$ & $633426(986204)$ & 12 & $111(6)$ & 11 & $305(13)$ & 10 & $194(11)$ \\
\hline & FS 25 & $2578(337)$ & $407(210)$ & $781(144)$ & $55(104)$ & $139333(148033)$ & 12 & $120(4)$ & 11 & $293(3)$ & 11 & $172(5)$ \\
\hline & FS 26 & $1432(512)$ & $537(553)$ & $987(381)$ & $79(115)$ & 463676 (720727) & 13 & $125(8)$ & 11 & $272(9)$ & 10 & $148(11)$ \\
\hline & FS 29 & $2303(1092)$ & $687(599)$ & $987(511)$ & $228(314)$ & $1544384(1561594)$ & 11 & $100(10)$ & 3 & 295 & 1 & 196 \\
\hline & FS 30 & $2769(404)$ & $704(300)$ & $9(11)$ & $54(98)$ & $490855(846422)$ & 13 & $133(18)$ & 11 & $282(9)$ & 11 & $149(17)$ \\
\hline & FS 52 & $2596(928)$ & $496(465)$ & $314(208)$ & $76(168)$ & $295600(639922)$ & 5 & $112(4)$ & 9 & $289(5)$ & 9 & $177(6)$ \\
\hline & FS 54a & $2684(1008)$ & $807(300)$ & $366(156)$ & $115(194)$ & $777600(1141225)$ & 5 & $104(1)$ & 2 & & & \\
\hline & FS 54b & $3380(256)$ & $784(203)$ & $148(70)$ & $78(89)$ & $555500(633794)$ & 4 & 102 & 1 & & & \\
\hline & FS 55 & $2531(347)$ & $526(439)$ & $982(308)$ & $155(249)$ & $918040(1377715)$ & 11 & $109(6)$ & 10 & $312(9)$ & 10 & $203(9)$ \\
\hline & FS 60 & 3341 (347) & $1073(682)$ & $171(47)$ & $223(378)$ & $1063571(1693233)$ & 14 & $109(6)$ & 11 & $299(6)$ & 11 & $190(6)$ \\
\hline & FS 64 & $2418(523)$ & $584(551)$ & $626(206)$ & $62(111)$ & $552205(1169380)$ & 13 & $92(14)$ & 9 & $316(5)$ & 11 & $225(16)$ \\
\hline & FS 65 & $1985(570)$ & 764 (599) & $17(20)$ & $301(459)$ & $1952200(2717328)$ & 10 & $102(7)$ & 10 & $294(9)$ & 11 & $193(10)$ \\
\hline & FS 76 & $3409(273)$ & $1391(1152)$ & $235(90)$ & $390(573)$ & $2150143(3090683)$ & 14 & $114(5)$ & 11 & $304(8)$ & 11 & $190(7)$ \\
\hline & FS 81 & $3199(911)$ & $974(740)$ & $23(18)$ & $277(373)$ & $2112600(2541536)$ & 10 & $98(10)$ & 7 & $281(14)$ & 9 & $180(7)$ \\
\hline & FS 88 & $2923(391)$ & $503(247)$ & $298(103)$ & $61(151)$ & 417231 (1051238) & 13 & $111(6)$ & 11 & $282(15)$ & 11 & $171(17)$ \\
\hline & & $2736(906)$ & $770(647)$ & $389(430)$ & $174(319)$ & $1112053(1888072)$ & 219 & $112(12)$ & 173 & $294(15)$ & 173 & $182(22)$ \\
\hline
\end{tabular}

Online Resource 3 Crown and fruit production and phenology for the 48 broadleaved stands of the network RENECOFOR. Biomass $=$ Biomass of seeds in $\mathrm{kg} \mathrm{ha}^{-1} \mathrm{y}^{-1}$ Number $=$ number of seeds in nb ha-1 $\mathrm{y}^{-1}$ (mean and std; 1994-2007). LU = Leaf unfolding day (in julian day); LC = leaf coloring day (in julian day) (mean and std; 1997 2007; see text for details). $\mathrm{n}=$ number of available years for each site. GSL = growing season lenght (in days) calculated as the number of days between LC and LU. 
Online Resource 4 Dendrometric characteristics of the RENECOFOR network stands

\begin{tabular}{|c|c|c|c|c|c|c|c|c|c|c|c|c|c|c|c|c|c|}
\hline \multirow{2}{*}{ Species } & \multirow{2}{*}{$\begin{array}{l}\text { Site } \\
\text { code }\end{array}$} & \multicolumn{3}{|c|}{ Height (m) } & \multicolumn{3}{|c|}{ Diameter (m) } & \multicolumn{3}{|c|}{ Density (N ha ${ }^{-1}$ ) } & \multicolumn{3}{|c|}{$\operatorname{SBA}\left(\mathrm{m}^{2} \mathrm{ha}^{-1}\right)$} & \multirow{2}{*}{\multicolumn{2}{|c|}{$\begin{array}{l}\% \mathrm{LCr} \quad \mathrm{CA}\left(\mathrm{m}^{2}\right) \\
\quad \text { (in 1995) }\end{array}$}} & \multirow{2}{*}{$\begin{array}{c}\mathrm{RW} \\
(1994-2007)\end{array}$} & \multirow{2}{*}{$\begin{array}{c}\text { Age (years) } \\
2007\end{array}$} \\
\hline & & 1995 & 2000 & 2004 & 1995 & 2000 & 2004 & 1995 & 2000 & 2004 & 1995 & 2000 & 2004 & & & & \\
\hline \multirow{9}{*}{ 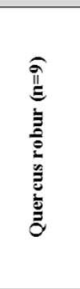 } & QR 10 & $25.5(1.7)$ & $25.6(1.7)$ & $27.0(2.2)$ & $49.3(8.3)$ & $50.8(8.6)$ & $52.4(8.9)$ & 155 & 155 & 129 & 25 & 26 & 24 & 53 & $91.9(41.1)$ & $1.78(0.60)$ & $146(24)$ \\
\hline & QR 18 & $17.7(1.4)$ & $18.8(1.4)$ & $19.5(1.5)$ & $24.9(4.0)$ & $28.1(5.5)$ & $29.9(5.8)$ & 618 & 598 & 424 & 16 & 18 & 16 & 37 & $19.0(13.9)$ & $2.48(0.86)$ & $69(10)$ \\
\hline & QR 40 & $25.0(1.5)$ & $26.3(2.0)$ & $27.8(2.3)$ & $33.9(3.7)$ & $37.8(6.1)$ & $40.4(6.2)$ & 236 & 232 & 164 & 18 & 21 & 18 & 50 & $45.9(13.6)$ & & 59 \\
\hline & QR 49 & $28.1(2.0)$ & $29.4(1.5)$ & $29.3(1.6)$ & $44.3(8.7)$ & $46.9(8.5)$ & $48.3(8.7)$ & 210 & 202 & 154 & 24 & 26 & 23 & 29 & $68.4(30.7)$ & $2.48(0.93)$ & $86(9)$ \\
\hline & QR 55 & $20.5(1.4)$ & $19.9(1.4)$ & $20.6(1.4)$ & $40(11.5)$ & $38.9(9.2)$ & $40.5(9.5)$ & 66 & 62 & 58 & 7 & 8 & 8 & 41 & $65.6(27.6)$ & $1.58(0.55)$ & $129(58)$ \\
\hline & QR 59 & $22.8(1.0)$ & $23.8(1.2)$ & $24.9(1.2)$ & $35.9(5.8)$ & $40.6(6.9)$ & $43.2(7.0)$ & 242 & 144 & 140 & 22 & 17 & 18 & 31 & $45.2(20.4)$ & & 83 \\
\hline & QR 65 & $23.9(1.6)$ & $25.0(1.7)$ & $27.3(2.0)$ & $30.9(5.2)$ & $34.1(5.6)$ & $36.1(5.9)$ & 257 & 255 & 255 & 16 & 19 & 21 & 45 & $33.9(13.8)$ & $2.44(0.96)$ & $68(6)$ \\
\hline & QR 70 & $19.3(1.1)$ & $20.9(1.4)$ & $23.0(1.4)$ & $20.9(3.0)$ & $24.4(3.5)$ & $26.4(3.8)$ & 1318 & 778 & 436 & 23 & 20 & 15 & 42 & $21.5(8.0)$ & $2.55(0.95)$ & $46(6)$ \\
\hline & QR 71 & $25.6(2.5)$ & $26.1(2.0)$ & $28.0(1.9)$ & $35.8(8.6)$ & $40(8.8)$ & $42.0(9.1)$ & 263 & 196 & 196 & 19 & 17 & 19 & 49 & $50.9(27.7)$ & $1.89(0.88)$ & $80(6)$ \\
\hline \multirow{19}{*}{ 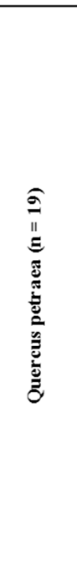 } & QP 01 & $25.8(1.6)$ & $27.8(1.6)$ & $27.9(1.8)$ & $34.8(5.0)$ & $37.5(4.8)$ & $38.8(5.0)$ & 285 & 279 & 223 & 22 & 24 & 22 & 39 & $37.7(15)$ & $2.32(0.96)$ & $105(11)$ \\
\hline & QP 03 & $30.4(2.0)$ & $33.1(1.9)$ & $33.6(1.8)$ & $42.0(5.5)$ & $44.6(5.5)$ & $46.1(5.7)$ & 308 & 258 & 258 & 30 & 27 & 29 & 32 & $41.2(15)$ & $1.99(0.74)$ & $125(7)$ \\
\hline & QP 10 & $24.9(1.7)$ & $26.5(1.5)$ & $27.1(1.6)$ & $35.9(5.4)$ & $39.0(4.9)$ & $41.3(5.1)$ & 336 & 203 & 201 & 19 & 15 & 17 & 49 & $54.5(18.9)$ & $2.67(0.92)$ & $94(9)$ \\
\hline & QP 18 & $27.4(1.3)$ & $29.8(1.4)$ & $29.4(1.4)$ & $35.5(5.6)$ & $39.5(6.1)$ & $41.3(6.4)$ & 250 & 250 & 250 & 24 & 26 & 28 & 32 & $42(16.8)$ & $2.79(1.26)$ & $93(9)$ \\
\hline & QP 21 & $28.4(1.8)$ & $29.5(1.2)$ & $31.2(1.7)$ & $40.5(6.8)$ & $43.1(6.3)$ & $44.8(6.6)$ & 241 & 225 & 149 & 24 & 24 & 19 & 40 & $67.6(25)$ & $2.32(0.79)$ & $101(4)$ \\
\hline & QP 27 & $22.9(1.1)$ & $25.0(1.2)$ & $26.4(1.1)$ & $31.1(3.8)$ & $36.2(6.2)$ & $39.1(6.6)$ & 205 & 155 & 155 & 13 & 12 & 13 & 29 & $38.7(12)$ & $3.28(1.10)$ & $69(3)$ \\
\hline & QP 35 & $29.5(1.9)$ & $31.1(2.0)$ & $31.5(1.9)$ & $42.6(5.7)$ & $45.1(6.7)$ & $46.8(7.1)$ & 180 & 172 & 128 & 24 & 26 & 22 & 27 & $51.5(21.1)$ & $2.43(0.88)$ & $115(6)$ \\
\hline & QP 41 & $28.2(1.1)$ & $30.7(1.2)$ & $31.2(1.3)$ & $36.6(4.5)$ & $40.3(5.1)$ & $42.0(5.1)$ & 313 & 306 & 257 & 26 & 29 & 27 & 29 & $36.7(11.2)$ & $2.26(0.85)$ & $104(5)$ \\
\hline & QP 51 & $25.0(2.0)$ & $26.2(1.7)^{*}$ & $26.9(2.2)$ & $42.8(6.7)$ & $45.8(9.3)^{*}$ & $47.1(9.3)$ & 197 & $59 \%$ & 59 & 19 & $8^{*}$ & 8 & 27 & $56.6(20.5)$ & $2.08(0.70)$ & $151(13)$ \\
\hline & QP 57a & $27.7(1.2)$ & $28.8(1.0)$ & $29.9(1.4)$ & $38.5(5.3)$ & $40.9(5.4)$ & $43.4(5.8)$ & 285 & 224 & 224 & 26 & 23 & 26 & 38 & $43.6(16.7)$ & $2.31(0.84)$ & $98(3)$ \\
\hline & QP 57b & $28.6(1.3)$ & $29.3(1.4)$ & $29.9(1.3)$ & $40.8(5.0)$ & $42.3(4.9)$ & $43.1(5.2)$ & 221 & 221 & 221 & 24 & 25 & 26 & 20 & $43.5(17.5)$ & $1.23(0.38)$ & $142(5)$ \\
\hline & QP 58 & $23.5(1.4)$ & $24.2(1.2)$ & $25.9(1.4)$ & $27.0(4.1)$ & $30.1(4.3)$ & $31.6(4.4)$ & 576 & 584 & 380 & 22 & 24 & 18 & 40 & $24(9.9)$ & $2.39(0.86)$ & $75(2)$ \\
\hline & QP 60 & $25.2(1.3)$ & $26.3(1.3)$ & $28.4(1.4)$ & $34.6(5.8)$ & $39.4(6.4)$ & $42.0(6.9)$ & 208 & 206 & 206 & 19 & 21 & 24 & 27 & $46.3(16.3)$ & $2.79(0.85)$ & $73(3)$ \\
\hline & QP 61 & $26.8(1.1)$ & $28.4(1.4)$ & $29.4(1.3)$ & $34.0(3.5)$ & $36.7(3.6)$ & $38.5(3.9)$ & 363 & 262 & 262 & 25 & 22 & 23 & 26 & $37.4(9.1)$ & $2.21(0.66)$ & $102(1)$ \\
\hline & QP 68 & $21.6(1.2)$ & $21.3(1.6)$ & $21.7(1.2)$ & $44.6(9.9)$ & $43.7(9.3)$ & $44.9(9.2)$ & 53 & 37 & 37 & 9 & 6 & 6 & 22 & $73.2(28.9)$ & & 150 \\
\hline & QP 72 & $23.5(2.5)$ & $25.6(2.8)$ & $25.6(2.9)$ & $30.1(5.3)$ & $32.0(5.5)$ & $34.1(5.8)$ & 511 & 339 & 339 & 25 & 22 & 24 & 32 & $29.1(12.8)$ & $2.42(0.81)$ & $79(6)$ \\
\hline & QP 81 & $28.0(2.0)$ & $27.4(2.0)$ & $28.4(2.2)$ & $37.0(4.0)$ & $39.3(4.1)$ & $40.5(4.2)$ & 286 & 204 & 206 & 25 & 21 & 22 & 43 & $60.7(20.5)$ & $1.53(0.67)$ & $112(3)$ \\
\hline & QP 86 & $25.1(1.2)$ & $27.4(1.5)$ & $28.5(1.6)$ & $35.5(4.0)$ & $38.8(4.6)$ & $40.5(4.7)$ & 386 & 270 & 272 & 26 & 21 & 24 & 31 & $40.1(9.8)$ & $2.54(0.98)$ & $94(5)$ \\
\hline & QP 88 & $25.9(1.4)$ & $28.9(1.5)$ & $29.9(1.6)$ & $41.1(5.8)$ & $43.4(6.0)$ & $44.6(6.2)$ & 164 & 126 & 126 & 20 & 18 & 19 & 23 & $49.9(17.5)$ & $1.80(0.70)$ & $141(10)$ \\
\hline \multirow{20}{*}{ 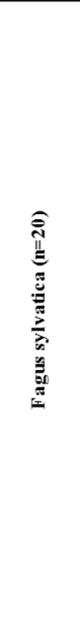 } & FS 02 & $29.2(2.0)$ & $30.6(1.7)$ & $32(1.8)$ & $40.5(9.6)$ & $44.1(8.8)$ & $46.7(8.8)$ & 346 & 328 & 280 & 22 & 25 & 23 & 39 & $65.5(31.7)$ & $3.41(1.11)$ & $68(4)$ \\
\hline & FS 03 & $28.9(1.7)$ & $30.6(1.3)$ & $30.6(1.5)$ & $36.1(5.8)$ & $38.7(5.6)$ & $41.2(5.8)$ & 261 & 259 & 194 & 22 & 24 & 21 & 50 & $41.2(17.2)$ & & 100 \\
\hline & FS 04 & $25.5(1.3)$ & $26.4(1.5)$ & $26.3(1.7)$ & $32.7(4.4)$ & $35.0(5.0)$ & $36.4(5.1)$ & 355 & 384 & 389 & 21 & 24 & 26 & 45 & $42.1(17.1)$ & & 101 \\
\hline & FS 09 & $21.4(1.4)$ & $20.2(1.4)$ & $21.4(2.0)$ & $33.3(5.4)$ & $33.9(5.3)$ & $35.0(5.5)$ & 470 & 468 & 419 & 28 & 29 & 27 & 53 & $42(16.6)$ & & 165 \\
\hline & FS 14 & $25.2(1.8)$ & $26.1(1.4)$ & $26.6(1.5)$ & $39.3(6.6)$ & $42.2(6.6)$ & $43.7(6.7)$ & 262 & 208 & 217 & 24 & 22 & 23 & 37 & $63.8(19.8)$ & & 96 \\
\hline & FS 21 & $28.6(1.5)$ & $25.8(5.4)$ & $28.1(3.6)$ & $37.6(6.0)$ & $39.3(4.0)$ & $41.2(4.4)$ & 231 & 111 & 113 & 20 & 9 & 9 & 54 & $63.4(23.1)$ & & 141 \\
\hline & FS 25 & $20.1(1.5)$ & $22.4(1.5)$ & $24.3(1.5)$ & $21.1(3.2)$ & $25.0(3.7)$ & $27.7(3.9)$ & 614 & 610 & 378 & 14 & 18 & 15 & 56 & $23.7(7.8)$ & $3.31(1.06)$ & $53(6)$ \\
\hline & FS 26 & $22.9(1.6)$ & $23.9(1.6)$ & $24.0(1.4)$ & $33.1(4.6)$ & $34.9(4.3)$ & $35.7(4.5)$ & 242 & 248 & 162 & 18 & 20 & 14 & 39 & $32.3(11.2)$ & & 171 \\
\hline & FS 29 & $23.1(1.8)$ & $23.6(1.6)$ & $23.7(2.2)$ & $28.8(4.6)$ & $29.8(4.5)$ & $30.9(4.8)$ & 640 & 538 & 553 & 25 & 21 & 21 & 28 & $28.3(12.4)$ & & 77 \\
\hline & FS 30 & $19.4(1.4)$ & $19.1(1.5)$ & $18.1(1.3)$ & $31.8(3.7)$ & $32.0(4.3)$ & $32.7(4.3)$ & 576 & 470 & 478 & 38 & 32 & 34 & 49 & $30.9(8.2)$ & & 156 \\
\hline & FS 52 & $30.2(1.5)$ & & & $38.3(4.7)$ & & & 286 & & & 24 & & & 51 & $64.2(19.1)$ & & 119 \\
\hline & FS 54a & $29.1(1.8)$ & & & $40.0(6.1)$ & & & 300 & & & 23 & & & 40 & $64.2(28.7)$ & & 108 \\
\hline & FS $54 \mathrm{~b}$ & $28.3(1.6)$ & & & $38.3(6.0)$ & & & 248 & & & 21 & & & 34 & $54.6(16.1)$ & & 112 \\
\hline & FS 55 & $29.3(1.7)$ & $31.9(1.7)$ & $32.4(1.9)$ & $44.3(5.6)$ & $47.9(6.1)$ & $50.1(6.1)$ & 212 & 168 & 168 & 19 & 16 & 17 & 38 & $69.7(20.5)$ & & 102 \\
\hline & FS 60 & $26.6(1.2)$ & $27.7(1.6)$ & $30.7(1.9)$ & $36.3(6.2)$ & $40.6(5.9)$ & $43.5(6.1)$ & 704 & 300 & 296 & 27 & 18 & 20 & 33 & $62.3(19.3)$ & $3.53(1.41)$ & $76(4)$ \\
\hline & FS 64 & $28.4(2.0)$ & $29.4(2.3)$ & $30.0(2.4)$ & $34.4(6.5)$ & $38.3(6.2)$ & $40.6(6.4)$ & 529 & 491 & 417 & 21 & 23 & 21 & 51 & $54.4(19.7)$ & & 80 \\
\hline & FS 65 & $29.5(1.9)$ & $29.5(2.4)$ & $30.9(2.7)$ & $48.6(6.9)$ & $48.6(7.5)$ & $50.0(7.5)$ & 306 & 419 & 554 & 26 & 26 & 28 & 39 & $64.3(23.5)$ & & 173 \\
\hline & FS 76 & $29.7(1.4)$ & $29.7(1.3)$ & $30.9(1.7)$ & $45.8(6.6)$ & $48.8(7.0)$ & $50.4(7.4)$ & 218 & 163 & 163 & 24 & 23 & 25 & 39 & $82.9(23.5)$ & $2.32(1.01)$ & $99(6)$ \\
\hline & FS 81 & $30.1(1.4)$ & $30.0(1.8)$ & $30.5(1.9)$ & $49.7(5.2)$ & $50.6(6.1)$ & $51.7(6.1)$ & 218 & 218 & 181 & 34 & 36 & 32 & 50 & $57.3(14)$ & & 113 \\
\hline & FS 88 & $24.7(2.4)$ & $27.0(2.3)$ & $28.2(2.5)$ & $30.5(5.7)$ & $32.4(5.9)$ & $34.3(6.1)$ & 914 & 739 & 739 & 24 & 21 & 23 & 31 & $31.2(11.8)$ & $2.81(1.08)$ & $85(5)$ \\
\hline
\end{tabular}

Online Resource 4 Dendrometric characteristics of the 48 broadleaved stands of the network RENECOFOR. Height $(\mathrm{m})$ and Diameter $(\mathrm{cm})=$ mean height, mean diameter and standard deviation for the 36 "observation" trees in the centrale fenced zone for the 3 inventories made between 1995 and 2004 except for FS52, FS54a and FS54b totally destroyed by a hurricane in 1999; Density $\left(\mathrm{N} \mathrm{ha}^{-1}\right)=$ total number of stem for the main species $\left(\mathrm{QR}, \mathrm{QS}\right.$ and FS, respectively); SBA ( $\mathrm{m}^{2}$ ha $\left.{ }^{-1}\right)=$ stand basal area for the main species (only stems with diameter $>15 \mathrm{~cm}$ have been taken into account); \% $\mathrm{LCr}=$ mean relative percentage of crown lenght (for the 36 "observation" trees in the centrale fenced zone); $\mathrm{CA}=$ mean and standard deviation crown projected area (in $\mathrm{m}^{2}$ for the 36 "observation" trees in the centrale fenced zone); $\mathrm{RW}=$ mean ring widths (std) in mm for the plots re-sampled in 2009 ( $\mathrm{n}=10$ trees per plot) (see text for details). For the stands which were not re-sampled in 2009 , the age in 2007 corresponds to the mean age of the trees found in 1994 plus 13 years. 

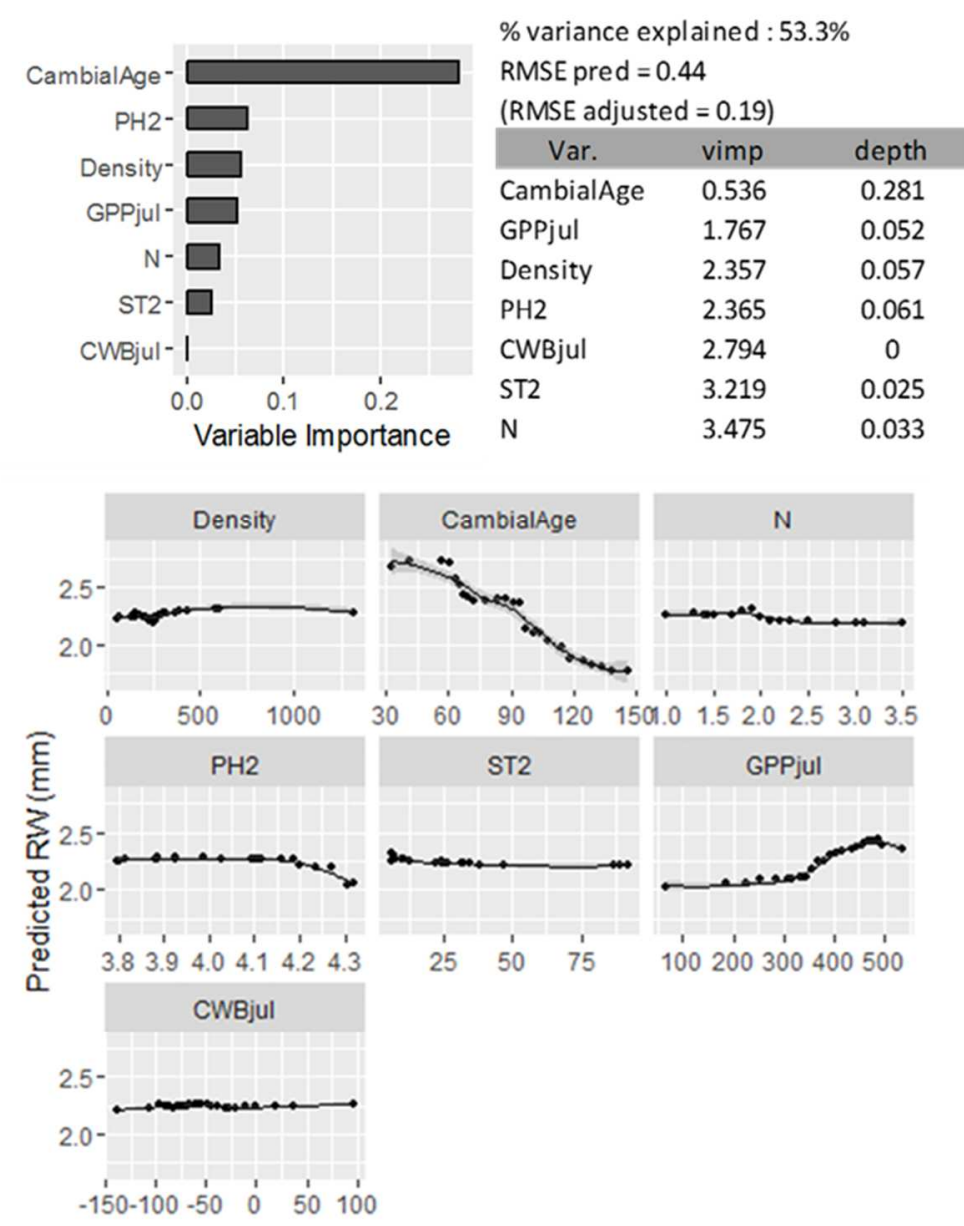

Predicted vs Observed

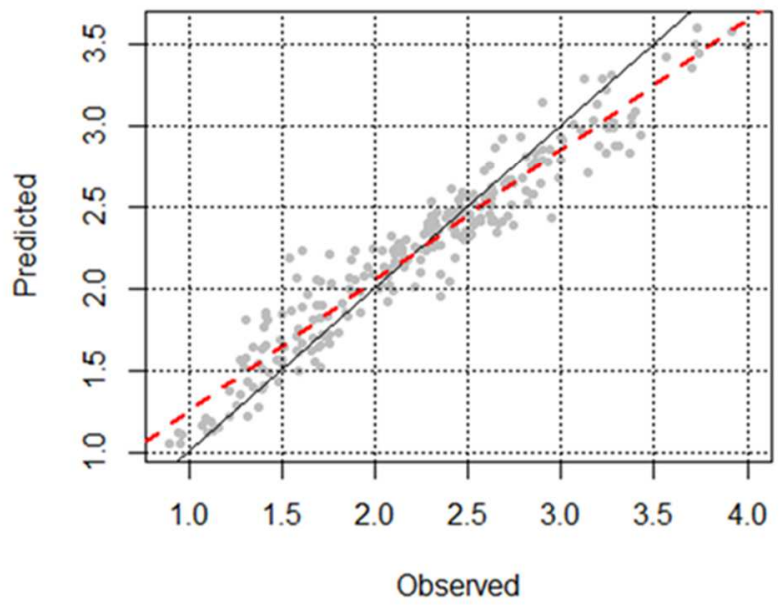

Online Resource 5 Partial dependence plots of the 7 most important variables driving the tree-ring widths (in $\mathrm{mm} \mathrm{y}^{-1}$ ) for the oaks stands of the Renecofor network (period 1994-2007, $\mathrm{n}=256$ data, ggRandomForest modeling). Each plot gives a graphical depiction of the marginal effect of the variable on the class response. Vimp and Depth are the two variable importance measures (see text for details, Ehrlinger, 2015). CambialAge $=$ age of the tree when the ring was formed. Stand Density $=$ number of trees per ha. $\mathrm{N}, \mathrm{pH}$ and $\mathrm{S} / \mathrm{T}=$ mineral soil characteristics $(2=$ second soil horizon). GPPjul $=$ Gross Primary Productivity in July $\left(\right.$ in $\left.\mathrm{gC} \mathrm{m}^{-2} \mathrm{month}^{-1}\right) . \mathrm{CWB}=$ climatic water balance in July (in $\mathrm{mm}$ ). See text for details. The last graph gives predicted values of tree-ring widths versus observed ones. black line: $\mathrm{Y}=\mathrm{X}$; dotted line $=$ linear regression line $\left(\mathrm{r}^{2}=0.92\right.$, pvalue $=0.0000$ ). 
Online Resource 6 Evaluation of the auto-correlation of the fruit (a) and pollen (b) time series
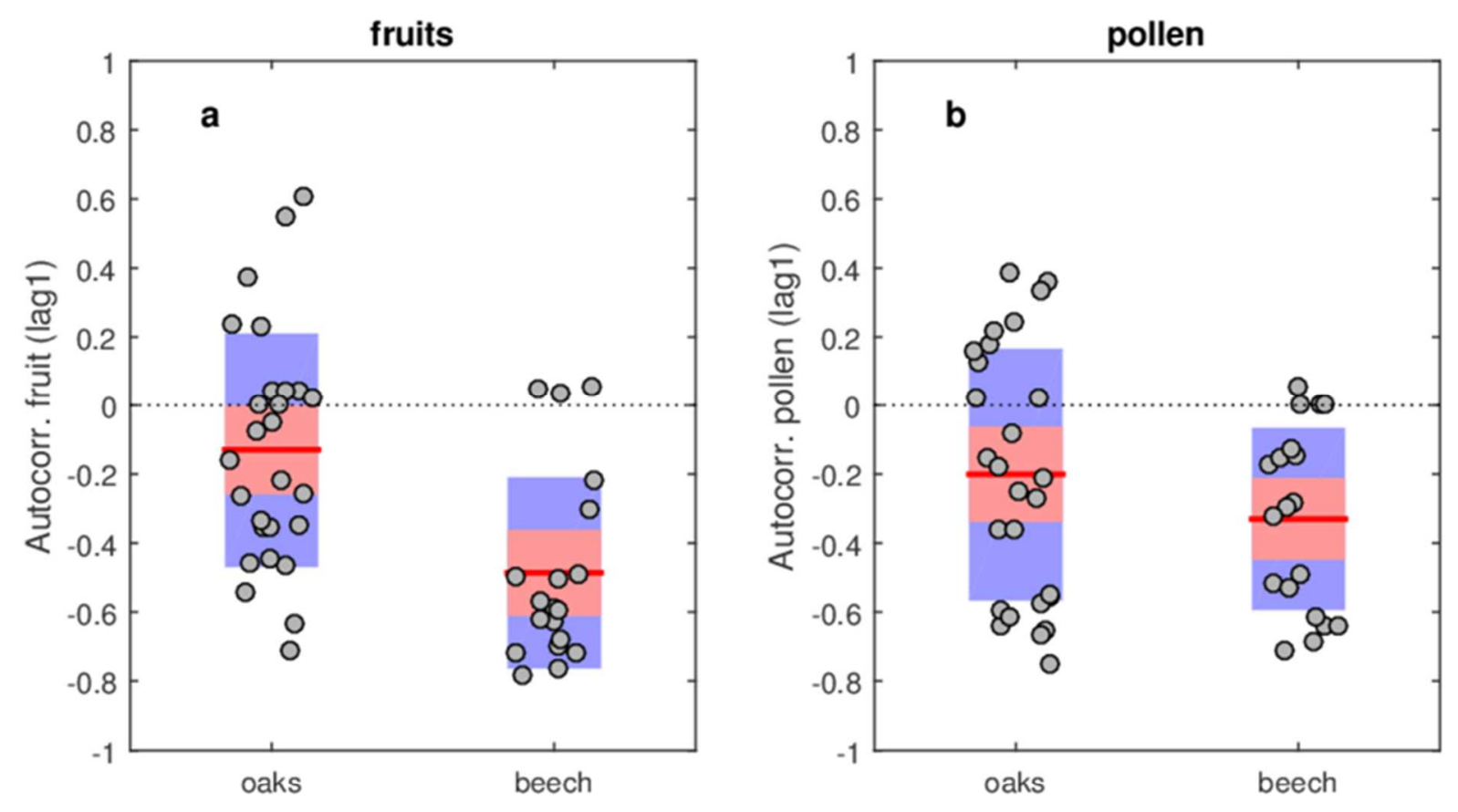

Online Resource 6 Evaluating the auto-correlation of fruit (a) and pollen (b) time series. Dots represent the autocorrelation coefficient (one-year lag, rank correlation) of the fructification (a) or pollen (b) time series calculated at each RENECOFOR site. Boxes summarize the across-populations variability of auto-correlation across RENECOFOR populations (red lines $=$ median, red box $=$ average \pm 1.96 standard error, blue box $=$ average \pm 1 standard deviation). 
Online Resource 7 Synchrony between stands and changes with distance

To judge the synchrony of fruit production between stands and to see how it changes with distance, we selected stands with a complete data set. Thus, for oak stands, we selected 15 sites with 13 continuous years from 1995-2007 (195 site-years data; 105 different pairs, QR49 vs QP61, QR49 vs QP86,...). For beech, we selected also 15 sites with 12 years from 1995-2006 (180 site-years data; 105 different pairs). We calculated the distance between sites for each pair (Figure 1). For beech, the distance varied from 33 (distance between FS60 and FS02) to 1118 $\mathrm{km}(\mathrm{FS} 29$ and FS04) with a mean value of $543( \pm 255) \mathrm{km}$. For oak, the mean distance was 284 $( \pm 127) \mathrm{km}$ with a range from $12(\mathrm{QR} 10$ and QP10) to $584 \mathrm{~km}$ (QP86 and QP57b).

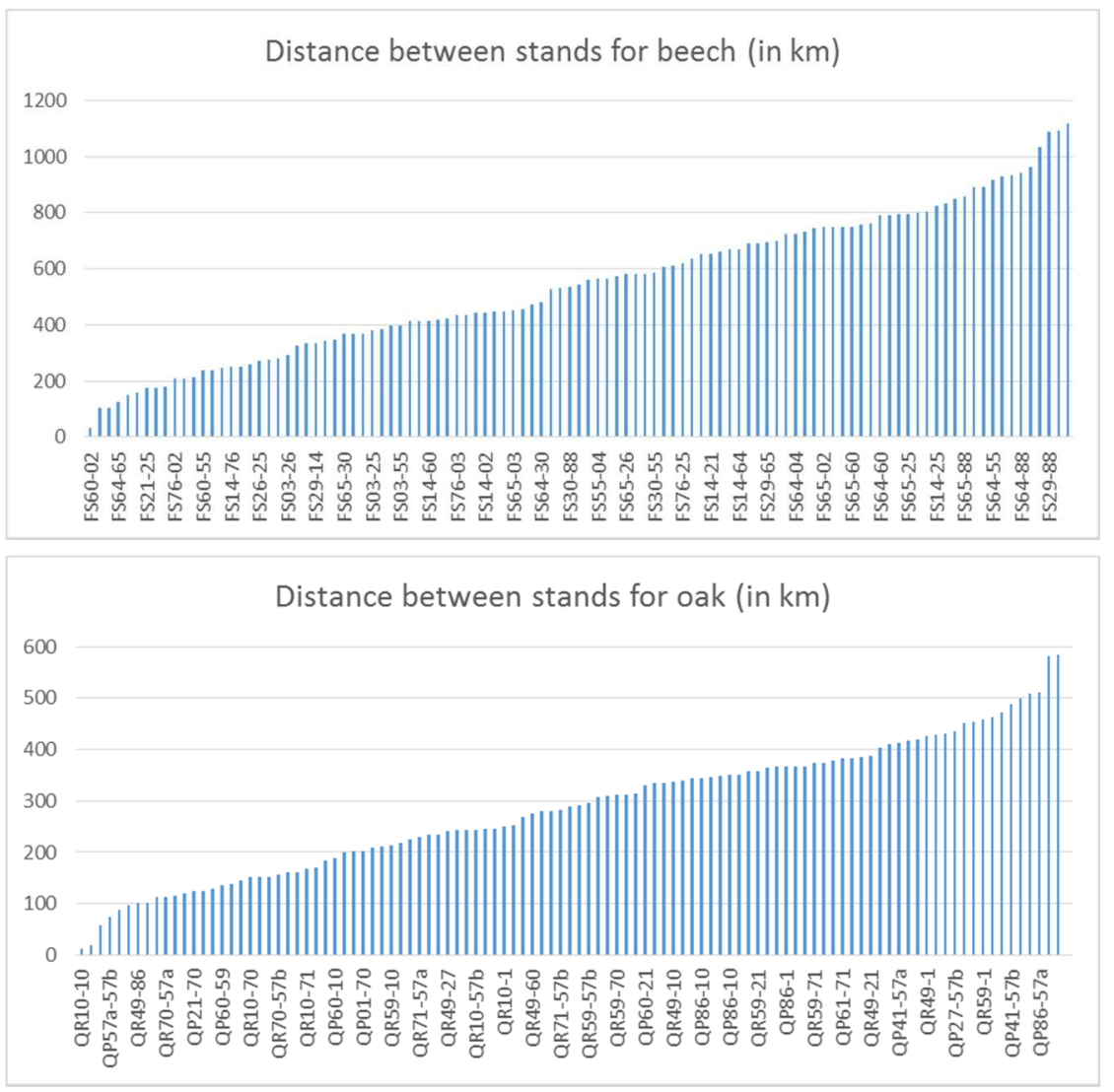

Figure 1. Distance (in $\mathrm{km}$ ) between each pair for beech and oak stands. 15 stands for each species and 105 different pairs. The mean distance is $543 \mathrm{~km}$ for beech and 284 for oaks.

To highlight how the fruit production was correlated between stands, we calculated a correlogram (i.e. correlation matrix) for oak and beech. It allows to analyze the relationship between each pair of numerical variables (here fruit production for each year) of a matrix. The correlation between each pair of variable is visualize through a scatterplot that represents the correlation (corrplot package in R). A synchrony between stands means that fruit production is synchronized (i.e. similar temporal variations) especially for the nearest stands. 


\section{Synchrony for oak}

The correlogram clearly showed that synchrony between oak stands was weak despite the proximity of the stands (mean distance $284 \mathrm{~km}$ ) (Figure 2). Thus, the correlation between fruit production was significant (p.value $=0.05$ ) for only 8 pairs (among the 105 ). QP10-QR59 (dist. 213), QP10-QR70 (139), QP10-QP57a (235), QR70-QR59 (312), QR70-QP57a (112), QP57aQR71 (230), QP41-QP57b (487 km), QP41-QP86 (119km). No correlation was observed for the nearest stands (QP10-QR10, $12 \mathrm{~km}$; QP21-QR71, $19 \mathrm{~km}$; QP27-QP60, $58 \mathrm{~km}$; QP57aQP57b, 74 km; QR70-QP01, 88 km...).

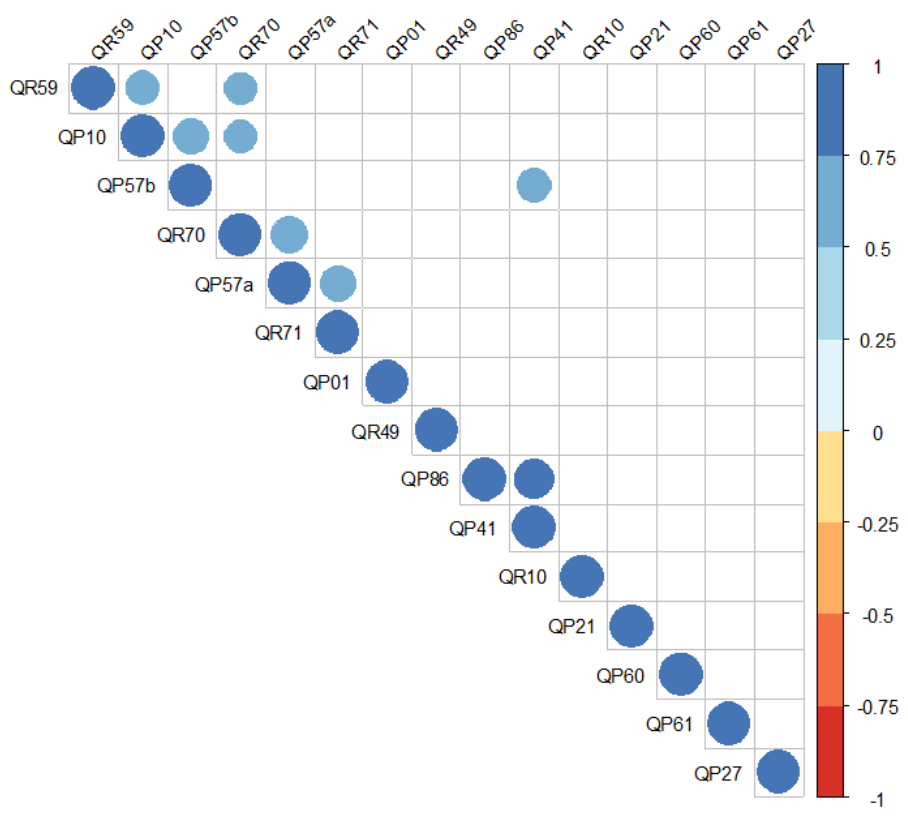

Figure 2. Correlogram for
oak stands (15 stands, 105
pairs). A circle indicates a
significant correlation ( $p$.
value $=0.05$ ) for fruit
production between stands.
The color and the size of the
circle change with the sign
of the correlation (from blue
o red) and the value
(increasing size with
increasing value). QR =
Quercus robur and QP =
Quercus petraea. The
number represents the

\section{Synchrony for beech}

The results for beech was quite different with 44 significant correlation confirming the high synchrony between stands despite the distance (mean distance $543 \mathrm{~km}$ ) (Figure 3). Only one stand (FS29) showed no correlation.

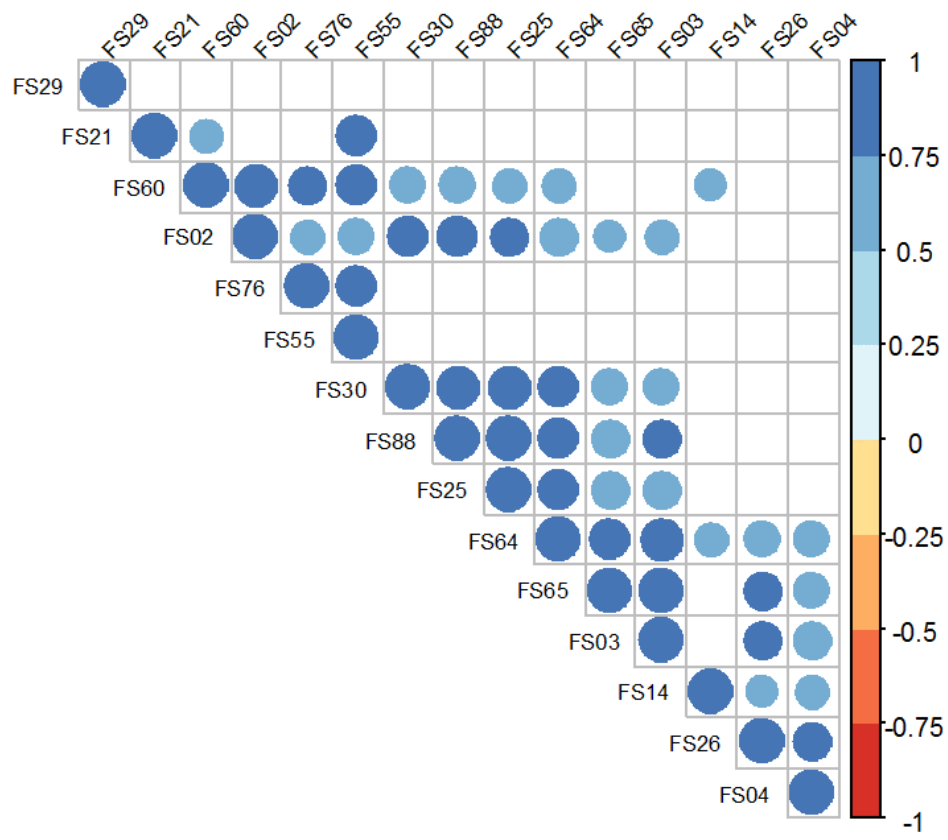

Figure 3. Correlogram for beech stands (15 stands, 105 pairs). A circle indicates a significant correlation ( $p$. value $=0.05$ ) for fruit production between stands. The color and the size of the circle change with the sign of the correlation (from blue o red) and the value (increasing size with increasing value). FS = Fagus sylvatica. The number represents the French department. 
The figure 4 shows the change of the frequency of significant correlations between stands according to the distance between the pairs. For example, for the class [0-200] km, the mean distance between the 9 pairs was $134 \mathrm{~km}$. For this class, 6 correlations were significant at the p.value $=0.05(=66 \%$ of significant correlations $)$ and the mean correlation was 0.86 . The frequency of significant correlations remained high until the distance of about $500 \mathrm{~km}$ and decreased hereafter.

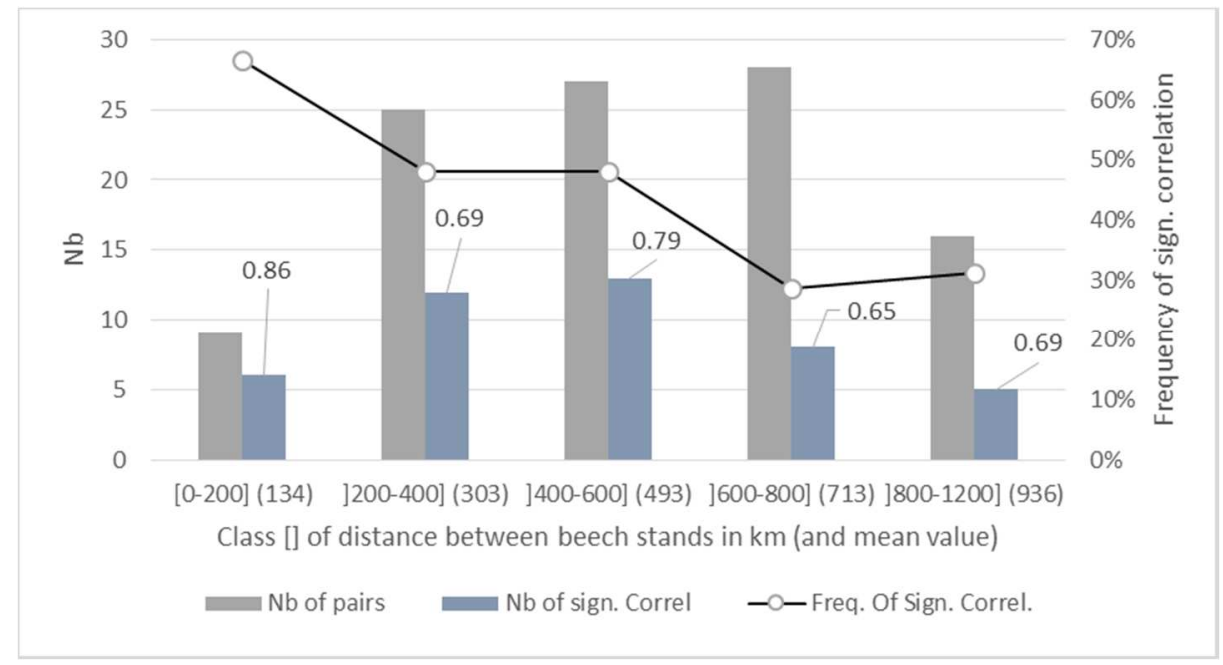

Figure 4. Change of the frequency of significant correlations $(p$. value $=$ 0.05) between beech stands according to the distance between the pairs ( $\mathrm{n}=15$ stands, 105 different pairs). The number above the blue histogram is the

The different clustering tested confirmed the decreasing correlation with increasing distance (Figure 5). The highest synchrony was observed for stands distant from less than $200 \mathrm{~km}$. A sharp decrease was observed for a distance higher than $500 \mathrm{~km}$.

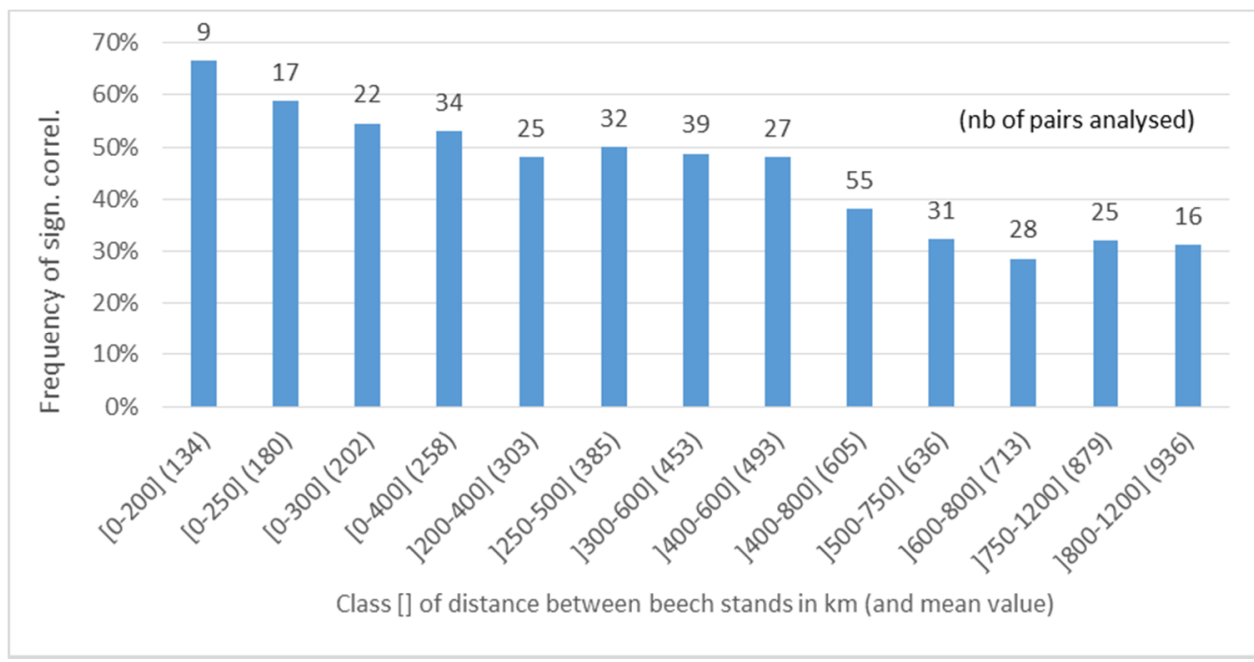

Figure 5. Change of the frequency of significant correlations $(p$. value $=$ 0.05) between beech stands according to the distance between the pairs ( $\mathrm{n}=15$ stands, 105 different pairs). The number above the blue histogram is the number of pairs analyzed. 
Online Resource 8 Mean predicted acorn biomass obtained with the CGPW model versus observed values

\begin{tabular}{|c|c|c|ccccc|}
\hline \multicolumn{7}{|c|}{ Biomass $\left(\mathrm{kg} \mathrm{ha}^{-1} \mathrm{y}^{-1}\right)$} \\
\hline Dif. Class & Obs. & Pred. & \multicolumn{3}{|c|}{ Overestim. } \\
N & Mean & N & Mean & Nt \\
\hline$\leq 10 \%$ & 319 & 315 & 11 & 12 & 16 & -20 & 27 \\
]10-20\%] & 370 & 344 & 10 & 33 & 16 & -85 & 26 \\
]20-30\%] & 523 & 464 & 8 & 75 & 25 & -192 & 33 \\
]30-40\%] & 578 & 453 & 13 & 76 & 16 & -325 & 29 \\
]40-50\%] & 503 & 381 & 2 & 96 & 4 & -340 & 6 \\
$>50 \%$ & 39 & 133 & 135 & 94 & & & 135 \\
\hline
\end{tabular}

Online Resource 8 Predicted mean fruit biomass of acorns obtained with the CGPW model (Pred.) versus observed values (Obs.) for the 23 oaks stands $(n=256$ data). The number of over- and underestimations by class of differences (between observations and predictions) and the related means are given. For example, 27 predictions showed a difference between observed and predicted values $\leq 10 \%: 11$ values are overestimated (mean difference: $12 \mathrm{~kg} \mathrm{ha}^{-1} \mathrm{y}^{-1}$ ) and 16 are underestimated $\left(-20 \mathrm{~kg} \mathrm{ha}^{-1} \mathrm{y}^{-1}\right)$. 
Online Resource 9 Mean predicted nut biomass obtained with the CGP* model versus observed values

\begin{tabular}{|c|c|c|c|c|c|c|c|}
\hline \multicolumn{8}{|c|}{ Biomass $\left(\mathrm{kg} \mathrm{ha}^{-1} \mathrm{y}^{-1}\right)$} \\
\hline \multirow[t]{2}{*}{ Dif. Class } & \multirow{2}{*}{ Obs. } & \multirow{2}{*}{ Pred. } & \multicolumn{2}{|c|}{ Overestim. } & \multicolumn{2}{|c|}{ Underestim. } & \multirow[b]{2}{*}{$\mathrm{Nt}$} \\
\hline & & & $\mathrm{N}$ & Mean & $\mathrm{N}$ & Mean & \\
\hline$\leq 10 \%$ & 335 & 326 & 10 & 9.2 & 16 & -27.4 & 26 \\
\hline$] 10-20 \%]$ & 315 & 300 & 10 & 36.2 & 16 & -65.6 & 26 \\
\hline ]20-30\%] & 516 & 443 & 5 & 57.9 & 11 & -202 & 16 \\
\hline$] 30-40 \%]$ & 398 & 340 & 4 & 76.7 & 11 & -193.7 & 15 \\
\hline$] 40-50 \%]$ & 216 & 170 & 5 & 48.1 & 1 & -139.1 & 6 \\
\hline$>50 \%$ & 17 & 61 & 115 & 43.5 & & & 115 \\
\hline & & & 149 & 45.3 & 55 & -125.6 & \\
\hline
\end{tabular}

Online Resource 9 Predicted mean fruit biomass of nuts obtained with the CGP* model (Pred.) versus observed values (Obs.) for the 20 beech stands. For both seed variables, the number of over- and underestimations by class of differences (between observations and predictions) and the related means are given. For example for biomass, 26 predictions show a difference between observed and predicted values $\leq 10 \%$ : 10 values are overestimated (mean difference: $9.2 \mathrm{~kg} \mathrm{ha}^{-1} \mathrm{y}^{-1}$ ) and 16 are underestimated $\left(-27.4 \mathrm{~kg} \mathrm{ha}^{-1} \mathrm{y}^{-1}\right)$. 
Online Resource 10 Length of the pollen emission window as related to temperature
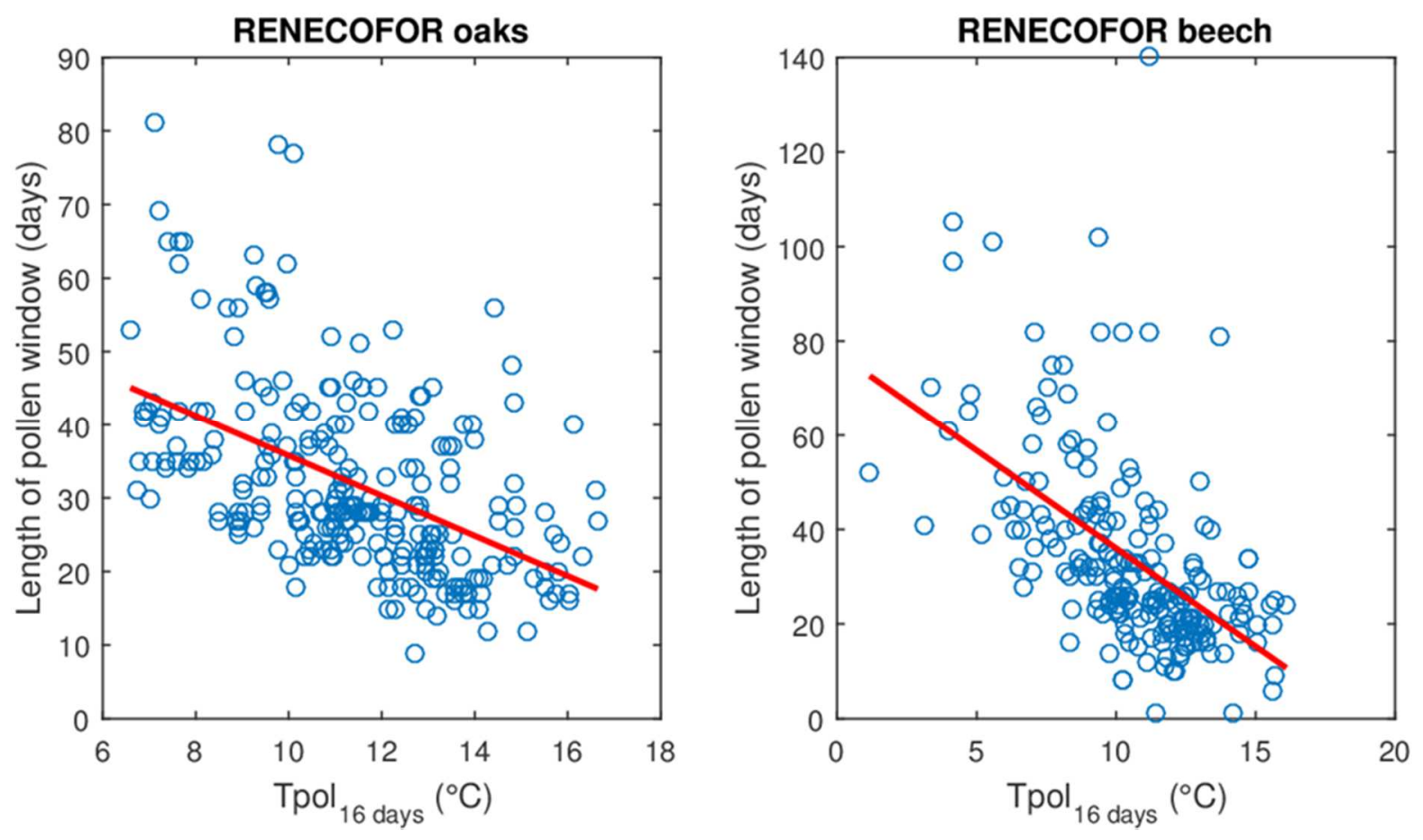

Online Resource 10 The length of pollen emission window depends on temperature. Ordinates: length of pollen emission window calculated as the duration (in days) from the start (i.e. date at which $5 \%$ of the cumulative annual pollen emissions are reached) to the end (i.e. date at which $95 \%$ of the cumulative annual emission are reached) date of pollen emission; Abscissa: average air temperature over the 16-day period from start of pollen emission. One point represents one site-year. Oaks: Spearman rank correlation $r=-0.53, p<10^{-9}$; Beech: $r=-0.62, p<10^{-9}$. 
Online Resource 11 Percentages of the variance of the fructification datasets explained by statistical models (Figure)

Online Resource 11 Percent variance of the fructification datasets explained by statistical models, as a function of the number of site-years considered. The data have been classified according to the type of variable transformation used in the papers. The data plotted on this graph are collated in Online resource 11. The figure illustrates the clear and expected decrease in the percent variance of fructification datasets explained by statistical models. This decrease is observed whatever the type of data considered (i.e. categorical, quantitative or log-transformed quantitative). The square dots represent results of the present study, conducted over an unprecedented number of siteyears.

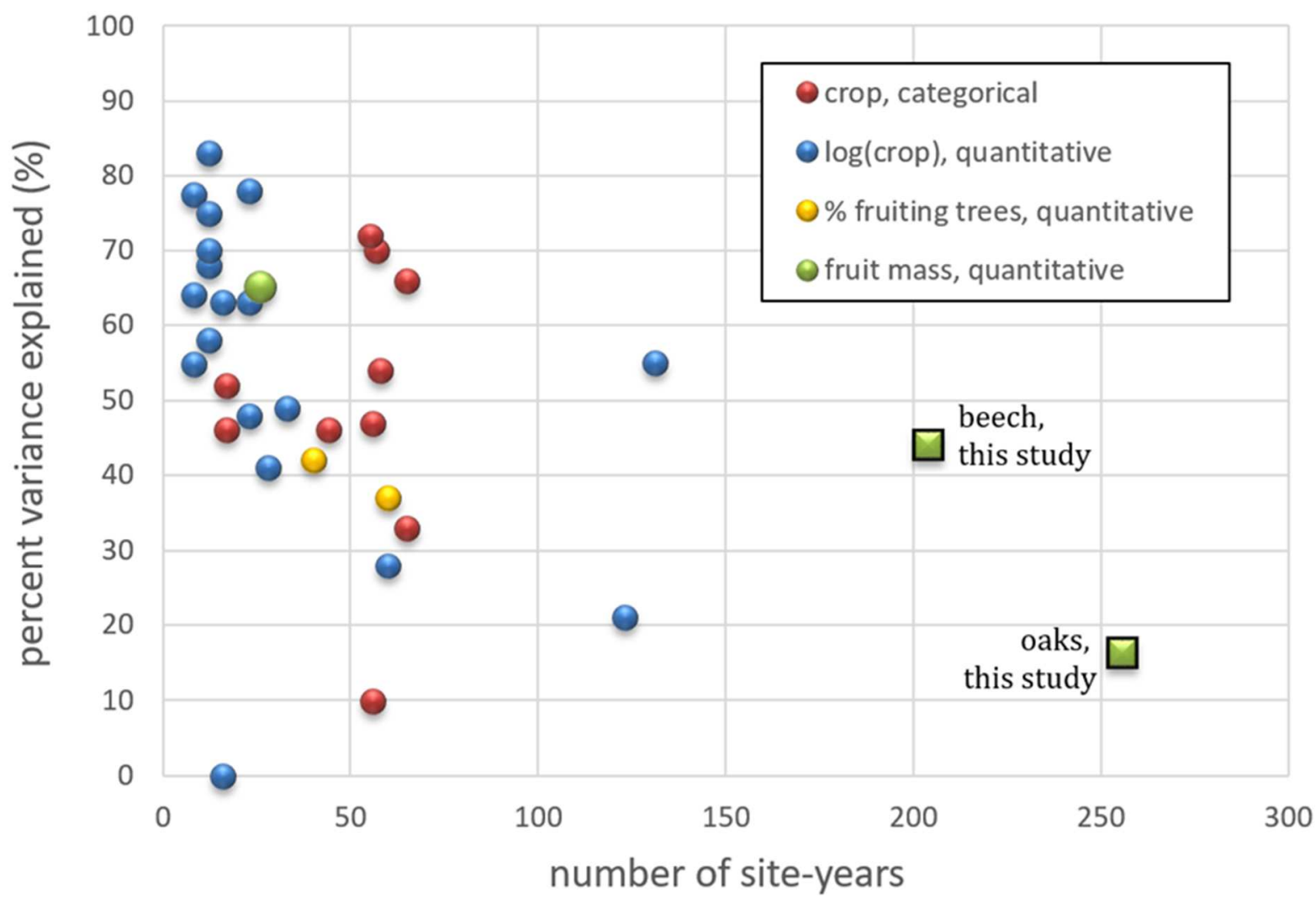




\begin{tabular}{|c|c|c|c|c|c|c|c|}
\hline Species & Climate zone & Model variable & \% variance explained & Variable explained & Number of populations & Number of site-years & Reference \\
\hline Quercus petraea & temperate & $\begin{array}{l}\text { Apr-Sep Temp } \\
\text { Jan Precip }\end{array}$ & 10 & crop score & 1 & 56 & Askeyev et al. 2005 \\
\hline Quercus robur & temperate & Precip feb & 46 & crop score & several & 17 & Kasprzyk et al. 2014 \\
\hline Fagus sylvatica & temperate & relative humidity Jan & 52 & crop score & several & 17 & Kasprzyk et al. 2014 \\
\hline Fagus sylvatica & temperate & Fruit $(y-1)+T j u l(y-1)+$ Tjul $(y-2)+T j u n(y-1)$ & 54 & crop score & 1 & 58 & Vacchiano et al. 2017 \\
\hline Fagus sylvatica & temperate & Precip Jun(y-1) + Tjul(y-1) + Tjul(y-2) + Tjun(y-1) + Tjun(y-2) & 33 & crop score & 1 & 65 & Vacchiano et al. 2017 \\
\hline Fagus sylvatica & temperate & Fruit $(y-1)+$ Pjul $(y-2)+$ Tjul(y-1) + Tjul(y-2) + Tjun $(y-1)+$ Tjun $(y-2)$ & 70 & crop score & 1 & 57 & Vacchiano et al. 2017 \\
\hline Fagus sylvatica & temperate & $\operatorname{Tjul}(y-1)+\operatorname{Tjul}(y-2)+\operatorname{Tjun}(y-2)$ & 46 & crop score & 1 & 44 & Vacchiano et al. 2017 \\
\hline Fagus sylvatica & temperate & Fruit $(y-1)+$ Pjul $(y-2)+T j u l(y-1)+$ Tjun(y-2) & 66 & crop score & 1 & 65 & Vacchiano et al. 2017 \\
\hline Fagus sylvatica & temperate & $\operatorname{Tjul}(y-1)+\operatorname{Tjul}(y-2)+\operatorname{Tjun}(y-2)$ & 47 & crop score & 1 & 56 & Vacchiano et al. 2017 \\
\hline Fagus sylvatica & temperate & Fruit $(y-1)+$ Pjun $(y-2)+$ Tjul $(y-1)+$ Tjul $(y-2)+$ Tjun $(y-1)$ & 72 & crop score & 1 & 55 & Vacchiano et al. 2017 \\
\hline Fagus sylvatica & temperate & Fruit $(y-1)+T j u l(y-1)+\operatorname{Tjul}(y-2)+T$ jun $(y-1)+\operatorname{Tjun}(y-2)$ & 63 & crop score & 1 & 65 & Vacchiano et al. 2017 \\
\hline Quercus velutina & continental & mean spring $\max T$ & 64 & $\log ($ nb fruits $)$ & 1 & 8 & Sork \& Bramble 1993 \\
\hline Quercus rubra & continental & mean spring $\max \mathrm{T}$ & 77.44 & $\log ($ nb fruits) & 1 & 8 & Sork \& Bramble 1993 \\
\hline Quercus alba & continental & mean spring $\max \mathrm{T}$ & 54.76 & $\log ($ nb fruits) & 1 & 8 & Sork \& Bramble 1993 \\
\hline Quercus lobata & mediterranean & April T + Fall T (y-1) & 78 & $\log ($ nb fruits $)$ & 2 & 23 & Koenig et al. 1996 \\
\hline Quercus douglasii & mediterranean & April T & 48 & $\log ($ nb fruits $)$ & 2 & 23 & Koenig et al. 1996 \\
\hline Quercus agrifolia & mediterranean & Rainfall $(y-1)$ & 63 & $\log ($ nb fruits) & 2 & 23 & Koenig et al. 1996 \\
\hline Quercus kelloggii & mediterranean & none & 0 & $\log$ (nb fruits) & 1 & 16 & Koenig et al. 1996 \\
\hline Quercus chrysolepis & mediterranean & Rainfall $(\mathrm{y}-2)+$ winter $\mathrm{T}(\mathrm{y}-1)+$ rainfall $(\mathrm{y}-1)$ & 63 & $\log ($ nb fruits $)$ & 1 & 16 & Koenig et al. 1996 \\
\hline Quercus lobata & mediterranean & $\operatorname{Apr} T(y+y-1)$ & 49 & $\log ($ nb fruits) & 1 & 33 & Pearse et al. 2014 \\
\hline various dec. Quercus sp. & temperate & Apr Temperature & 41 & $\log$ (nb fruits) & several & 28 & Fearer et al. 2008 \\
\hline Fagus crenata & temperate & Tmin apr-may & 68 & $\log$ (nb fruits) & 1 & 12 & Kon et al. 2005 \\
\hline Fagus crenata & temperate & Tmin apr-may + repro y-1 & 58 & $\log ($ nb fruits) & 1 & 12 & Kon et al. 2005 \\
\hline Fagus crenata & temperate & Tmin apr-may + repro y-1 & 70 & $\log ($ nb fruits) & 1 & 12 & Kon et al. 2005 \\
\hline Fagus crenata & temperate & Tmin apr-may + repro y-1 & 75 & $\log ($ nb fruits $)$ & 1 & 12 & Kon et al. 2005 \\
\hline Fagus crenata & temperate & Tmin apr-may + repro y-1 & 83 & $\log ($ nb fruits) & 1 & 12 & Kon et al. 2005 \\
\hline Fagus sylvatica & temperate & NAOaut+NAOspr+Psummer+Taut & 55 & $\log$ (fruit mass production) & 19 & 131 & Fernandez-Martinez et al. 2016 \\
\hline Quercus petraea & temperate & NAOautumn + Tautumn & 21 & $\log ($ fruit mass production) & 19 & 123 & Fernandez-Martinez 2016 \\
\hline Quercus robur & temperate & PrecipSummer+Taut+Twint & 28 & $\log$ (fruit mass production) & 10 & 60 & Fernandez-Martinez 2016 \\
\hline Quercus robur+petraea & temperate & $\mathrm{T}$ pollen season + Fruit $(\mathrm{y}-1)+$ site & 37 & percentage of fruiting trees & 3 & 60 & Bogdziewicz et al. 2017 \\
\hline Fagus sylvatica & temperate & Tsummer $(\mathrm{y}-1) *$ Fruit $(\mathrm{y}-1)+$ site & 42 & percentage of fruiting trees & 2 & 40 & Bogdziewicz et al. 2017 \\
\hline Quercus ilex & mediterranean & water stress index (summer) $+\mathrm{nb}$ days torrential rain (spring) & 65 & fruit mass production & 1 & 26 & Perez-Ramos et al. 2010 \\
\hline Quercus robur+petraea & temperate & see main text & 16.2 & fruit mass production & 23 & 256 & This study \\
\hline Fagus sylvatica & temperate & see main text & 44 & fruit mass production & 20 & 204 & This study \\
\hline
\end{tabular}


Online Resource 13 Spatial variability of fruit crop in a temperate oak forest (FR-Fon, ICOS research station, www.barbeau.u-psud.fr)

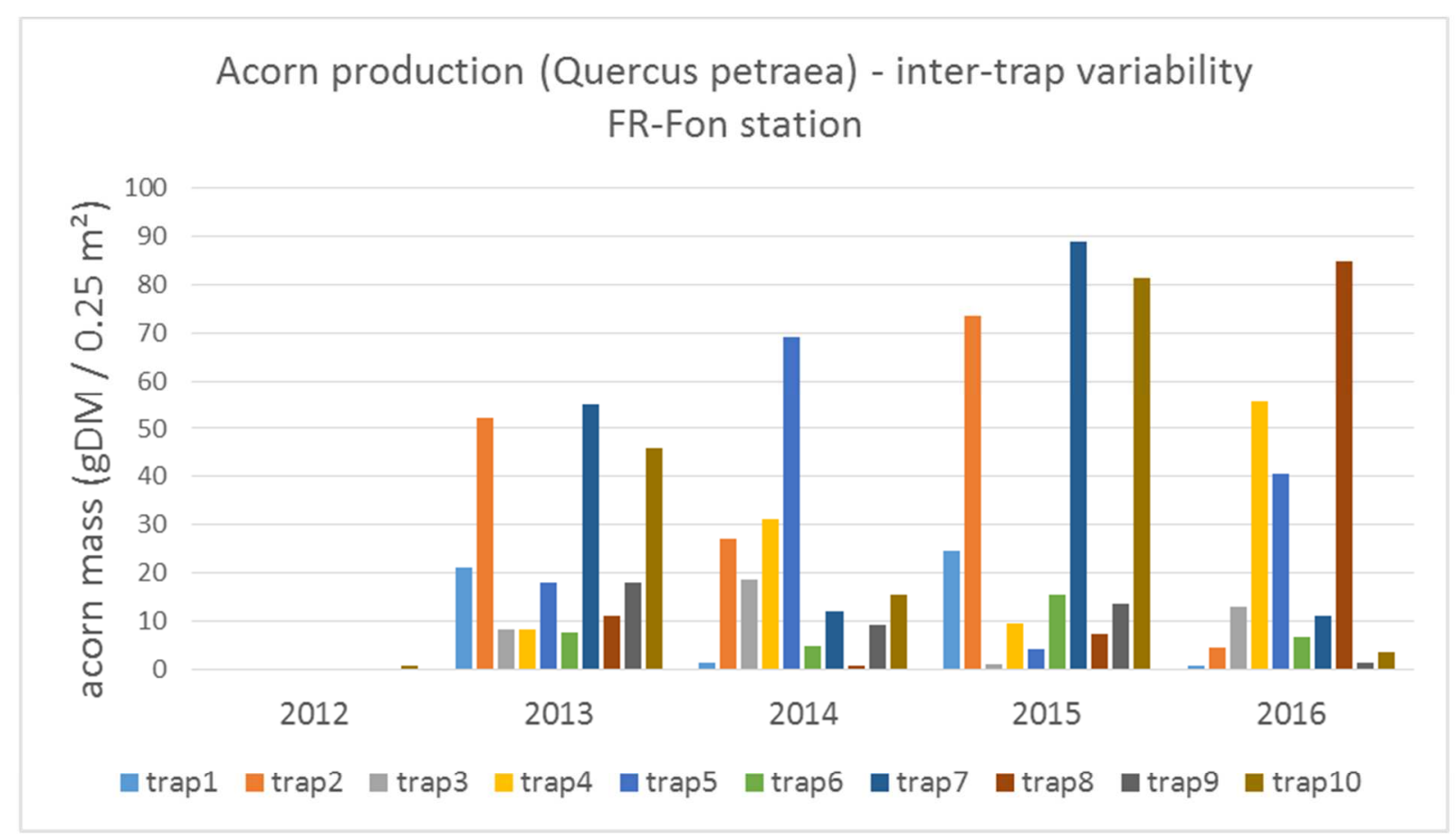

Online Resource 13 Spatial variability of fruit crop in a temperate oak forest (FR-Fon, ICOS research station, www.barbeau.u-psud.fr). The bars represent the annual acorn crop in each of 10 traps (each of $0.25 \mathrm{~m}^{2}$ area) located randomly over a 0.5 -ha fenced area. The among-trap coefficient of variation varies from $78 \%$ in 2013 to $130 \%$ in 2016 . Year 2012 crop was close to null. 
Online Resource 14 Partial dependence plots of the seven best significant predictors of fruit biomass for the 5 beech stands with tree-ring width data

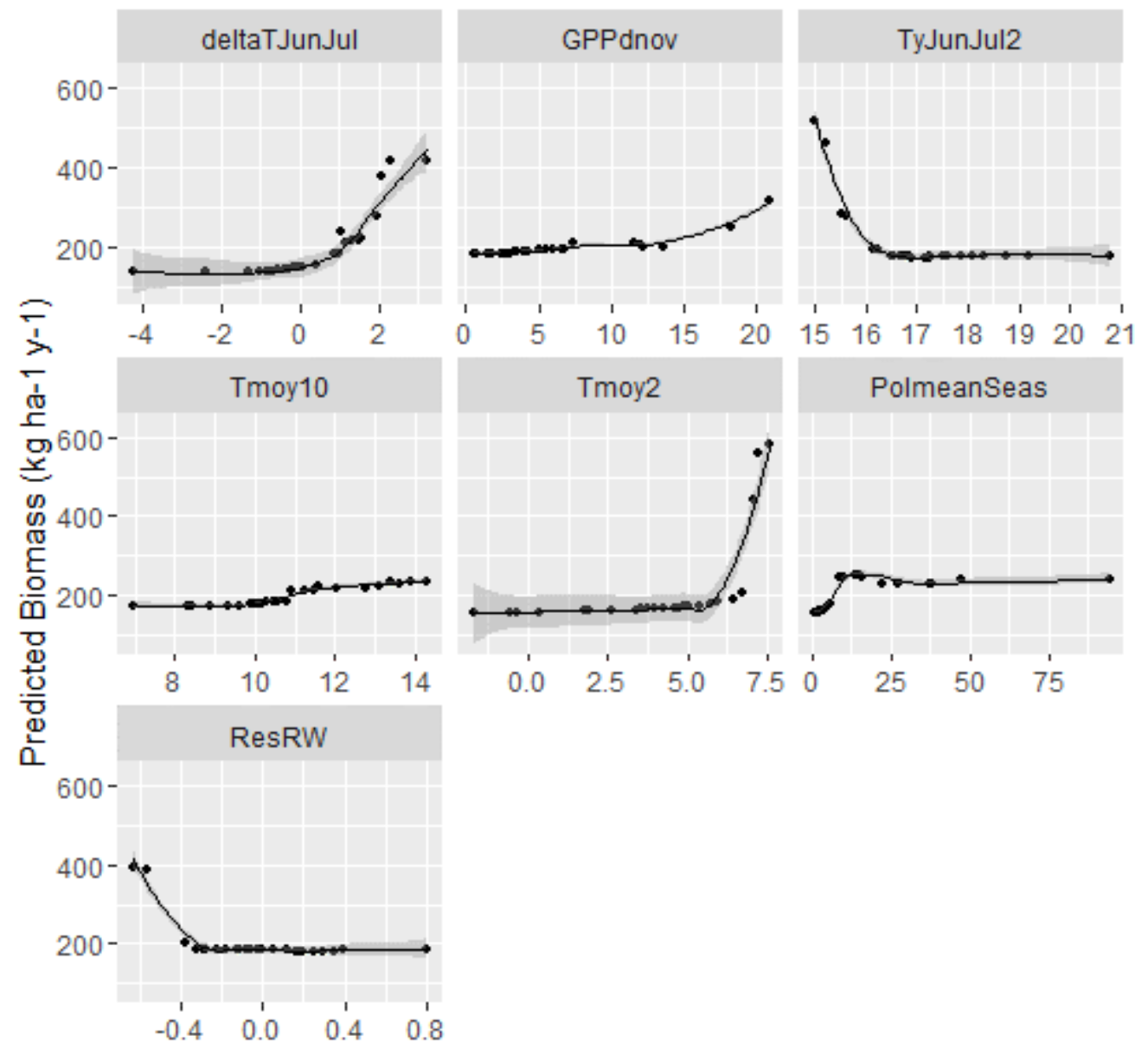

Online Resource 14 Partial dependence plots for the seven best significant predictors for predicted fruit biomass of nuts for the 5 beech stands with tree-ring width data $(\mathrm{n}=64$ data). Each plot gives a graphical depiction of the own effect of the predictor and highlights threshold response effects.VIMP and DEPTH values for each predictor. See Table 1 for the results obtained with the complete dataset (CGP* model).

Online Resource 14 Partial dependence plots for the seven best significant predictors for predicted fruit biomass of nuts for the 5 beech stands with tree-ring width data $(n=64$ data). Each plot gives a graphical depiction of the own effect of the predictor and highlights threshold response effects.VIMP and DEPTH values for each predictor. See Table 1 for the results obtained with the complete dataset (CGP* model). 
Interactive Minimal Depth
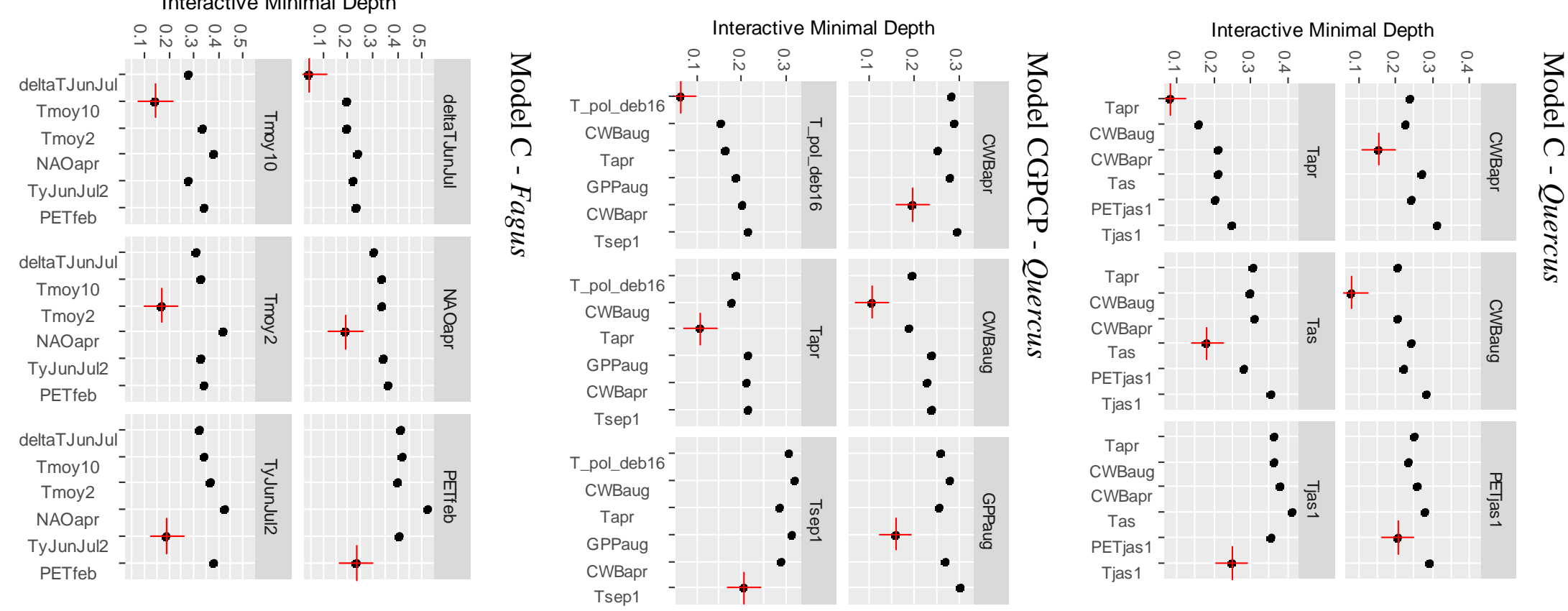

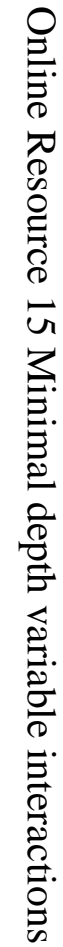
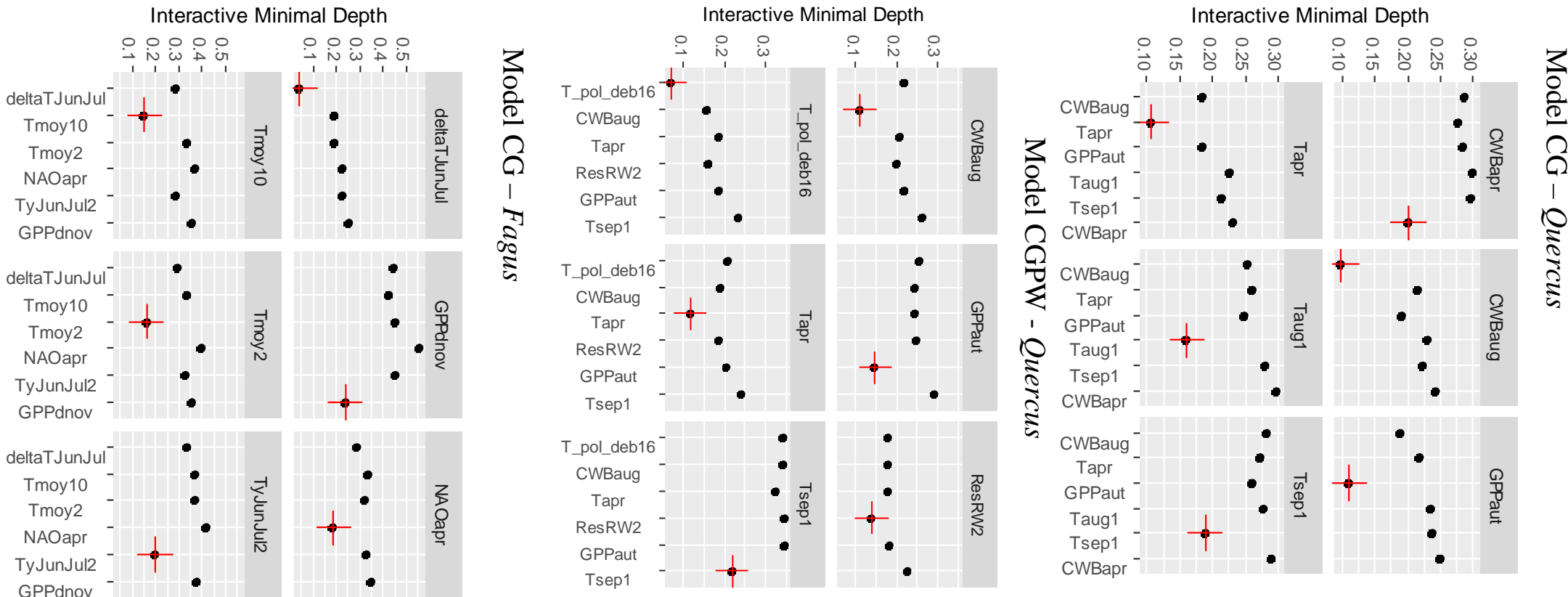

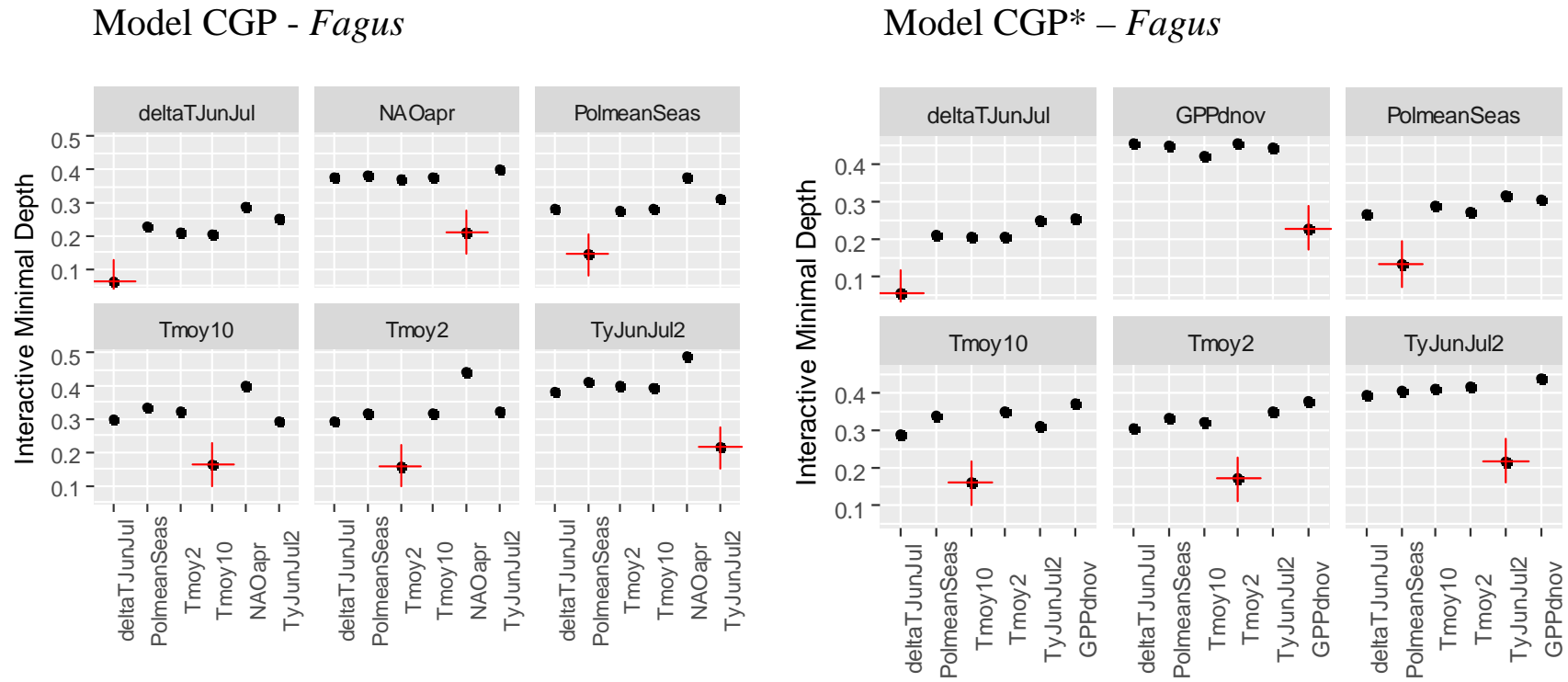

Online Resource 15 Minimal depth variable interactions. Reference variables are marked with red cross in each panel. Higher values indicate lower interactivity with reference variable. See Table 1 for the details. 